\title{
INVOLVING CHILDREN IN MEAL PREPARATION: IMPLICATIONS FOR INCREASING VEGETABLE INTAKE AT HOME AND SCHOOL
}

\author{
A THESIS \\ SUBMITTED TO THE FACULTY OF \\ UNIVERSITY OF MINNESOTA \\ BY
}

Andrew Clifford Lakanen

IN PARTIAL FULFILLMENT OF THE REQUIREMENTS

FOR THE DEGREE OF

MASTER OF SCIENCE

Marla Reicks, PhD, RD

April 2014 
(c) Andrew Clifford Lakanen 2014 


\section{Acknowledgements}

I would not have been able to complete my thesis work without my advisor, Marla Reicks, nor without my research team: Zata Vickers, Lucas Duppler, Stephanie Elsbernd, Elizabeth Mishler, and Sarah Berkowitz. Thank you all for your continued support and encouragement.

I am also grateful for the FSCN department for giving me the opportunity to function as a graduate teaching assistant during my graduate education, which allowed me to survive financially. 


\section{Dedication}

This thesis is dedicated to my parents, Dave and Sue Lakanen. 


\section{Introduction}

Childhood overweight and obesity are increasingly prevalent public health problems. The number of overweight children has doubled over the past 30 years. ${ }^{1}$ Currently, $28 \%$ of non-Hispanic White, $40 \%$ of Hispanic, and $43 \%$ of African American children aged 6-11 years qualify as overweight according to 2009-2010 NHANES data. ${ }^{2}$ Vegetable intake in U.S. children and adults has been well below recommendations for many years and has shown little improvement. ${ }^{3-8}$ Consequences of child and adolescent overweight/obesity include dyslipidemia, elevated blood pressure, insulin resistance, asthma, nonalcoholic fatty liver disease, musculoskeletal disorders, and elevated risk factors for chronic diseases such as type 2 diabetes and cardiovascular disease..$^{9-11}$ Prevalence of overweight and obesity have risen over the past five decades and have only recently begun to plateau. ${ }^{12,13}$ At current rates, the prevalence of overweight in U.S. children and overall overweight- and obesity-related health care costs are estimated to double by the year $2030 .{ }^{14}$

Important dietary habits and food-related skills are initiated and developed during childhood; these skills and habits tend to persist into adolescence and adulthood. ${ }^{15,16}$ Children with low vegetable intake may be less likely to consume recommended levels of vegetables as adults and therefore increase their risk of becoming overweight or obese, of acquiring chronic disease in adulthood, and of increased mortality rates from these diseases. ${ }^{17-22}$ Obesity and undesirable health outcomes may be prevented with healthy eating behaviors such as higher 
vegetable intake. ${ }^{23}$ Epidemiological evidence for the health benefits of vegetable intake is substantial. ${ }^{24}$ Observational and experimental research on the association between vegetable intake and health outcomes is less substantial in volume and strength. ${ }^{25}$

The majority of children aged 5-12 in the U.S. attend public elementary schools and use the school cafeteria as an important food source. The National School Lunch Program (NSLP) is available in nearly all public education institutions, making lunch meals available to low-income and food-insecure children. Given that students spend a considerable amount of time in school and consume a substantial portion of their calories in school, the cafeteria environment is ideal for interventions to increase children's consumption of vegetables. A number of interventions, both single- and multi-component, have been conducted with marginal success to improve children's overall vegetable intake. ${ }^{26}$ A simple, inexpensive, and effective method of increasing children's vegetable intake at school lunch would be beneficial.

A variety of environmental and behavioral theoretical constructs affecting intake have been incorporated into nutrition research and interventions to improve dietary intakes of children. These interventions have shown potential to improve intake in home and school environments. Interventions applying novel constructs that have potential to meaningfully improve vegetable intake are warranted, including involvement with meal preparation and behavioral economic approaches. 
Children's participation in meal preparation is not well characterized in research literature, nor is it widely applied in interventions to increase vegetable intake. Parents and caregivers are tasked with the primary responsibilities of choosing foods and preparing them for their families in the home, although children can impact parental food choices by virtue of their asking, selection, and meal preparation skills. Exploration of motivators/barriers for parents involving their children in meal preparation in the home is warranted to develop effective interventions that result in greater child involvement in meal preparation as a means to increase vegetable intake. The limited research available suggests a positive relationship exists between the frequency of children's involvement with meal preparation and vegetable intake. ${ }^{27}$ Interventions have utilized food-related skills ranging from gardening to food selection to meal preparation. Involvementbased interventions in home and school environments have the potential to meaningfully increase vegetable intake in children. This, in turn, may help address the obesity crisis faced by the U.S.

The present research is comprised of two studies: an environmental behavioral intervention aimed at increasing elementary school children's consumption of vegetables during school lunch using a "do-it-yourself" (DIY) salad, and a survey of parents of 5- to 12-year-old children that investigates children's participation in home meal preparation, and barriers and facilitators to participation. The first study took place in an elementary school in Minneapolis, $\mathrm{MN}$ and gave school-aged children the opportunity to mix their own salads-a 
simple task children can complete during school lunch. The second study was an internet-based survey of parents regarding the frequency of their children's involvement in meal preparation, as well as motivators/barriers to involving children in meal preparation. 


\section{Table of Contents}

Acknowledgements i

Dedication ii

Introduction

Table of Contents vii

List of Tables _ ix

Literature Review 1

Vegetable Intake Recommendations for Children 2

Health Benefits of Childhood Vegetable Intake 6

$\begin{array}{ll}\text { Vegetable Intake Among Children } & 13\end{array}$

Theories and Concepts Used to Explain Children's Vegetable Intake

Theoretical Constructs and Factors Related to Children's Vegetable Intake

Research Related to Increasing Children's Vegetable Intake 39

$\begin{array}{ll}\text { References } & 49\end{array}$

$\begin{array}{ll}\text { Purpose and Hypotheses } & 64\end{array}$

Study 1: Applying the IKEA Effect to School Lunch 66

$\begin{array}{ll}\text { Methods } & 67\end{array}$

$\begin{array}{ll}\text { Results } & 74\end{array}$

$\begin{array}{ll}\text { References } & 79\end{array}$

Study 2: The Kids Cooking Survey $\quad \mathbf{8 0}$ 
Methods

Results

91

References

103

Discussion

References

121

Comprehensive Bibliography

122

Appendices

141 


\section{List of Tables}

\section{Literature Review Table}

Table 1. 2010 U.S. Dietary Guidelines Vegetable Intake Recommendations for Children

\section{IKEA Effect Tables}

Table 1: Demographic Information for Students Eating Lunch

Table 2: Frequency of Students Taking Spinach Salad by Intervention Condition

Table 3: Frequency of Students Taking Garden Salad by Intervention Condition

Table 4: Mean Spinach Salad Intake by Intervention Condition

Table 5: Mean Garden Salad Intake by Intervention Condition

Table 6: Mean Spinach Salad Intake by Grade

Table 7: Mean Garden Salad Intake by Grade

Table 8: Mean Spinach Salad Intake by Eligibility

Table 9: Mean Garden Salad Intake by Eligibility

Kids Cooking Survey Tables

Table 1: Factors Related to Child Involvement with Meal Preparation

Table 2: Demographic Characteristics of Kids Cooking Survey Participants 92

Table 3: Number of Children by Gender and Age

Table 4. Parent Food Preparation Practices and Child Consumption Practices

Table 5: Factors Related to Child Involvement with Meal Preparation

Table 6: Social-Cognitive Factors Related to Child Involvement with Meal 
Table 8: Linear Regression Analysis to Predict Child Meal Preparation Involvement 


\section{Literature Review}




\section{Vegetable Intake Recommendations for Children}

The 2010 US Dietary Guidelines for Americans (DGA) issued by the U.S.

Department of Agriculture (USDA) and U.S. Department of Health and Human Services (US DHHS) set general recommendations for children's vegetable intake (Table 1). ${ }^{4}$ The Guidelines promote vegetables as important foods for maintaining nutrient adequacy and overall good health, as well as preventing disease. One of the key recommendations is that Americans "increase vegetable [and fruit] intake, [and] eat a variety of vegetables, especially dark green, red, and orange vegetables." ${ }^{4}$ The recommendations include increasing consumption of nutrient-dense foods such as vegetables as they are important sources of nutrients largely under consumed by Americans and are also less energy-dense than other foods. ${ }^{28}$

Table 1. 2010 U.S. Dietary Guidelines Vegetable Intake Recommendations for Children $^{\mathrm{a}}$

\begin{tabular}{|l|c|c|c|c|c|}
\hline $\begin{array}{l}\text { Children (age } \\
\text { and gender) }\end{array}$ & $\begin{array}{c}\text { All } \\
\text { vegetables } \\
\text { (per day) }\end{array}$ & $\begin{array}{c}\text { Dark, leafy } \\
\text { greens } \\
\text { (per week) }\end{array}$ & $\begin{array}{c}\text { Red/orang } \\
\text { e } \\
\text { (per week) }\end{array}$ & $\begin{array}{c}\text { Starchy } \\
\text { (per } \\
\text { week) }\end{array}$ & $\begin{array}{c}\text { Other } \\
\text { (per } \\
\text { week) }\end{array}$ \\
\hline $\begin{array}{l}\text { 4-8 yrs (all } \\
\text { children) }\end{array}$ & 1.5 & 1 & 3 & 2.5 & 2.5 \\
\hline $\mathbf{9 - 1 3}$ yrs boys & 2 & 1.5 & 4 & 4 & 3.5 \\
\hline $\mathbf{9 - 1 3}$ yrs girls & 2.5 & 1.5 & 5.5 & 5 & 4 \\
\hline
\end{tabular}

${ }^{a}$ Vegetable servings are given in cup-equivalents; cup equivalent $=1$ cup cut-up raw or cooked vegetables, 0.5 cups dried vegetables, 1 cup juice, 2 cups raw leafy greens, or 1 cup cooked dry beans or peas 


\section{School Lunch Meal Requirements}

Schools participating in the NSLP have minimum requirements for vegetables served in the lunch meal and over the school week. In 2010, the Healthy, Hunger-Free Kids Act promulgated several changes to the NSLP. The final rule was issued in January, 2012 to align school meal patterns and nutrition standards with the 2010 DGA. ${ }^{29}$ These new school meal regulations require schools to offer more fruits, vegetables, and whole grains. They require schools to offer only low-fat or fat-free milk, to reduce sodium, saturated fat, and caloric content over time, and to eliminate trans fat in school meals. The updated school regulations require schools to offer a minimum of 0.75 cup equivalents of vegetables per day (3.75 cup equivalents per week). The minimum weekly requirements by vegetable type are 0.5 cups of dark green, 0.75 cups of red/orange, 0.5 cups of starchy, and 0.5 cups of other vegetables. ${ }^{29}$

The USDA's Food and Nutrition Service (FNS) sponsors the School Nutrition Dietary Assessment (SNDA) study, a continual assessment of nutritional characteristics of children's meals provided by the NSLP. ${ }^{29}$ Conducted by Mathematica Policy Research for 2009-2010, SNDA-IV is the most recent nationally representative school meal assessment study available. ${ }^{29}$ Findings indicated that over $75 \%$ of schools served lunches that either met or came within $10 \%$ of meeting School Meal Initiative (SMI) guidelines. The average U.S. elementary school lunch program offered about $29 \%$ of the daily recommended amount of vegetables and children selected $23 \%$ of the daily recommendation. ${ }^{29}$ 
While schools were providing a substantial amount of vegetables, children were not taking or consuming the recommended amounts. The benchmark used in the SNDA-IV final report was based on the rule that NSLP lunches should provide $71 \%$ of weekly requirements. This would provide $23 \%$ of daily requirements of each vegetable group at school lunch since children enrolled in the NSLP would eat school lunch five out of seven days per week. ${ }^{29}$ The final report indicated that on average, only $7 \%, 16 \%, 20 \%$ and $19 \%$ of the daily recommended amounts were served for dark green, red and orange, starchy, and other vegetables, respectively in elementary schools across the United States. ${ }^{29}$ Ultimately, the amount of vegetables served to students fell below the recommendation to provide $33 \%$ of the daily recommended amount of vegetables per school lunch meal per day.

SNDA-IV also collected data from schools participating in the Healthier US Schools School Challenge (HUSSC) and compared data from these schools to non-HUSSC schools nationwide. The HUSSC is a voluntary initiative created by USDA's FNS in which schools can enroll to receive recognition certificates for meeting school meal standards. HUSSC schools offered raw vegetables more frequently than non-HUSSC schools ( $63 \%$ of daily lunch menus vs. $57 \%$ ). HUSSC schools also performed better in terms of offering and serving lunches which met SMI standards for calories and important nutrients such as fat, and some vitamins and minerals; however, both HUSSC schools and schools 
nationwide experienced difficulty in serving lunches meeting all SMI standards $\left(14 \%\right.$ and $9 \%$, respectively) ${ }^{29}$ 


\section{Health Benefits of Childhood Vegetable Intake}

Vegetable Intake, Adiposity, and Weight in Children

Evidence for a protective relationship between vegetable intake and adiposity among children is inconsistent, although the association is more apparent for elementary school-age children than for preschool- age children. ${ }^{25}$ Vernarelli et al. ${ }^{30}$ reported that dietary energy density was associated with weight status among children aged 2-8 years using national intake data, and reported that children eating a diet higher in energy density tended to eat fewer vegetables. On the other hand, Patterson et al. ${ }^{31}$ reported an association between lower energy density and diet quality, including a diet higher in vegetables, in a study of children and adolescents. Evidence analysts for the Academy of Nutrition and Dietetics reviewed 18 different observational studies investigating fruit and/or vegetable intake and childhood overweight and reported an overall modest protective effect. ${ }^{32}$ Both nationally representative crosssectional studies included in the review were conducted by Lin et al. ${ }^{33,34}$ One study showed an inverse relationship between fruits and/or vegetables in boys, but not girls, and the other showed no association between a vegetarian diet and obesity. ${ }^{33,34}$ A longitudinal study $(n=1,379)$ conducted using food frequency questionnaire (FFQ) data and a follow-up of six to twelve months conducted by Newby et al. ${ }^{35}$ showed no association between fruit and vegetable intake and adiposity in children based on multiple linear regression analysis, but fruits and vegetables were not separate categories in the data analysis in this study. 
Several case-control and cross-sectional studies included analyses of vegetables alone $^{33,34,36-42}$ Of these, only one yielded the expected inverse association between vegetable intake and childhood overweight. ${ }^{33}$ This study, based on nationally representative data from the Supplemental Continuing Survey of Food Intake by Individuals Children's Survey (1998), separated vegetables and fruits in a multiple regression analysis of two-day diet records from a sample of 2,181 children aged 6-12 years. Those who ate more fruits and vegetables did not weigh significantly less than children at lower intake levels. ${ }^{33}$ The results did, however, indicate a weak correlation for overweight boys, who consumed less total vegetables per week than boys at-risk of overweight or healthy weight boys (2.5 versus 3.0 servings). ${ }^{33}$

Some of the studies reviewed by the Academy analysts did not include certain vegetables in their analysis (e.g., carrots, potatoes) despite the potential nutritional value of these foods. One study examined the association between both white potatoes and vegetables in general and weight and found the expected inverse association for only white potatoes in boys. ${ }^{34}$ In some cases, these foods were not included because preparation methods typically diminish their nutritional value and often add some unhealthy ingredients. In at least one study, potatoes were included but French fries were not. ${ }^{35}$ The Academy analysts reported that the evidence in support of the protective effect of vegetables against childhood adiposity is weaker than that for fruit alone or fruits and vegetables combined. Studies including fruit juice in their classification for "fruit" 
may tend to overestimate fruit intake, which is important in studies where fruit and vegetable intakes are not separated. If they are not, vegetable intake will likewise be overestimated. Fruit juice is not strongly associated with desirable health outcomes.

A recent review by Ledoux et al. ${ }^{25}$ reported on the association between vegetable intake and adiposity and/or obesity among children. This review included four longitudinal studies and one experimental study. ${ }^{35,43-46}$ One of the four longitudinal studies found the expected inverse association. ${ }^{43}$ Wang et al. ${ }^{43}$ followed children aged 6-13 years old in China for two years, collected anthropometric data and three-day dietary intake records, and reported that urban boys were three times as likely to be overweight during this period compared to rural boys. The children who remained overweight at follow-up were less likely to eat a high-vegetable diet, although the difference in means pre- and post- follow-up (about 20 milligrams per dietary kcalorie) was not statistically significant. ${ }^{43}$ Ledoux et al. ${ }^{25}$ note in their review that the longitudinal studies where the expected results were not observed recruited preschool-age children (1-2 to 5 years of age) and used different methods than those studies which found mixed or the expected results (based on FFQ and 24-hour recalls, respectively). One of these studies did not include carrots, potatoes, or salad in its analysis. ${ }^{44}$ The experimental study, despite employing robust methods (including an intensive intervention) did not find the expected inverse association 
between vegetable intake and adiposity among children, while the expected inverse association was observed among parents involving in the study. ${ }^{45}$

A longitudinal study conducted by Wang et al. ${ }^{43}$ found the expected inverse association between vegetable intake and adiposity in a nationally representative sample of elementary school age children. The authors concluded that overweight children aged 6-13 who consumed more vegetables at baseline in the study were less likely to be overweight at its conclusion two years later. ${ }^{43} \mathrm{~A}$ longitudinal study conducted by Field et al. ${ }^{46}$ yielded mixed results. The study investigated the association between fruit and vegetable intake and change in BMI among children over a two-year period. ${ }^{46}$ The authors found a significant association between vegetable intake and BMI z-score change in boys, but not girls; however, this association disappeared when energy intake was statistically controlled for in the analysis. ${ }^{46}$ Newby et al. ${ }^{35}$ reported no association between total vegetable intake and weight change in low-income preschool age children. A longitudinal study conducted by Matthews et al. ${ }^{47}$ examined the association between the types of food consumed and overweight during childhood and adolescence. Based on a 106-item FFQ and application of a logistic regression model to stratify levels of vegetable intake, those in the highest quartile or tertile of vegetable intake compared to the lowest had about two-thirds the risk (odds ratio $=0.67$ ) of being overweight compared to those with lower vegetable intake. ${ }^{47}$ Overall, results from observational studies reporting on the relationship between vegetable consumption and childhood overweight have 
produced inconsistent results. ${ }^{48}$ Several explanations exist to explain these mixed results. Vegetable preparation methods such as frying may add fat and additional calories, which may exacerbate adiposity. ${ }^{47}$ The association between vegetable intake and adiposity/obesity may be more pronounced in elementary than preschool or high-school age children. ${ }^{25}$ Various limitations in the studies reviewed, such as not controlling for energy expenditure, short (less than three years) follow-up time, and small sample size, may have limited the ability to detect statistically significant results. ${ }^{25}$

\section{Chronic Disease-Related Measures in Adolescence and Adulthood}

Epidemiological evidence strongly supports the protective role of vegetables against chronic disease..$^{24}$ Low vegetable intake during childhood is a risk factor for type 2 diabetes and metabolic syndrome (including insulin resistance) in youth and young adulthood, obesity and chronic disease in adulthood, and for earlier puberty/menarche in girls. ${ }^{49,50}$ Conversely, a diet high in vegetables has a protective effect against various chronic diseases, including obesity, cardiovascular disease, type 2 diabetes, cerebrovascular diseases, and certain types of cancer among adults. ${ }^{24,50-52}$ Dietary behaviors are initiated and developed during childhood and have a tendency to be maintained in adulthood. ${ }^{18-21}$ Thus, a childhood dietary pattern with a high vegetable intake may lead to a similar dietary pattern in adulthood and reduce risk factors for undesirable health outcomes such as chronic disease, cerebrovascular 
disorders, and disease-related mortality. ${ }^{11,15,53-56}$ Early dietary behaviors can become habits which persist later in life. Habits strongly influence vegetable intake in adults; however, habit strength as a mediator of vegetable intake has not been thoroughly examined in children. ${ }^{57}$

\section{Mechanisms of Action of Vegetables' Health Benefits}

Vegetables help prevent overweight, obesity, and chronic disease in adulthood by several mechanisms. ${ }^{24}$ Vegetables contain relatively high amounts of fiber, water, vitamins and minerals, are low in energy density, and have a low glycemic load. The fiber in vegetables is a satiating component of foods, resulting in fewer calories consumed in a meal. ${ }^{28,48}$ The low energy density and glycemic load contribute to improved postprandial hormonal shifts. ${ }^{58,59}$ Insulin resistance is thought to cause and exacerbate chronic diseases, such as type 2 diabetes and some types of cancers, respectively. ${ }^{49}$ Thus, a diet higher in vegetables may help regulate insulin levels and reduce insulin resistance. Consumption of flavanoid and antioxidant components of vegetables throughout life is associated with improved markers for cancer risk and reduced risk of certain cancers including colon cancer. ${ }^{11,51,60,61}$ The low energy-density of vegetables can lower overall energy density and energy intake in children's diets; thus, a diet high in vegetables may protect against overweight and obesity. ${ }^{62}$

Given the potential health benefits of vegetables for children and adults, meeting the dietary recommendations for vegetable intake represents a positive 
dietary pattern and should be encouraged. Studies assessing typical dietary intake of vegetables can inform interventionists regarding the need for public health approaches to address intake. 


\section{Vegetable Intake Among Children}

\section{Overall Vegetable Intake}

Only a small proportion of Americans eat the recommended number of servings of vegetables per day on average, including children. ${ }^{63}$ Data from $1999-$ 2004 NHANES indicated that the average U.S. child aged 4-8 years ate 1.0 cup/day of vegetables, while the average male aged $9-13$ years ate 1.3 cups/day and the average female aged $9-13$ years ate 1.2 cups/day. ${ }^{3}$ A vegetable cup equivalent is defined as either 1 cup cut-up raw or cooked vegetables, 0.5 cups dried vegetables, 1 cup juice, 2 cups raw leafy greens, or 1 cup cooked dry beans or peas. Lorson et al. ${ }^{6}$ reported that children ages 6-11 consumed about 1 cup equivalent of vegetables (less than $60 \%$ of recommendations) per day. In this study, the low intake of vegetables did not differ by BMI category of the child, household income, or food security status, although boys consumed significantly more vegetables than girls and consumption differed significantly between age groups. ${ }^{6}$ Data from the $2009-2010$ NHANES indicated that about $90 \%$ of children aged 8 years and older did not meet federal recommendations for vegetable intake. ${ }^{63}$ Recent data from the Healthy People 2010 Midcourse Review showed no progress toward meeting Healthy People 2010 objectives to increase the proportion of the population aged $\geq 2$ years who consume at least three servings of vegetables, with at least one-third being dark green or orange. ${ }^{8}$ In addition to not meeting recommendations, the vegetables eaten most often by children tend to be energy- but not nutrient-dense. ${ }^{5}$ National data indicated that 
nearly a quarter of the vegetables eaten by children were French fries, while about $6 \%$ of vegetables were consumed as vegetable-based mixtures and $7 \%$ consumed with fats such as salad dressing. ${ }^{5}$ Overall, intakes of vegetables such as dark, leafy greens were very low compared to recommendations. ${ }^{5}$

A recent study conducted by Hiza et al. ${ }^{64}$ investigated diet quality of U.S. children using 2003-2004 NHANES data and the 2005 Healthy Eating Index (HEl), which measures compliance with the 2005 DGA. ${ }^{65}$ The $\mathrm{HEl}$ is calculated by compiling scores from 10 equally weighted dietary components, each with a maximum score of 10; thus, a higher HEI vegetable component score indicates a higher vegetable intake relative to the 2005 DGA. ${ }^{66}$ While children had better relative intakes than adults in the sample, they did not meet 2005 DGA recommendations in any vegetable category, scoring the lowest in dark green and orange vegetables. Children at higher income levels had better HEI scores than children at lower income levels, girls had better HEI scores than boys, and Hispanic children had the highest HEI scores for total vegetables and dark green and orange vegetables compared to other ethnic groups. No differences were seen in children's HEI score by age, which is in contrast with the report by Ledoux et al. ${ }^{25}$ which indicated that elementary school-aged children consumed more vegetables than younger or older children. HEI scores for total vegetables $(47,95 \% \mathrm{Cl}=44,49)$ and dark green/orange vegetables and legumes $(12,95 \%$ $\mathrm{Cl}=10,14)$ remained fairly constant over all age groups. Krølner et al. ${ }^{67}$ also reported in a review that early age was a significant determinant of higher 
vegetable intake in children. Therefore, the evidence in the literature examining possible relationships between children's vegetable intake and age or educational status is inconclusive.

\section{Children's Vegetable Intake in Schools}

Schools play an influential role in determining children's food intake, including vegetables, which can address risks of obesity. ${ }^{68}$ Constant exposure to school meals provides an important opportunity to promote a healthy diet in children. ${ }^{68}$ About $95 \%$ of children aged 5-17 attend schools in the U.S. ${ }^{68}$ Children consume a large portion of their daily calories during the school day, and participation in school lunch demonstrably improves children's diets. ${ }^{69-72}$ Nearly all public (99\%) and most private (83\%) schools participate in the NSLP, and they are expected to meet minimum requirements for servings of vegetables offered to students for school lunch. ${ }^{73,74}$ Despite the regular access to vegetables provided in the NSLP in most elementary schools, a low proportion of children take and eat vegetables for the school lunch meal. ${ }^{75}$ Only $51 \%$ of students in a recent national study ate at least one vegetable for the school lunch meal. ${ }^{75}$ Of the students who do take a vegetable for school lunch, intake remains low compared with recommendations. ${ }^{76}$ In a recent study of school intakes in the United Kingdom (UK), the majority (94\%) of students aged 4-11 years consumed less than 75 grams of vegetables during lunch ( 80 grams is about a half-cup serving), with most consuming between 26 and 50 grams, or about a quarter 
cup-equivalent serving of vegetables. ${ }^{76}$ The low intake of vegetables among children in schools has resulted in a number of school-based interventions to improve intake, many of which are based on various theories and concepts to enhance effectiveness. 


\section{Theories and Concepts Used to Explain Children's Vegetable Intake}

Children's vegetable intake falls well below dietary guidelines. Therefore, research continues to determine influences on vegetable intake and to apply

theoretical constructs to improve children's diets and health. ${ }^{26,77}$ Three theories or concepts were utilized in designing the present research: Social Cognitive Theory (SCT), the Social-Ecological Model (SEM), and behavioral economics. Within these behavioral theories and concepts, a multitude of personal, social, and environmental factors are proposed to influence children's vegetable intake in schools and at home. ${ }^{78}$

\section{Social Cognitive Theory}

Social Cognitive Theory (SCT) was derived from social learning theory as the result of work by Miller and Dollard in the 1940s, and has been further developed via work by Bandura ${ }^{79}$ into an interpersonal behavior theory which describes how people acquire and maintain certain behavioral patterns. Behavior plays an interrelated role with personal and environmental factors in the SCT model based on a construct known as reciprocal determinism. Gaines and Turner $^{80}$ identified nine behavioral SCT constructs: environment, behavioral capacity (knowledge and skill), expectations (anticipated outcomes), expectancies (values placed on an outcome), self-control (self-regulation), observational learning, reinforcements (responses to behavior which increase or decrease the likelihood of a behavior's reoccurrence), self-efficacy (confidence in 
ability), and emotional coping (strategies used to manage emotional stimuli). Within the environmental domain, availability and accessibility are important determinants of eating behavior. A recent review of SCT-based interventions showed that this theory has been used by researchers and health professionals to learn more about children's health behavior and ways to improve it. ${ }^{80}$

SCT is a relevant framework to apply to eating behavior of children in the school setting. Children spend a considerable amount of time in school learning from their teachers, peers, and their environment, all of which shape their dietary behaviors. ${ }^{68}$ Children consume a large portion of their daily calories at school and most public elementary schools offer a variety of vegetables at lunch, making school lunch an opportunity for nutrition interventions to increase vegetable intake.

\section{Social Ecological Model}

The Social Ecological Model (SEM) was used in public health promotion efforts even before it was formalized as a theory by McLeroy et al. ${ }^{81}$ The SEM was developed to describe the complex interrelations between personal and environmental factors and how they influence individual behavior. SEM has two broad, key concepts: multiple levels and reciprocal causation. Reciprocal causation refers to the dynamic, interrelated person-environment relationships which exist at multiple levels: intrapersonal, interpersonal, organizational, community, and public policy. To illustrate, the environment may influence 
preferences for vegetables in children, as low availability or accessibility in the environment may lead to relatively lower preferences, in part by limiting children's exposure to vegetables. ${ }^{82}$ SEM has been applied to nutrition intervention research in an effort to improve dietary habits of Americans and thus reduce the prevalence of overweight and chronic disease. ${ }^{80}$

The SEM can shed some light on the complex issue of children's vegetable intake at home and school. SEM stands in contrast with other theories, as it transcends gaps between smaller settings (e.g., homes) and larger settings (e.g., institutions, large communities) often discretely applied in research studies. ${ }^{26,83-85}$ Health behavior interventions have historically been aimed at improving health behaviors at the individual level. Only somewhat recently have environment (both physical and social), policy, and culture been addressed for their role in moderating health behaviors such as eating habits (i.e., children's vegetable intake) ${ }^{86}$

The elementary $(\mathrm{K}-5)$ school itself sits at the organizational level of this model, but all levels come into play when we consider children's eating behaviors. Children's eating behaviors are intrapersonal as they are based on knowledge of foods and taste. They are also interpersonal as students talk to each other about their food and may also silently watch what others eat, which influences their choices. Notably, this observational learning is a tenet of Social Cognitive Theory; thus, there is some overlap between the various theories applied in nutrition research and interventions. At the organizational level, 
environmental factors such as availability of food (e.g., menu options) through the NSLP and minimum requirements for servings of vegetables offered have a profound impact on what children eat. At the broadest levels, the minimum standards of the NSLP and food availability in the U.S. are products of federal and local policies. As mentioned, the minimum requirement for fruits and vegetables offered and served for school lunch has recently increased. This broadest level also includes large scale environmental factors. Cultural factors are included in most SEM models, although the level that culture sits in varies among models, suggesting culture may transcend the levels of the SEM model. ${ }^{81,87,88}$

\section{Behavioral Economics}

Behavioral economics is a relatively new field which has been incorporated into health behavior theory and interventions. It employs small environmental changes to "nudge" people into making healthy behavior choices. These approaches do not change the availability of vegetables, nor do they remove the element of choice in selecting vegetables. Behavioral economic approaches such as nudges have been applied to the school setting with some successful results. ${ }^{89,90-92}$ For example, simply pre-slicing or cutting food in a school lunch line, a tactic also used by mothers in homes, or giving vegetables attractive names demonstrably increases intake of these foods. ${ }^{90-92}$ These nudges are efficient in that they are low-cost, easy to implement, and potentially 
powerful ways to increase children's vegetable intake at school lunch. This also makes them attractive alternatives in the school cafeteria setting, where the environment is often not conducive to more time- and effort-intensive nutrition interventions, or where school staff may have objections about proposed logistical changes to the school lunch protocol. Behavioral economic approaches have been criticized for ignoring powerful forces outside the local environment (e.g., policy) which can have the most powerful effect on food choice in the school environment. ${ }^{93}$ This is especially true when one considers that elementary school children often have little choice in which foods are served at school lunch and in the home.

A potentially effective behavioral economic approach is called the "IKEA effect," as reported by Norton et al. ${ }^{94}$ The "IKEA effect" can be defined as the increase in valuation of self-made products. In the study, ${ }^{94}$ both sets of participants who completed construction of folded origami and Lego sets reported that they viewed their creations as similar in value to expertly crafted ones including those who qualified themselves as "do-it-yourselfers" and those who did not.. Participants who did not complete or destroyed their creation did not experience the "IKEA effect," as people have a fundamental human need for effectance (the ability to successfully produce desired outcomes in one's environment), in this case, via objects such as possessions. ${ }^{95-98}$ Notably, effectance is a requisite for positive self-efficacy, a construct of SCT. The results of the study by Norton et al ${ }^{94}$ indicate that labor alone may induce greater liking 
for "the fruits of one's labor." This effect can result in people over-valuing their self-made creations, even if they are poorly constructed. Therefore, the "IKEA effect" could result in higher valuation of vegetable dishes that children prepared at home or in school. Depending on a child's age and maturity, he or she may be capable of preparing dishes from raw ingredients or mixing pre-prepared component parts. Based on participation and valuation of the resulting product, the effect may influence intake among children.

\section{Summary}

A variety of theories or concepts posit a multitude of factors affecting vegetable consumption among children. The complexity of the multitude of factors affecting children's vegetable intake is most comprehensively described by the Social Ecological Model (SEM). Researchers interested in applying the SEM require considerable resources including time, staff, money, and energy. One solution to that problem is employing behavioral economic approaches in nutrition interventions, which are not so resource-intensive and are comparably effective in increasing vegetable intake in children. Behavioral economic practitioners and their approaches have nonetheless been criticized for ignoring those important, large-scale factors (e.g., policy and culture) which directly and profoundly affect children's vegetable intake. In addition, Social Cognitive Theory is a well-accepted behavioral theory commonly applied in nutrition intervention research with children. ${ }^{80} \mathrm{SCT}$ is similar to SEM in that it attempts to describe the 
complex web of person-environment interrelationships which dynamically affect children's food choices and eating behavior. 


\section{Theoretical Constructs and Factors Related to Children's Vegetable Intake}

Theoretical constructs which have been studied in relation to vegetable intake among children in various settings come from several theories and may be overlapping. Some have been shown to be more salient than others in reviews of factors affecting intake. ${ }^{82,77,99}$ Factors such as availability and accessibility, ${ }^{100,101}$ preferences, ${ }^{102}$ acceptance of new foods, ${ }^{103,104}$ home support, ${ }^{105,106}$ knowledge (e.g., of nutrition recommendations), ${ }^{107,108}$ interest in a healthy diet, ${ }^{109}$ and verbal encouragement ${ }^{110}$ were independently associated with higher vegetable intakes in children. ${ }^{78,99,111,112}$

A review published by Rasmussen et al. ${ }^{77}$ as a part of the Pro Children Project explored factors which influence the intake of fruits and vegetables among children and adolescents. ${ }^{77}$ The Pro Children Project is an international study including nine European countries that aims to assess and increase fruit and vegetable consumption among school-age children. ${ }^{113}$ Of the 98 papers identified in Rasmussen's review, ${ }^{77} 8$ were longitudinal studies and 16 were based on testing or exploring pertinent theoretical frameworks. Many of the studies used conventional methods such as FFQs (58 studies) or 24-hour recalls (15 studies) to estimate vegetable consumption. Determinants of vegetable intake were divided into several broad factors: sociodemographic; personal; family-, friends-, and school-related; and meal patterns/TV watching/eating fast food. Each of these factors is further subdivided into specific determinants (e.g., 
gender and age are considered sociodemographic factors determining vegetable intake).

\section{Sociodemographic Factors}

Rasmussen et al. ${ }^{77}$ identified an impressive 49 papers which analyzed gender differences in fruit and vegetable intake. In general, girls have higher or more frequent intake of vegetables than boys. ${ }^{107,108,110,114-119}$ Only four studies reviewed reported that boys ate more vegetables or ate them more frequently than girls. ${ }^{120-123}$ Notably, these gender differences were more salient in Europe than the U.S and a considerable number of studies analyzing gender were conducted in adolescents. ${ }^{77}$

Rasmussen et al. ${ }^{77}$ reported there is a weak negative association between age/grade and fruit/vegetable intake, citing that nearly half of papers reviewed reported vegetable consumption decreasing with age. However, methodology and geographic location differed between many studies. ${ }^{107,108,110,119,124-126}$ These differences make it more difficult to draw meaningful conclusions from the existing body of literature.

Socioeconomic status (SES) has been linked to vegetable intake, as those in lower SES strata tended to consume fewer vegetables or consume them less frequently than those in higher SES strata. ${ }^{107,108,116,117,119,127,128}$ Operationalization of SES differs widely in the literature and includes family 
income, parental occupation, and parental education; the association was strongest for family income. ${ }^{77}$

Much of the literature examining the relationship between race and ethnicity and vegetable consumption has been done in the U.S. ${ }^{77}$ Various ethnic groups have been compared and the results are too inconsistent and confounded (e.g., many papers did not control for SES) to draw meaningful inferences from the research available. ${ }^{70,71,125,129-131}$

Geographic location may play a role in determining vegetable intake. ${ }^{77}$ Of the limited research available, three recent studies have reported rural children have higher vegetable consumption than urban children. ${ }^{43,122,132}$

\section{Personal Factors}

Use of knowledge in nutrition and health promotion research has a historical precedent. Knowledge is a component of most theories employed in nutrition and health promotion research. Therefore, education is widely used to improve knowledge and facilitate behavior change. However, use of knowledge in nutrition interventions does not share this historical precedent with the field at large. Nutrition interventions which include an educational component operate under the assumption that people will use nutrition knowledge to improve their diets. The Academy of Nutrition and Dietetics Evidence Analysis Library analysts concluded that insufficient evidence exists to determine whether education is an 
effective intervention strategy to increase vegetable intake in elementary school age children. ${ }^{133-35}$

Research efforts to increase vegetable intake via knowledge have collectively yielded inconclusive results. ${ }^{118,136-139}$ In a model proposed by Reynolds et al., ${ }^{118}$ which was derived from data from multiple 24-hour recalls and behavioral surveys, motivation (outcome expectations, self-efficacy, and preferences), modeling, and nutrition education all influenced knowledge. Knowledge, in turn, significantly influenced consumption of fruits and vegetables for females, but not males, in their model $(r=0.24, \mathrm{P}<0.05)$. Vegetables were not analyzed in isolation. Notably, motivation (as described by Reynolds et al.) $)^{118}$ significantly influenced knowledge for both boys and girls. Knowledge appears to be a pre-requisite for increasing vegetable intake in nutrition interventions and influences consumption indirectly, although its independent effect is unknown. ${ }^{99}$ Knowledge of the daily recommended vegetable servings may influence vegetable intake. ${ }^{139}$ As described, education is an integral role of most children's experience; therefore, efforts should be made to educate young children about the benefits of eating fruits and vegetables.

Preferences have consistently been shown to be a primary determinant of vegetable intake in children. ${ }^{136,140-142}$ Not surprisingly, preferences are also the most extensively examined personal factor related to children's vegetable intake. ${ }^{77}$ Preferences are independently associated with children's vegetable intake, ${ }^{137}$ and act in concert via reciprocal determinism with other factors. ${ }^{142}$ 
Resnicow et al. ${ }^{136}$ examined social-cognitive predictors of vegetable intake in third grade children and found that preferences and positive outcome expectations were significantly associated with vegetable intake. In their multivariate analysis, these two variables together explained about $10 \%$ of the variability in vegetable intake in children $(r=0.29$ for fruits and vegetables in a bivariate analysis). Notably, these associations were stronger during weekdays than on weekends and stronger for lunch than for breakfast. Reynolds et al. ${ }^{118}$ examined preferences as part of their latent construct, motivation, and found that it both directly and indirectly (via knowledge) influenced vegetable consumption significantly.

Birch $^{82}$ describes humans' innate preferences for calorie-dense, sweet, and salty foods. This stands in contrast with humans' apparent innate distaste for low-calorie, bitter, and sour tasting foods. Preferences can be further explained by food neophobia, a concept explaining children's aversion to new foods. ${ }^{143}$ The modern food milieu illustrates how preferences can be changed over time (i.e., humans enjoy a variety of bitter and sour flavors in foods); thus, preferences are modifiable (e.g., via repeated exposure). ${ }^{82,144}$ Using rewards to shape preferences and increase vegetable intake (e.g., incentivizing the consumption of vegetables) is not recommended, as it can negatively affect children's liking of vegetables. ${ }^{82}$ However, previous intervention studies that incentivized the consumption of vegetables have had some positive results. ${ }^{145-148}$ 
Outcome expectations are both the perceived positive and negative consequences of a behavior, in this case vegetable consumption, and the benefits and costs to engaging in the behavior. ${ }^{149}$ Children are not often cognizant of the benefits of eating vegetables, as the benefits are often delayed and difficult to conceptualize. Therefore, children may not spend much time thinking about chronic disease or the long-term negative health consequences of being overweight or obese. The lack of a strong association between outcome expectations and vegetable intake consistently found in the literature is not surprising. ${ }^{77,150}$ In one of five papers reviewed by Rasmussen et al., ${ }^{77}$ a positive relationship was observed between outcome expectations and fruit and vegetable consumption in children. ${ }^{136}$ Resnicow et al. ${ }^{136}$ found a positive association between outcome expectations and vegetable intake by measuring vegetable intake via 7-day food records and exploring correlations between social-cognitive constructs and vegetable intake in children. Reynolds et al. ${ }^{118}$ reported that outcome expectations as a part of motivation (which was included with self-efficacy and preferences in their model) had a significant positive influence on fruit and vegetable consumption, both independently and by virtue of enhancing knowledge. Interventionists may need to focus on immediate benefits, such as energy to play, rather than long term health benefits. Despite the shortcomings or null results of past interventions, outcome expectations as a personal factor should be accounted for in future nutrition interventions to increase children's vegetable intake. 
Self-efficacy, defined as one's confidence in the ability to perform a behavior, is a potentially significant driver of vegetable intake in children. ${ }^{79}$ Selfefficacy includes selection efficacy (the ability to select healthy food options when presented with both healthy and unhealthy options) and general self-efficacy. Self-efficacy is difficult to measure, as it is a complex set of behaviors influenced by a number of various other factors. However, researchers can assess selfefficacy in children in a number of ways. For example, assessment could include observation of simple tasks children are capable of completing or asking parents about their perceptions of their children's self-efficacy with regard to diet. Several studies in the literature apply survey methods developed and validated by Domel et al. ${ }^{151}$ Their results indicated that self-efficacy was not a good independent predictor of vegetable intake. The only significant determinant of vegetable consumption found by Domel et al. ${ }^{151}$ was preferences, which explained nearly $13 \%$ of the variance in vegetable intake in their sample.

The results from work by Resnicow et al. ${ }^{136}$ with regard to self-efficacy stood in contrast to another study conducted by Parcel et al., ${ }^{152}$ where selfefficacy was found to explain $34 \%$ of the variance in vegetable intake in a similarly-aged cohort (third to fourth graders); however, the methods used by Parcel et al. ${ }^{152}$ were considerably different than those used by Resnicow et al. ${ }^{136}$ Resnicow et al. ${ }^{136}$ used a 7-day food diary while Parcel et al. ${ }^{152}$ asked students to choose between a list of paired foods, which may have induced a selection bias from students, as they are subject to normative expectations and social 
desirability bias. ${ }^{136}$ In light of this discrepancy, Resnicow et al. ${ }^{136}$ suggested that dietary behaviors may be too constrained in children and vegetable consumption too complex for self-efficacy and SCT to adequately explain. While this may or may not be true for the home environment, self-efficacy could be especially salient in schools, where children may not typically influence or directly choose some of their menu options.

Self-efficacy is powerful in that it can directly influence behavioral skills such as asking skills (the ability to ask a parent to buy or prepare a food or meal), selection of healthy lunch options, and preparation of simple vegetable recipes. ${ }^{118}$ Development and regular use of these skills may be positively associated with vegetable intake.

Children who participate in meal preparation in the home may have healthier food preferences and greater self-efficacy than those who do not. ${ }^{153}$ In a cross-sectional study conducted by Chu et al., ${ }^{153}$ fifth grade children were asked about their vegetable preferences, how often they help prepare meals in the home, and their self-efficacy using a survey appropriate for children. About a third of the children in the sample (32\%) reported helping with meal preparation 1-3 times per week, while more than a third $(37 \%)$ reported helping with meal preparation once a month or less frequently. After adjusting for confounding variables such as gender and household income, their results indicate that children who helped more frequently with meal preparation in the home had higher self-efficacy for choosing and eating vegetables. 
Self-efficacy may not be independently associated with higher vegetable consumption in school-aged children. The lack of control children have over their food choices in many environments seems to play a large role as a barrier to vegetable intake, and is consistently mentioned in the literature as an explanation for null results. ${ }^{80,151}$ Environmental behavioral interventionists should focus on finding ways for children to gain control over food choices to enhance selectionand self-efficacy and increase vegetable consumption. The literature suggests that one feasible way of doing this may be to involve children with meal preparation as frequently as possible, as this helps develop self-efficacy. It may also improve children's preferences for vegetables and therefore vegetable consumption. ${ }^{153}$

Intentions and motivation are frequently used in health behavior change ("stages of change"-based) interventions and related research. ${ }^{154}$ Intention, as it is synonymous with "motivation", is a prerequisite for any behavior; however, intention to perform a behavior does not always lead to its performance. ${ }^{155,156}$ This phenomenon is sometimes called the "intention-behavior gap," and researchers have attempted to increase motivation in health behavior change research. ${ }^{154}$ Intention can interact with other factors related to vegetable intake, such as perceived knowledge. People often overestimate their vegetable intake and underestimate their intakes of less healthy foods. ${ }^{157}$ Participants in recent studies reported little intention to improve their diets because they 
underestimated the fat content of their diet and thus may not have felt the need to change their eating habits. ${ }^{158,159}$

The association between intentions and vegetable intake in children is generally positive, but literature reporting on the association between intention and vegetable intake is limited. ${ }^{77}$ Two of the four papers reviewed by Rasmussen et al. ${ }^{77}$ reported a positive association between intentions and vegetable intake in children and adolescents, ${ }^{117,160}$ while the other two did not. ${ }^{161,162}$ De Bourdeaudhuij et al. ${ }^{160}$ and Lien et al. ${ }^{117}$ conducted their studies with adolescents and parents. Lien et al. ${ }^{117}$ conducted surveys six months apart assessing vegetable consumption frequency in relation to psychosocial variables including attitudes, norms, barriers to consumption, and intentions. They used their assessments to predict how well the Theory of Planned Behavior predicted frequency of vegetable consumption, and found that $31 \%$ of the variation in intention to eat more fruits and vegetables was explained by their statistical model. ${ }^{117}$ Bere and Klepp ${ }^{161,162}$ conducted two studies measuring intention among other social-cognitive predictors of vegetable intake, both as a part of a Norwegian intervention study called "Fruits and Vegetables Make the Marks." The studies involved participation of $38^{161}$ and $20^{162}$ schools in surveys taken 8 months apart by children and their parents; thus, their methods were nearly identical. Ultimately, intention did not explain a significant amount of variation in frequency of vegetable consumption in either study's model, nor did it correlate well with vegetable intake. Notably, the surveys administered by Bere and 
Klepp ${ }^{161,162}$ only had one intention-related item, and intention (to eat five servings of vegetables per day) was consistently low pre- and post-survey.

\section{Family- and Friend-Related Factors}

Familial factors demonstrably influence children's vegetable intake, as parents play a major role in determining what their children eat. ${ }^{110,137,140,144,163}$ Children tend to model the consumption behaviors of their parents; thus, a high parental intake of vegetables is positively associated with a higher intake of vegetables in children. ${ }^{77,82,110}$ Parenting style can either positively or negatively influence children's vegetable intake: a highly controlling parenting style can negatively influence children's intake of vegetables, while an authoritative parenting style is most strongly associated with higher vegetable intake. ${ }^{77,140}$ Based on the limited literature available, parental support is strongly associated with vegetable consumption. ${ }^{111,112,160,164}$ Outside of the family, there is limited and inconclusive research reporting on the effect of peer influences on children's vegetable intake, although social norms have been shown to influence children's vegetable intake. ${ }^{110,138}$

\section{Meal Patterns, Meal Time Activities, and Fast Food Consumption}

Meal patterns are an important determinant of children's vegetable intake. Parenting practices such as the frequency of shared meals between parents and children can have a positive effect on children's vegetable intake. ${ }^{72,111,112,126,165-}$ 
Involvement with shared family meals has a positive association with vegetable consumption, but the body of research is limited and much of the research in this area was done in adolescents. ${ }^{72,111,112,126,166}$ Roos et al. $^{72}$ conducted a study in Finnish adolescents exploring associations between meal patterns and consumption of raw (but not cooked) vegetables and found a positive association. However, the authors also reported that meal pattern (including school and evening home meals) had no effect on the association between household education level (knowledge) and vegetable consumption. ${ }^{72}$ Gillman et al. ${ }^{166}$ explored associations between dinner meal frequency and diet quality, including vegetable consumption. Using data for children aged 9-14 from the Nurses' Health Study II, the authors reported that $83 \%$ of participants ate dinner with members of their family on most days or every day. ${ }^{166}$ While over $50 \%$ of 9 year-old children ate dinner with their families every day, only about $33 \%$ of 14 year-old children did so. Children who ate dinner meals at home more frequently were more likely to eat five servings of fruits and vegetables per day $(\mathrm{OR}=1.45,95 \% \mathrm{Cl}=1.37,1.53) .{ }^{166}$ Higher frequency of home meal preparation among older children and adolescents was also associated with a healthier diet profile in a cross-sectional survey of Project EAT participants in the Minneapolis, MN metropolitan area. ${ }^{27}$ Recent evidence suggests food preparation behaviors track over time and engagement in food preparation is associated with higher vegetable consumption during the mid-to-late twenties, but not adolescence; this tracking is not as well documented in young or older children. ${ }^{168}$ Given the 
potential dietary and behavioral benefits of regularly eating family meals, interventions to increase the proportion of children who regularly eat dinner meals with their families are warranted.

Meal time activities include anything a child might do during mealtime, including non-eating activities. There is limited research reporting on the negative association between screen-time activities such as television viewing and children's vegetable intake. ${ }^{99}$ However, of the $150-200$ hours of advertisements viewed by children annually, unhealthy food advertisements far outnumber those for healthier options, which is hypothesized to negatively influence children's vegetable intake. ${ }^{169}$ Television viewing is only one of many activities which could distract children from consuming a meal that includes vegetables. Socializing with peers and interacting with school personnel can also potentially distract from students' time spent eating, which is already quite limited. Lastly, fast food consumption may influence vegetable intake in children, as greater frequency of fast food consumption is associated with lower frequency of vegetable consumption; but research in this area is somewhat limited. ${ }^{170-172}$ Cullen et al. ${ }^{110}$ reported that families in their sample reported eating out at least twice a week. 


\section{Environment}

The environment plays a crucial role in moderating children's vegetable intake. Availability and accessibility are identified as primary factors affecting vegetable intake in both home and school environments, although other factors such as food variety and quality should not be discounted. ${ }^{142,173}$ Availability of foods in the home is positively associated with child consumption, and higher availability of certain foods in the home is also positively associated with preferences for those foods (e.g., vegetables). ${ }^{100,101,142,174}$ This effect may be caused in part by the need to have new foods available so children can be exposed to them, thus diminishing food neophobia. ${ }^{175}$ Cullen et al. ${ }^{142}$ reported that availability and accessibility explained $35 \%$ of the variance of fruit, fruit juice, and vegetable intake for girls in their model. Preferences had an impact on their model, as children with low preferences for vegetables tended to have higher consumption if they were both available and accessible, while availability was the only significant predictor of consumption for children with high preferences. ${ }^{142}$ Some discrepancies in the literature exist regarding the relationship between availability and accessibility and vegetable consumption, depending on whether researchers asked parents and/or children about food availability and accessibility in the home. ${ }^{101,110,142}$ Availability of vegetables at dinner meals may be a factor underlying the positive relationship between vegetable intake among children and frequency of family dinner meals. ${ }^{176}$ 
The results from two recent studies suggest a positive association between availability of fruit and vegetables in schools and their consumption. ${ }^{161,177}$ Ninety-five percent of schools participating in the NSLP offer a variety of vegetables on a daily basis; however, only about half of students take a vegetable for lunch on any given school day. ${ }^{75}$ Thus, while the school environment has made vegetables easily available and accessible for children, other environmental factors may play a larger role in determining whether children choose to eat vegetables at school lunch. ${ }^{99,175}$ These factors include the competitive availability of more palatable foods, parental behaviors (e.g., modeling), peer influences, and media (television) influences. 


\section{Research Related to Increasing Children's Vegetable Intake}

Researchers have incorporated behavioral theoretical constructs in nutrition research related to children's vegetable intake and various health outcomes. $^{26,99,133-135}$ Researchers have explored how well children's vegetablerelated behaviors align with relevant theoretical frameworks and have used results to design and implement nutrition interventions to increase children's vegetable intake..$^{26,99}$

Nutrition interventions to increase vegetable intake in children may be single- or multi-component in design. Many single-component interventions involve distributing free or subsidized vegetables to children, while multicomponent interventions tend to include programs to increase vegetable intake which involve students, their families, and/or school personnel. Distribution programs are relatively easy to implement and have been implemented effectively for fruit on a national basis. ${ }^{29}$ With NSLP and HHFK-related legislative changes in 2012, schools must now offer a half-cup equivalent of fruit and a three-quarters cup equivalent of vegetables to each student each day as part of school lunch. Multi-component interventions often include free vegetable distribution, but may also include classroom curricula (educational components), environmental changes, and family involvement (e.g., home-based projects). Multi-component interventions more frequently include novel intervention methods such as food tastings, various marketing tactics, goal-setting activities, or problem-solving activities. The Academy of Nutrition and Dietetics highly 
recommends multi-component interventions over single-component interventions and also recommends that interventions include a physical activity component. ${ }^{178}$ Multi-component interventions are more effective than single-component interventions, according to anthropometric and behavioral outcomes, and address the complex etiology of childhood overweight comprehensively. ${ }^{81,179,180}$ Although multi-component interventions can be more powerful, they are not without limitations. Multi-component interventions are more intensive ${ }^{181}$ costing more time, energy, and money than single-component interventions. Therefore, they are more difficult to replicate. Due to their intensive cost, they may be impossible in low-income settings or in settings where the built (community) environment does not support multi-component interventions. Evans et al. ${ }^{26}$ reported that too few interventions have been conducted to draw meaningful conclusions about the differences between single- and multi-component interventions.

Several studies have utilized constructs from behavioral and environmental theories, especially SCT, in nutrition interventions to increase children's vegetable intake. ${ }^{26,99}$ Behavioral strategies have included pre-cutting or slicing, ${ }^{182,183}$ making vegetables more convenient to eat, ${ }^{184}$ giving incentives or rewards, ${ }^{145-148}$ using marketing tactics such as branding, ${ }^{92,185}$ priming children to alter taste expectations, ${ }^{90,186}$ exploiting visual illusion bias, ${ }^{187}$ changing portion size ${ }^{188}$ involving children with meal preparation or gardening, ${ }^{153,189}$ pairing or hiding vegetables with other liked foods, ${ }^{190,191}$ varying the timing of serving with 
regard to the meal of interest, ${ }^{192-194}$ offering children a variety of vegetable choices, ${ }^{195}$ using assortment allocation cues (i.e., labeling of compartments), ${ }^{89}$ and using verbal encouragement. ${ }^{85,196}$

Christian et al. ${ }^{182}$ conducted a recent cross-sectional survey in elementary schools and found that, on average, children consumed a half-portion more of fruits and vegetables when parents cut up or sliced their vegetables for them. Wengreen et al. ${ }^{148}$ reported that non-monetary rewards such as pencils and hand-stamps significantly improved children's consumption of vegetables. Likewise, Raju et al. ${ }^{147}$ reported that children who made pledges and competed for incentives increased the proportion of children choosing selection by up to $25 \%$, although there was a significant effect of age in this study. The potential negative effects of incentivizing vegetable consumption have been discussed.

Fisher et al. ${ }^{190}$ reported that offering a dip with vegetables can substantially increase consumption of bitter vegetables such as broccoli by $80 \%$. Similarly, hiding vegetables may be an effective strategy to increase consumption. ${ }^{191}$ Spill et al. ${ }^{191}$ recently served pureed vegetables to children in entrées and found an increase in overall vegetable intake and no significant differences in liking ratings between manipulated foods and the control foods.

As mentioned, behavioral economic approaches capitalize on small environmental cues to nudge people to make healthier food choices. Wansink et al. have conducted a number of studies in this area, using methodological strategies such as serving vegetables first in the lunch line, offering salad options 
to lunch patrons, placing relatively unhealthy lunch options out of direct sight, using attractive names to market vegetables, placing low-fat and skim milk in easier to reach places than sweetened (i.e., chocolate) or fuller-fat milk options, and pre-slicing or cutting fruit to make it more convenient to take and eat. ${ }^{90-92,184}$ Wansink et al. ${ }^{90}$ conducted a recent study using a familiar character (Batman) to prime taste expectations in children, and results indicated $45 \%$ of children (compared to a non-primed control) chose apple slices over French fries.

Wansink et al. ${ }^{187}$ also conducted a study exploiting visual illusion bias by serving ice cream in larger bowls to nutrition experts and reported that the subjects served themselves $31 \%$ more ice cream in the larger bowls, as well as $15 \%$ more ice cream when given a larger serving spoon. While this study was conducted in adults, similar results have been reported in children given larger spoons to serve themselves macaroni and cheese. ${ }^{197}$

Promotion and encouragement have been used in research to increase vegetable intake.$^{85,198-201}$ Perry et al.$^{85}$ conducted a multi-component intervention to increase vegetable intake in school-age children. The researchers asked foodservice staff to encourage students going through the lunch line to eat vegetables by asking them which vegetable they would like to have for lunch. This encouragement was significantly associated with consumption of vegetables (excluding potatoes) post-intervention. ${ }^{85}$ Similarly, Schwartz et al. ${ }^{196}$ conducted a study in two schools and asked foodservice staff to verbally prompt children by asking if students would like a fruit with their lunch. Their results indicated a $30 \%$ 
increase in the proportion of students taking a fruit in the school employing verbal encouragement versus the control school ( $90 \%$ of students versus $60 \%) .{ }^{196}$

The impact of school-based nutrition interventions on children's vegetable intake has been minimal. ${ }^{26}$ Evans et al. ${ }^{26}$ conducted a meta-analysis to assess the effectiveness of interventions to increase fruit and vegetable intake in 5-12 year-old children in elementary schools. The analyses indicated an overall improvement of 0.07 half-cup servings ( $95 \% \mathrm{Cl}:-0.03,0.16)$, which is about one quarter to one third of a portion or $20-30 \mathrm{~g}$. School-based intervention studies were generally described as being of poor quality. Studies often failed to take into account children's vegetable intake at home, which may be altered to compensate for relatively higher intakes at school. Several studies lacked a control group or did not clearly describe blinding of participants or personnel involved in the study. Interventions need to be adequately implemented if they are to be effective; fidelity is a factor which significantly influences the impact of nutrition interventions. ${ }^{179,202,203}$

Many of the studies included in the meta-analysis by Evans et al. ${ }^{26}$ aimed to increase both fruit and vegetable intake. Results indicated that interventions were more effective for fruit, raising questions about barriers that exist to increasing vegetable intake in children at school. Ransley et al. ${ }^{204}$ conducted a single-component intervention, and found that mean consumption of vegetables surprisingly decreased by 0.2 half-cup servings in 5 year-olds and 0.3 half-cup servings in 6 year-olds after six months. Similarly, a study by Reinaerts et al. ${ }^{205}$ 
found no difference in vegetable intake after nine months of free vegetable distribution in an elementary school in the Netherlands. A multi-component intervention conducted by Reinaerts et al. ${ }^{205}$ involved a curriculum and homebased projects, yet yielded zero change in vegetable intake in elementary school age children. Spiegel et al. ${ }^{206}$ conducted a similar multi-component intervention in the U.S. which resulted in a 0.45 half-cup serving increase in children aged 911. Spiegel et al. ${ }^{206}$ implemented a 9-month curriculum as a part of the WAY Program in the U.S.; the curriculum included problem solving and home-based projects. Taylor et al. ${ }^{207}$ conducted a similar intervention in New Zealand which resulted in a 0.3 half-cup serving increase in 5-12 year old children after 9 months. Taylor et al. ${ }^{207}$ conducted a 9-month curriculum in New Zealand including free fruit and vegetable distribution and home-based projects. Most impressively, a 9 month intervention conducted by Reynolds et al. ${ }^{200,201}$ in the U.S. resulted in a net difference of 1.68 half-cup servings (2.28 in the control group, 3.96 in the intervention group) of fruits and vegetables one year after the intervention. The difference between intervention and control groups diminished somewhat two years after the intervention (2.21 in the control and 3.20 half-cup servings in the intervention group). This intervention included food tasting, food service, and problem-solving components, which is somewhat unique compared to many multi-component interventions. Baranowski et al. ${ }^{208}$ conducted another unique intervention to increase vegetable intake under the name "Squire's Quest." This was a five-week intervention in 8-12 year old children in the U.S. 
which included an educational multimedia game called "Squire's Quest." Ultimately the intervention yielded a 0.2 half-cup serving increase in vegetable intake after a short follow-up period (less than three months).

School-based nutrition intervention programs have the potential to moderately increase vegetable intake; however, they have historically proved to be largely ineffective. The heterogeneity of the limited evidence available compounds the difficulty of drawing inferences from it. Methods, characteristics of the sample population, duration, and follow-up time vary widely between school-based intervention studies. Effective strategies to increase vegetable intake in school-aged children are warranted.

Some programs which involve children in growing, preparing, cooking, and tasting food have shown potential. Evans et al. ${ }^{26}$ reported there are a limited number of intervention studies utilizing gardening or participation in meal preparation as a means to increase vegetable intake, and that incorporating these activities into nutrition interventions has the potential to yield significant improvements in vegetable intake. ${ }^{153,209,210}$ Future interventions which include these activities may be more effective than past efforts to increase children's vegetable intake. Chu et al. ${ }^{153}$ recently reported that children more involved with meal preparation in the home have significantly higher self-efficacy and preferences for vegetables than those who do not. This study, conducted in fifth grade children in Canada, included a cross-sectional survey. ${ }^{153}$ Results indicated higher frequency of meal preparation and cooking at home was 
significantly associated with higher vegetable selection efficacy and preferences for vegetables. Meinen et al. ${ }^{189}$ conducted a garden-based intervention which included a classroom component in elementary school-age children and found that, compared to control classrooms, children in the intervention group had higher vegetable consumption. Notably, the measure of vegetable consumption in this study was a simple parental report which asked parents how many times their child ate vegetables that day. ${ }^{189}$

Recently, the Robert Woods Johnson Foundation funded a study by Tester et al. ${ }^{211}$ investigating the effects of mobile fruit and vegetable carts to increase availability and accessibility of those foods in schools and several studies examining the obesogenic effects of competitive and a la carte food options at school lunch. ${ }^{211,212,213}$ Larson and Story ${ }^{212}$ and Sanchez et al. ${ }^{213}$ independently found that competitive foods were lowering the quality of U.S. elementary students' diets; this has been addressed in part by recent legislative changes related to competitive foods. ${ }^{74}$ Tester et al. ${ }^{211}$ reported that their mobile fruit vender was moderately successful: on average, one additional unit (bag) of fruits and vegetables was sold to elementary school students each day of the study. Furthermore, an average of 1.5 fewer competitive food units were sold each day. ${ }^{211}$

Overall, taste preferences and availability and accessibility are the two most important factors influencing children's vegetable intake, but parental behaviors, food preparation, asking, and recognition skills, television viewing, 
and child feeding practices ${ }^{82,140}$ are also salient factors. ${ }^{99}$ There is limited research in a number of these areas, and some theoretical frameworks or concepts have not been thoroughly explored in certain contexts. Future interventions utilizing these theoretical frameworks or concepts may prove to be successful in improving child vegetable intake.

\section{Summary of Literature Reviewed}

The literature reviewed indicates that low vegetable consumption in young children tracks into adulthood, precipitating overweight and adiposity in adolescence, and may contribute to chronic disease and related morbidities and mortality as an adult. Recent research grounded in environmental behavioral theories and concepts has examined the complexity of children's behavior reported on a variety of personal, social, and environmental factors, all of which influence dietary behaviors. Interventions have used these theoretical constructs and concepts to increase children's vegetable intake with moderate effectiveness. While research has investigated the importance of meal patterns, meal-time activities, and familial influences on children's vegetable intake, there is a lack of literature characterizing the mediating effects of children's involvement in meal preparation on vegetable consumption. Likewise, despite the potential, interventions to increase children's vegetable intake have not yet fully explored the potential of child participation in meal preparation as a means to successfully increase vegetable consumption. Using theoretical constructs 
and concepts and considering the limited available literature, the present study attempts to help fill gaps in the literature regarding children's involvement in home meal preparation along with parental perceptions of factors that influence child involvement. The present study also explores the potential for involving children in meal preparation to increase vegetable intake in the school setting. A second study aims to explore the relationship between child involvement in home meal preparation and possible explanatory theoretical constructs. 


\section{References}

1. Deckelbaum RJ, Williams CL. Childhood obesity: the health issue. Obes Res. 2001;9 Suppl 4(11S):239S-243S. doi:10.1038/oby.2001.125.

2. Ogden CL, Carroll MD, Kit BK, Flegal KM. Prevalence of obesity and trends in body mass index among US children and adolescents, 1999-2010. JAMA. 2012;307(5):483-90. doi:10.1001/jama.2012.40.

3. National Cancer Institute. Usual Intake of Dark-green \& Orange Vegetables. Risk Factor Monitoring and Methods Branch Web site. Applied Research Program. http://riskfactor.cancer.gov/diet/usualintakes/pop/veg_drkgreen_orange.html. 2010. Updated August 25, 2010. Accessed August 13, 2013.

4. U.S. Department of Agriculture and U.S. Department of Health and Human Services. Dietary Guidelines for Americans, 2010. $7^{\text {th }}$ Edition, Washington, DC: U.S. Government Printing Office, December 2010. http://www.health.gov/dietaryguidelines/dga2010/DietaryGuidelines2010.pdf

5. Krebs-Smith SM. Fruit and Vegetable Intakes of Children and Adolescents in the United States. Arch Pediatr Adolesc Med. 1996;150(1):81. doi:10.1001/archpedi.1996.02170260085014.

6. Lorson BA, Melgar-Quinonez HR, Taylor CA. Correlates of fruit and vegetable intakes in US children. J Am Diet Assoc. 2009;109(3):474-8. doi:10.1016/j.jada.2008.11.022.

7. Patterson BH, Block G, Rosenberger WF, Pee D, Kahle LL. Fruit and vegetables in the American diet: data from the NHANES II survey. Am J Public Health. 1990;80(12):1443-1449. doi:10.2105/AJPH.80.12.1443.

8. Healthy People 2010 midcourse review [Internet]. Washington: Department of Health and Human Services, Office of Disease Prevention and Health Promotion; 2007. Available from: http://www.healthypeople.gov/2010/Data/midcourse/html/focusareas/FA19Progres sHP.htm. Updated April 7, 2007. Accessed May 3, 2013.

9. Appel LJ, Moore TJ, Obarzanek E, et al. A clinical trial of the effects of dietary patterns on blood pressure. DASH Collaborative Research Group. N Engl J Med. 1997;336(16):1117-24. doi:10.1056/NEJM199704173361601.

10. Daniels SR. Complications of obesity in children and adolescents. Int J Obes (Lond). 2009;33 Suppl 1:S60-5. doi:10.1038/ijo.2009.20.

11. Holt EM, Steffen LM, Moran A, et al. Fruit and vegetable consumption and its relation to markers of inflammation and oxidative stress in adolescents. J Am Diet Assoc. 2009;109(3):414-21. doi:10.1016/j.jada.2008.11.036.

12. Ogden CL, Fryar CD, Carroll MD, Flegal KM. Mean body weight, height, and body mass index, United States 1960-2002. Adv Data. 2004;(347):1-17. http://www.ncbi.nlm.nih.gov/pubmed/15544194.

13. Parikh NI, Pencina MJ, Wang TJ, et al. Increasing trends in incidence of overweight and obesity over 5 decades. Am J Med. 2007;120(3):242-50. http://www.ncbi.nlm.nih.gov/pubmed/17349447.

14. Wang Y, Beydoun MA, Liang L, Caballero B, Kumanyika SK. Will all Americans become overweight or obese? estimating the progression and cost of the US obesity epidemic. Obesity (Silver Spring). 2008;16(10):2323-30. doi:10.1038/oby.2008.351. 
15. Johnson SL, Taylor-Holloway LA. Non-Hispanic white and Hispanic elementary school children's self-regulation of energy intake. Am J Clin Nutr. 2006;83(6):127682. http://www.ncbi.nlm.nih.gov/pubmed/?term=16762937.

16. Maynard M, Gunnell D, Ness AR, Abraham L, Bates CJ, Blane D. What influences diet in early old age? Prospective and cross-sectional analyses of the Boyd Orr cohort. Eur J Public Health. 2006;16(3):316-24. doi:10.1093/eurpub/cki167.

17. Hung $\mathrm{HC}$, Joshipura $\mathrm{KJ}$, Jiang $\mathrm{R}$, et al. Fruit and vegetable intake and risk of major chronic disease. J Natl Cancer Inst. 2004;96(21):1577-84. doi:10.1093/jnci/djh296.

18. Kelder SH, Perry CL, Klepp KI, Lytle LL. Longitudinal tracking of adolescent smoking, physical activity, and food choice behaviors. Am J Public Health. 1994;84(7):1121-6. http://www.ncbi.nlm.nih.gov/pubmed/?term=8017536.

19. Mikkilä V, Räsänen L, Raitakari O, Pietinen P, Viikari J. Consistent dietary patterns identified from childhood to adulthood: The Cardiovascular Risk in Young Finns Study. BJN. 2005;93(06):923. doi:10.1079/BJN20051418.

20. Resnicow K, Smith M, Baranowski T, Baranowski J, Vaughan R, Davis M. 2-year tracking of children's fruit and vegetable intake. J Am Diet Assoc. 1998;98(7):7859. http://www.ncbi.nlm.nih.gov/pubmed/9664920.

21. Singer MR, Moore LL, Garrahie EJ, Ellison RC. The tracking of nutrient intake in young children: the Framingham Children's Study. Am J Public Health. 1995;85(12):1673-1677. doi:10.2105/AJPH.85.12.1673.

22. Zhang $X$, Shu $X O$, Xiang $Y B$, et al. Cruciferous vegetable consumption is associated with a reduced risk of total and cardiovascular disease mortality. Am J Clin Nutr. 2011;94(1):240-6. doi:10.3945/ajcn.110.009340.

23. Birch LL, Ventura AK. Preventing childhood obesity: what works? Int J Obes (Lond). 2009;33 Suppl 1:S74-81. doi:10.1038/ijo.2009.22.

24. Van Duyn MA, Pivonka E. Overview of the health benefits of fruit and vegetable consumption for the dietetics professional: selected literature. J Am Diet Assoc. 2000;100(12):1511-21. http://www.ncbi.nlm.nih.gov/pubmed/?term=11138444.

25. Ledoux TA, Hingle MD, Baranowski T. Relationship of fruit and vegetable intake with adiposity: a systematic review. Obes Rev. 2011;12(5):e143-50. doi:10.1111/j.1467-789X.2010.00786.x.

26. Evans CE, Christian MS, Cleghorn CL, Greenwood DC, Cade JE. Systematic review and meta-analysis of school-based interventions to improve daily fruit and vegetable intake in children aged 5 to 12 y. Am J Clin Nutr. 2012;96(4):889-901. doi:10.3945/ajen.111.030270.

27. Larson NI, Story M, Eisenberg ME, Neumark-Sztainer D. Food preparation and purchasing roles among adolescents: associations with sociodemographic characteristics and diet quality. J Am Diet Assoc. 2006;106(2):211-8. doi:10.1016/j.jada.2005.10.029.

28. Howarth NC, Saltzman E, Roberts SB. Dietary fiber and weight regulation. Nutr Rev. 2001;59(5):129-39. http://www.ncbi.nlm.nih.gov/pubmed/11396693.

29. Fox MK, Condon E, Crepinsek, MK, et. al. School Nutrition Dietary Assessment Study IV, Vol. I: School Foodservice Operations, School Environments, and Meals Offered and Served. Alexandria, VA: U.S. Department of Agriculture, Food and Nutrition Service, Office of Research and Analysis; 2012. http://www.fns.usda.gov/sites/default/files/SNDA-IV_Vol1Pt1_0.pdf.

30. Vernarelli JA, Mitchell DC, Hartman TJ, Rolls BJ. Dietary energy density is associated with body weight status and vegetable intake in U.S. children. $J$ Nutr. 2011;141(12):2204-10. doi:10.3945/jn.111.146092. 
31. Patterson E, Wärnberg J, Poortvliet E, Kearney JM, Sjöström M. Dietary energy density as a marker of dietary quality in Swedish children and adolescents: the European Youth Heart Study. Eur J Clin Nutr. 2010;64(4):356-63. doi:10.1038/ejcn.2009.160.

32. Academy of Nutrition and Dietetics. Fruit and Vegetable Intake and Childhood Overweight. Evidence Analysis Library. http://andevidencelibrary.com/evidence.cfm?evidence_summary_id=25. Accessed February 14, 2013.

33. Lin B-H, Morrison RM. Higher fruit consumption linked with lower body mass index. Food Rev. 2002;25:28-32.

34. Lin B-H, Huang CL, French SA. Factors associated with women's and children's body mass indices by income status. Int J Obes Relat Metab Disord. 2004;28(4):536-42. http://www.nature.com/ijo/journal/v28/n4/full/0802604a.html.

35. Newby PK, Peterson KE, Berkey CS, Leppert J, Willett WC, Colditz GA. Dietary composition and weight change among low-income preschool children. Arch Pediatr Adolesc Med. 2003;157(8):759-64. doi:10.1001/archpedi.157.8.759.

36. Bandini LG, Vu D, Must A, Cyr H, Goldberg A, Dietz WH. Comparison of highcalorie, low-nutrient-dense food consumption among obese and non-obese adolescents. Obes Res. 1999;7(5):438-43. http://www.ncbi.nlm.nih.gov/pubmed/10509600.

37. Gillis LJ, Bar-or O. Food away from home, sugar-sweetened drink consumption and juvenile obesity. J Am Coll Nutr. 2003;22(6):539-45. http://www.ncbi.nlm.nih.gov/pubmed/?term=14684760.

38. Kelishadi R, Pour MH, Sarraf-Zadegan N, et al. Obesity and associated modifiable environmental factors in Iranian adolescents: Isfahan Healthy Heart Program Heart Health Promotion from Childhood. Pediatr Int. 2003;45(4):435-42. http://www.ncbi.nlm.nih.gov/pubmed/?term=12911481.

39. Tanasescu M, Ferris AM, Himmelgreen DA, Rodriguez N, Pérez-escamilla R. Biobehavioral factors are associated with obesity in Puerto Rican children. $J$ Nutr. 2000;130(7):1734-42. http://www.ncbi.nlm.nih.gov/pubmed/?term=10867044.

40. Melgar-Quiñonez HR, Kaiser LL. Relationship of child-feeding practices to overweight in low-income Mexican-American preschool-aged children. J Am Diet Assoc. 2004;104(7):1110-9. http://www.ncbi.nlm.nih.gov/pubmed/?term=15215770.

41. Rockett HR, Berkey CS, Field AE, Colditz GA. Cross-sectional measurement of nutrient intake among adolescents in 1996. Prev Med. 2001;33(1):27-37. http://www.ncbi.nlm.nih.gov/pubmed/?term=11482993.

42. Hanley AJ, Harris SB, Gittelsohn J, Wolever TM, Saksvig B, Zinman B. Overweight among children and adolescents in a Native Canadian community: prevalence and associated factors. Am J Clin Nutr. 2000;71(3):693-700. http://www.ncbi.nlm.nih.gov/pubmed/?term=10702161.

43. Wang Y, Ge K, Popkin BM. Why do some overweight children remain overweight, whereas others do not? Public Health Nutr. 2003;6(6):549-58. http://www.ncbi.nlm.nih.gov/pubmed/14690036.

44. Faith MS, Dennison BA, Edmunds LS, Stratton HH. Fruit juice intake predicts increased adiposity gain in children from low-income families: weight status-byenvironment interaction. Pediatrics. 2006;118(5):2066-75. http://www.ncbi.nlm.nih.gov/pubmed/?term=17079580. 
45. Epstein LH, Gordy CC, Raynor HA, Beddome M, Kilanowski CK, Paluch R. Increasing fruit and vegetable intake and decreasing fat and sugar intake in families at risk for childhood obesity. Obes Res. 2001;9(3):171-8. doi:10.1038/oby.2001.18.

46. Field AE, Gillman MW, Rosner B, Rockett HR, Colditz GA. Association between fruit and vegetable intake and change in body mass index among a large sample of children and adolescents in the United States. Int J Obes Relat Metab Disord. 2003;27(7):821-6. http://www.ncbi.nlm.nih.gov/pubmed/?term=12821968.

47. Matthews VL, Wien M, Sabaté J. The risk of child and adolescent overweight is related to types of food consumed. Nutr J. 2011;10(1):71. doi:10.1186/1475-289110-71.

48. Newby PK. Plant foods and plant-based diets: protective against childhood obesity? Am J Clin Nutr. 2009;89(5):1572S-1587S. doi:10.3945/ajcn.2009.26736G.

49. Biro FM, Wien M. Childhood obesity and adult morbidities. Am J Clin Nutr. 2010;91(5):1499S-1505S. http://www.ncbi.nlm.nih.gov/pmc/articles/PMC2854915/.

50. Bazzano LA. The high cost of not consuming fruits and vegetables. J Am Diet Assoc. 2006;106(9):1364-8. doi:10.1016/j.jada.2006.06.021.

51. Muñoz de Chávez $M$, Chávez $A$. Diet that prevents cancer: recommendations from the American Institute for Cancer Research. Int J Cancer Suppl. 1998;11:85-9. http://www.ncbi.nlm.nih.gov/pubmed/9876487.

52. Ludwig DS, Pereira MA, Kroenke $\mathrm{CH}$, et al. Dietary fiber, weight gain, and cardiovascular disease risk factors in young adults. JAMA. 1999;282(16):1539-46. http://www.ncbi.nlm.nih.gov/pubmed/?term=10546693.

53. Mikkilä V, Räsänen L, Raitakari OT, Pietinen P, Viikari J. Longitudinal changes in diet from childhood into adulthood with respect to risk of cardiovascular diseases: The Cardiovascular Risk in Young Finns Study. Eur J Clin Nutr. 2004;58(7):103845. http://www.ncbi.nlm.nih.gov/pubmed/?term=15220946.

54. He FJ, Nowson CA, MacGregor GA. Fruit and vegetable consumption and stroke: meta-analysis of cohort studies. The Lancet. 2006;367(9507):320-326. http://www.ncbi.nlm.nih.gov/pubmed/16443039.

55. Northstone K, Emmett PM. Are dietary patterns stable throughout early and midchildhood? A birth cohort study. Br J Nutr. 2008;100(5):1069-76. doi:10.1017/S0007114508968264.

56. Schwartz C, Scholtens PA, Lalanne A, Weenen H, Nicklaus S. Development of healthy eating habits early in life. Review of recent evidence and selected guidelines. Appetite. 2011;57(3):796-807. doi:10.1016/j.appet.2011.05.316.

57. Van't Riet J, Sijtsema SJ, Dagevos H, De Bruijn GJ. The importance of habits in eating behaviour. An overview and recommendations for future research. Appetite. 2011;57(3):585-96. doi:10.1016/j.appet.2011.07.010.

58. Ebbeling CB, Leidig MM, Sinclair KB, Hangen JP, Ludwig DS. A reduced-glycemic load diet in the treatment of adolescent obesity. Arch Pediatr Adolesc Med. 2003;157(8):773-9. doi:10.1001/archpedi.157.8.773.

59. Livesey G, Taylor R, Hulshof T, Howlett J. Glycemic response and health--a systematic review and meta-analysis: relations between dietary glycemic properties and health outcomes. Am J Clin Nutr. 2008;87(1):258S-268S. http://www.ncbi.nlm.nih.gov/pubmed/?term=18175766.

60. Knekt P, Kumpulainen J, Järvinen R, et al. Flavonoid intake and risk of chronic diseases. Am J Clin Nutr. 2002;76(3):560-8. http://www.ncbi.nlm.nih.gov/pubmed/12198000. 
61. Maynard M, Gunnell D, Emmett P, Frankel S, Davey Smith G. Fruit, vegetables, and antioxidants in childhood and risk of adult cancer: the Boyd Orr cohort. $J$ Epidemiol Community Health. 2003;57(3):218-25. http://www.ncbi.nlm.nih.gov/pubmed/12594199.

62. Rolls BJ. The relationship between dietary energy density and energy intake. Physiol Behav. 2009;97(5):609-15. doi:10.1016/j.physbeh.2009.03.011.

63. Krebs-Smith SM, Guenther PM, Subar AF, Kirkpatrick SI, Dodd KW. Americans do not meet federal dietary recommendations. J Nutr. 2010;140(10):1832-8. doi:10.3945/jn.110.124826.

64. Hiza HA, Casavale KO, Guenther PM, Davis CA. Diet quality of Americans differs by age, sex, race/ethnicity, income, and education level. J Acad Nutr Diet. 2013;113(2):297-306. doi:10.1016/j.jand.2012.08.011.

65. Guenther PM, Reedy J, Krebs-Smith SM. Development of the Healthy Eating Index-2005. J Am Diet Assoc. 2008;108(11):1896-901. doi:10.1016/j.jada.2008.08.016.

66. Guenther PM, Casavale KO, Reedy J, et al. Update of the Healthy Eating Index: HEI-2010. J Acad Nutr Diet. 2013;113(4):569-80. doi:10.1016/j.jand.2012.12.016.

67. Krølner R, Rasmussen M, Brug J, Klepp KI, Wind M, Due P. Determinants of fruit and vegetable consumption among children and adolescents: a review of the literature. Part II: qualitative studies. Int J Behav Nutr Phys Act. 2011;8(1):112. doi:10.1186/1479-5868-8-112.

68. Story $\mathrm{M}$, Kaphingst KM, French $\mathrm{S}$. The role of schools in obesity prevention. Future Child. 2006;16(1):109-42. http://www.ncbi.nlm.nih.gov/pubmed/16532661.

69. Gleason P, and Suitor C. Children's Diets in the Mid-1990s: Dietary Intake and Its Relationship with School Meal Participation. Mathematica Policy Research. 2001. http://ideas.repec.org/p/mpr/mprres/2443.html.

70. Lantz EM, Wood P. Nutritional condition of New Mexican children. J Am Diet Assoc. 1958;34(11):1199-207. http://www.ncbi.nlm.nih.gov/pubmed/13587156.

71. Melnik TA, Rhoades SJ, Wales KR, Cowell C, Wolfe WS. Food Consumption Patterns of Elementary Schoolchildren in New York City. J Am Diet Assoc. 1998;98(2):159-164. doi:10.1016/S0002-8223(98)00040-6.

72. Roos EB, Hirvonen T, Mikkilä V, Karvonen S, Rimpelä M. Household educational level as a determinant of consumption of raw vegetables among male and female adolescents. Prev Med. 2001;33(4):282-91. doi:10.1006/pmed.2001.0882.

73. Fox, MK, Hamilton, WL, Lin, B-H. Effects Of Food Assistance And Nutrition Programs On Nutrition And Health: Volume 4, Executive Summary Of The Literature Review. 2004. http://ideas.repec.org/p/ags/uersfa/33871.html.

74. Department of Agriculture. Nutrition standards in the national school lunch and school breakfast programs; final rule. 2012;77(17):4088-4167. http://www.gpo.gov/fdsys/pkg/FR-2012-01-26/pdf/2012-1010.pdf.

75. Condon EM, Crepinsek MK, Fox MK. School meals: types of foods offered to and consumed by children at lunch and breakfast. J Am Diet Assoc. 2009;109(2 Suppl):S67-78. doi:10.1016/j.jada.2008.10.062.

76. Upton D, Upton $\mathrm{P}$, Taylor C. Fruit and vegetable intake of primary school children: a study of school meals. J Hum Nutr Diet. 2012;25(6):557-62. doi:10.1111/j.1365277X.2012.01270.x.

77. Rasmussen M, Krølner R, Klepp KI, et al. Determinants of fruit and vegetable consumption among children and adolescents: a review of the literature. Part I: 
Quantitative studies. Int J Behav Nutr Phys Act. 2006;3:22.

http://www.ncbi.nlm.nih.gov/pubmed/16904006.

78. De Bourdeaudhuij I, Te Velde S, Brug J, et al. Personal, social and environmental predictors of daily fruit and vegetable intake in 11-year-old children in nine European countries. Eur J Clin Nutr. 2008;62(7):834-41. doi:10.1038/sj.ejcn.1602794.

79. Bandura A. Social Foundations of Thought and Action: A Social Cognitive Theory. Prentice Hall; 1986.

80. Gaines, A, Turner, LW. Improving Fruit and Vegetable Intake Among Children : A Review of Interventions Utilizing the Social Cognitive Theory. Californian J Health Promot. 2009;7(1);52-66. http://cjhp.fullerton.edu/Volume7_2009/Issue1/gaines.pdf.

81. McLeroy KR, Bibeau D, Steckler A, Glanz K. An ecological perspective on health promotion programs. Health Educ Q. 1988;15(4):351-77.

http://www.uib.no/filearchive/filetopic paper-ecological-perspective-mcleroy.pdf.

82. Birch LL. Development of food preferences. Annu Rev Nutr. 1999;19(1):41-62. doi: 0.1146/annurev.nutr.19.1.41.

83. Bernstein A, Nelson ME, Tucker KL, et al. A home-based nutrition intervention to increase consumption of fruits, vegetables, and calcium-rich foods in community dwelling elders. J Am Diet Assoc. 2002;102(10):1421-7.

http://www.ncbi.nlm.nih.gov/pubmed/12396159.

84. French SA, Stables $\mathrm{G}$. Environmental interventions to promote vegetable and fruit consumption among youth in school settings. Prev Med. 2003;37(6 Pt 1):593-610. http://www.ncbi.nlm.nih.gov/pubmed/?term=14636793.

85. Perry CL, Bishop DB, Taylor GL, et al. A randomized school trial of environmental strategies to encourage fruit and vegetable consumption among children. Health Educ Behav. 2004;31(1):65-76.

http://www.ncbi.nlm.nih.gov/pubmed/?term=14768658.

86. Townsend N, Foster $\mathrm{C}$. Developing and applying a socio-ecological model to the promotion of healthy eating in the school. Public Health Nutr. 2013;16(6):1101-8. doi:10.1017/S1368980011002655.

87. Fitzgerald, N, Spaccarotella, K. Barriers to a healthy lifestyle: from individuals to public policy -an ecological perspective. Journal of Extension. 2009;47(1). http://www.joe.org/joe/2009february/a3.php.

88. Glanz K, Rimer BK, Viswanath K. Health Behavior and Health Education: Theory, Research, and Practice. John Wiley \& Sons; 2008.

89. Reicks M, Redden JP, Mann T, Mykerezi E, Vickers Z. Photographs in lunch tray compartments and vegetable consumption among children in elementary school cafeterias. JAMA. 2012;307(8):784-5. doi:10.1001/jama.2012.170.

90. Wansink B, Shimizu M, Camps G. What would Batman eat?: priming children to make healthier fast food choices. Pediatr Obes. 2012;7(2):121-3. doi:10.1111/j.2047-6310.2011.00003.x.

91. Wansink B, Just DR, Hanks AS, Smith LE. Pre-sliced fruit in school cafeterias: children's selection and intake. Am J Prev Med. 2013;44(5):477-80. doi:10.1016/j.amepre.2013.02.003.

92. Wansink $B$, Just $D R$, Payne $C R$, Klinger MZ. Attractive names sustain increased vegetable intake in schools. Prev Med. 2012;55(4):330-2. doi:10.1016/j.ypmed.2012.07.012. 
93. Moore L, De Silva-Sanigorski A, Moore SN. A socio-ecological perspective on behavioural interventions to influence food choice in schools: alternative, complementary or synergistic? Public Health Nutr. 2013;16(6):1000-5. doi:10.1017/S1368980012005605.

94. Norton MI, Mochon D, Ariely D. The IKEA effect: When labor leads to love. $J$ Consum Psychol. 2012;22(3):453-460. doi:10.1016/j.jcps.2011.08.002.

95. Ahuvia AC. Beyond the extended self: Loved objects and consumers' identity narratives. J Consum Res. 2005;32(1):171-184. http://ideas.repec.org/a/ucp/jconrs/v32y2005i1p171-184.html

96. Belk RW. Possessions and the extended self. Journal of Consumer Research. 1988;15(22):139-168. http://www.jstor.org/stable/2489522.

97. Dittmar H. The Social Psychology of Material Possessions: To Have Is to Be. Harvester Wheatsheaf; 1992.

98. Furby L. Understanding the psychology of possession and ownership: A personal memoir and an appraisal of our progress. J Soc Behav Pers. 1991;66:457-463.

99. Blanchette L, Brug J. Determinants of fruit and vegetable consumption among 612-year-old children and effective interventions to increase consumption. J Hum Nutr Diet. 2005;18(6):431-43. doi:10.1111/j.1365-277X.2005.00648.x.

100. Hanson NI, Neumark-Sztainer D, Eisenberg ME, Story M, Wall M. Associations between parental report of the home food environment and adolescent intakes of fruits, vegetables and dairy foods. Public Health Nutr. 2005;8(1):77-85. http://www.ncbi.nlm.nih.gov/pubmed/15705248.

101. Kratt P, Reynolds K, Shewchuk R. The role of availability as a moderator of family fruit and vegetable consumption. Health Educ Behav. 2000;27(4):471-82. http://www.ncbi.nlm.nih.gov/pubmed/10929754.

102. Brug J, Tak NI, Te Velde SJ, Bere E, De Bourdeaudhuij I. Taste preferences, liking and other factors related to fruit and vegetable intakes among schoolchildren: results from observational studies. Br J Nutr. 2008;99 Suppl 1(S1):S7-S14. doi:10.1017/S0007114508892458.

103. Birch LL, Mcphee L, Shoba BC, Pirok E, Steinberg L. What kind of exposure reduces children's food neophobia? Looking vs. tasting. Appetite. 1987;9(3):171-8. http://www.ncbi.nlm.nih.gov/pubmed/3435134.

104. Galloway AT, Lee Y, Birch LL. Predictors and consequences of food neophobia and pickiness in young girls. J Am Diet Assoc. 2003;103(6):692-8. doi:10.1053/jada.2003.50134.

105. Oliveria SA, Ellison RC, Moore LL, Gillman MW, Garrahie EJ, Singer MR. Parentchild relationships in nutrient intake: the Framingham Children's Study. Am J Clin Nutr. 1992;56(3):593-8. http://www.ncbi.nlm.nih.gov/pubmed/1503074.

106. Pearson N, Biddle SJ, Gorely T. Family correlates of fruit and vegetable consumption in children and adolescents: a systematic review. Public Health Nutr. 2009;12(2):267-83. doi:10.1017/S1368980008002589.

107. Vereecken CA, Maes L, De Bacquer D. The influence of parental occupation and the pupils' educational level on lifestyle behaviors among adolescents in Belgium. $J$ Adolesc Health. 2004;34(4):330-8. doi:10.1016/j.jadohealth.2003.07.011.

108. Vereecken CA, Keukelier E, Maes L. Influence of mother's educational level on food parenting practices and food habits of young children. Appetite. 2004;43(1):93-103. doi:10.1016/j.appet.2004.04.002. 
109. Johansson L, Thelle DS, Solvoll K, Bjørneboe GE, Drevon CA. Healthy dietary habits in relation to social determinants and lifestyle factors. $\mathrm{Br} \mathrm{J}$ Nutr. 1999;81(3):211-20. http://www.ncbi.nlm.nih.gov/pubmed/?term=10434847.

110. Cullen KW, Baranowski T, Rittenberry L, Olvera N. Social-environmental influences on children's diets: results from focus groups with African-, Euro- and MexicanAmerican children and their parents. Health Educ Res. 2000;15(5):581-90. http://www.ncbi.nlm.nih.gov/pubmed/?term=11184217.

111. Neumark-Sztainer D, Wall M, Perry C, Story M. Correlates of fruit and vegetable intake among adolescents. Findings from Project EAT. Prev Med. 2003;37(3):198208. http://www.ncbi.nlm.nih.gov/pubmed/?term=12914825.

112. Neumark-Sztainer D, Hannan PJ, Story M, Croll J, Perry C. Family meal patterns: associations with sociodemographic characteristics and improved dietary intake among adolescents. J Am Diet Assoc. 2003;103(3):317-22. doi:10.1053/jada.2003.50048.

113. Klepp KI, Pérez-Rodrigo C, De Bourdeaudhuij I, et al. Promoting fruit and vegetable consumption among European schoolchildren: rationale, conceptualization and design of the pro children project. Ann Nutr Metab. 2005;49(4):212-20. http://www.ncbi.nlm.nih.gov/pubmed/?term=16088084.

114. Baranowski T, Smith M, Hearn MD, et al. Patterns in children's fruit and vegetable consumption by meal and day of the week. J Am Coll Nutr. 1997;16(3):216-23. http://www.ncbi.nlm.nih.gov/pubmed/9176827.

115. Glynn L, Emmett $P$, Rogers I. Food and nutrient intakes of a population sample of 7-year-old children in the south-west of England in 1999/2000 - what difference does gender make? J Hum Nutr Diet. 2005;18(1):7-19. doi:10.1111/j.1365277X.2004.00582.X

116. Lien N, Jacobs DR, Klepp KI. Exploring predictors of eating behaviour among adolescents by gender and socio-economic status. Public Health Nutr. 2002;5(5):671-81. doi:10.1079/PHN2002334.

117. Lien N, Lytle LA, Komro KA. Applying theory of planned behavior to fruit and vegetable consumption of young adolescents. Am J Health Promot. 2002;16(4):189-97. http://www.ncbi.nlm.nih.gov/pubmed/?term=11913324.

118. Reynolds KD, Baranowski T, Bishop DB, et al. Patterns in child and adolescent consumption of fruit and vegetables: effects of gender and ethnicity across four sites. J Am Coll Nutr. 1999;18(3):248-54.

http://www.ncbi.nlm.nih.gov/pubmed/?term=10376781.

119. Vereecken CA, Inchley J, Subramanian SV, Hublet A, Maes L. The relative influence of individual and contextual socio-economic status on consumption of fruit and soft drinks among adolescents in Europe. Eur J Public Health. 2005;15(3):224-32. doi:10.1093/eurpub/cki005.

120. Burdine JN, Chen MS, Gottlieb NH, Peterson FL, Demetri Vacalis T. The effects of ethnicity, sex and father's occupation on heart health knowledge and nutrition behavior of school children: the Texas youth health awareness survey. J Sch Health. 1984;54(2):87-90. http://www.ncbi.nlm.nih.gov/pubmed/?term=6563319.

121. Musaiger AO, Gregory WB. Dietary habits of school-children in Bahrain. $J R$ Soc Health. 1992;112(4):159-62. http://www.ncbi.nlm.nih.gov/pubmed/1433145.

122. Monge Rojas R. Fruits and vegetables consumption among Costa Rican adolescents. Arch Latinoam Nutr. 2001;51(1):81-5. http://www.ncbi.nlm.nih.gov/pubmed/11515237. 
123. Woodward DR. What sort of teenager has high intakes of energy and nutrients? $\mathrm{Br}$ J Nutr. 1985;54(2):325-33. http://www.ncbi.nlm.nih.gov/pubmed/4063320.

124. Woodward DR, Boon JA, Cumming FJ, Ball PJ, Williams HM, Hornsby H. Adolescents' reported usage of selected foods in relation to their perceptions and social norms for those foods. Appetite. 1996;27(2):109-17. doi:10.1006/appe.1996.0039.

125. Lowry R, Kann L, Collins JL, Kolbe LJ. The effect of socioeconomic status on chronic disease risk behaviors among US adolescents. JAMA. 1996;276(10):7927. http://www.ncbi.nlm.nih.gov/pubmed/8769588.

126. Videon TM, Manning CK. Influences on adolescent eating patterns: the importance of family meals. J Adolesc Health. 2003;32(5):365-73. http://www.ncbi.nlm.nih.gov/pubmed/12729986.

127. Adamson AJ, Rugg-Gum AJ, Appleton DR, Butler TJ, Hackett AF. Dietary sources of energy, protein, unavailable carbohydrate and fat in 11-12-year-old English children in 1990 compared with results in 1980. J Hum Nutr Diet. 1992;5(6):371385. doi:10.1111/j.1365-277X.1992.tb00177.x.

128. Sweeting $H$, Anderson A, West $P$. Socio-demographic correlates of dietary habits in mid- to late adolescence. Eur J Clin Nutr. 1994;48(10):736-48. http://www.ncbi.nlm.nih.gov/pubmed/7835328.

129. Cartwright M, Wardle J, Steggles N, Simon AE, Croker H, Jarvis MJ. Stress and dietary practices in adolescents. Health Psychol. 2003;22(4):362-9. http://www.ncbi.nlm.nih.gov/pubmed/12940392.

130. Osler M, Hansen ET. Dietary knowledge and behaviour among schoolchildren in Copenhagen, Denmark. Scand J Soc Med. 1993;21(2):135-40. http://www.ncbi.nlm.nih.gov/pubmed/8367681.

131. Rafiroiu AC, Anderson EP, Sargent RG, Evans A. Dietary practices of South Carolina adolescents and their parents. Am J Health Behav. 2002;26(3):200-12. http://www.ncbi.nlm.nih.gov/pubmed/12018756.

132. Wrieden W. Fruit and vegetable consumption of 10-11-year-old children in a region of Scotland. Health Education Journal. 1996;55(2):185-193. doi:10.1177/001789699605500206.

133. Brown T, Summerbell C. Systematic review of school-based interventions that focus on changing dietary intake and physical activity levels to prevent childhood obesity: an update to the obesity guidance produced by the National Institute for Health and Clinical Excellence. Obes Rev. 2009;10(1):110-41. doi:10.1111/j.1467789X.2008.00515.x.

134. Connelly JB, Duaso MJ, Butler G. A systematic review of controlled trials of interventions to prevent childhood obesity and overweight: a realistic synthesis of the evidence. Public Health. 2007;121(7):510-7. doi:10.1016/j.puhe.2006.11.015.

135. Kropski JA, Keckley PH, Jensen GL. School-based obesity prevention programs: an evidence-based review. Obesity (Silver Spring). 2008;16(5):1009-18. doi:10.1038/oby.2008.29.

136. Resnicow K, Davis-Hearn M, Smith M, et al. Social-cognitive predictors of fruit and vegetable intake in children. Health Psychol. 1997;16(3):272-6. http://www.ncbi.nlm.nih.gov/pubmed/?term=9152706.

137. Gibson EL, Wardle J, Watts CJ. Fruit and vegetable consumption, nutritional knowledge and beliefs in mothers and children. Appetite. 1998;31(2):205-28. http://www.ncbi.nlm.nih.gov/pubmed/?term=9792733. 
138. Reynolds KD, Yaroch AL, Franklin FA, Maloy J. Testing mediating variables in a school-based nutrition intervention program. Health Psychol. 2002;21(1):51-60. http://www.ncbi.nlm.nih.gov/pubmed/11846345.

139. Reynolds KD, Bishop DB, Chou CP, Xie B, Nebeling L, Perry CL. Contrasting mediating variables in two 5-a-day nutrition intervention programs. Prev Med. 2004;39(5):882-93. doi:10.1016/j.ypmed.2004.03.022.

140. Birch LL, Fisher JA. Appetite and eating behavior in children. Pediatr Clin North Am. 1995;42(4):931-53. http://www.ncbi.nlm.nih.gov/pubmed/7610021.

141. Domel SB, Baranowski T, Davis H, Leonard SB, Riley P, Baranowski J. Measuring fruit and vegetable preferences among 4th- and 5th-grade students. Prev Med. 1993;22(6):866-79. doi:http://www.ncbi.nlm.nih.gov/pubmed/8115344.

142. Cullen KW, Baranowski T, Owens E, Marsh T, Rittenberry L, De Moor C. Availability, accessibility, and preferences for fruit, $100 \%$ fruit juice, and vegetables influence children's dietary behavior. Health Educ Behav. 2003;30(5):615-26. http://www.ncbi.nlm.nih.gov/pubmed/?term=14582601.

143. Rozin P. Acquisition of food preferences and attitudes to food. Int J Obes. 1980;4(4):356-63. http://www.ncbi.nlm.nih.gov/pubmed/?term=6998884.

144. Wardle J, Herrera ML, Cooke L, Gibson EL. Modifying children's food preferences: the effects of exposure and reward on acceptance of an unfamiliar vegetable. Eur $\mathrm{J}$ Clin Nutr. 2003;57(2):341-8. doi:10.1038/sj.ejcn.1601541.

145. Cooke LJ, Chambers LC, Añez EV, et al. Eating for pleasure or profit: the effect of incentives on children's enjoyment of vegetables. Psychol Sci. 2011;22(2):190-6. doi:10.1177/0956797610394662.

146. Pittman DW, Parker JS, Getz BR, et al. Cost-free and sustainable incentive increases healthy eating decisions during elementary school lunch. Int J Obes (Lond). 2012;36(1):76-9. doi:10.1038/ijo.2011.205.

147. Raju S, Rajagopal P, Gilbride TJ. Marketing healthful eating to children: the effectiveness of incentives, pledges, and competitions. Journal of Marketing. 2010;74(3):93-106.

http://connection.ebscohost.com/c/articles/49071066/marketing-healthful-eatingchildren-effectiveness-incentives-pledges-competitions

148. Wengreen HJ, Madden GJ, Aguilar SS, Smits RR, Jones BA. Incentivizing children's fruit and vegetable consumption: results of a United States pilot study of the Food Dudes Program. J Nutr Educ Behav. 2013;45(1):54-9. doi:10.1016/j.jneb.2012.06.001.

149. Rosenstock IM, Strecher VJ, Becker MH. Social learning theory and the Health Belief Model. Health Educ Q. 1988;15(2):175-83. http://www.ncbi.nlm.nih.gov/pubmed/3378902.

150. Sheeshka JD, Woolcott DM, Mackinnon NJ. Social Cognitive Theory as a Framework to Explain Intentions to Practice Healthy Eating Behaviors1. J Appl Social Pyschol. 1993;23(19):1547-1573. doi:10.1111/j.1559-1816.1993.tb01047.x.

151. Domel S, Thompson W, Davis H, Baranowski T, Leonard S, Baranowski J. Psychosocial predictors of fruit and vegetable consumption among elementary school children. Health Educ Res. 1996;11(3):299-308. doi:10.1093/her/11.3.299.

152. Parcel GS, Edmundson E, Perry CL, et al. Measurement of self-efficacy for dietrelated behaviors among elementary school children. J Sch Health. 1995;65(1):237. http://www.ncbi.nlm.nih.gov/pubmed/?term=7731197.

153. Chu YL, Farmer A, Fung C, Kuhle S, Storey KE, Veugelers PJ. Involvement in home meal preparation is associated with food preference and self-efficacy among 
Canadian children. Public Health Nutr. 2013;16(1):108-12.

doi:10.1017/S1368980012001218.

154. Brug J, Oenema A, Ferreira I. Theory, evidence and Intervention Mapping to improve behavior nutrition and physical activity interventions. Int $J$ Behav Nutr Phys Act. 2005;2(1):2. doi:10.1186/1479-5868-2-2.

155. Gollwitzer PM. Implementation intentions: Strong effects of simple plans. American Psychologist. 1999;54(7):493-503. doi:10.1037/0003-066X.54.7.493.

156. Sheeran P. Intention-Behavior Relations: A Conceptual and Empirical Review. European Review of Social Psychology. 2002;12(1):1-36. doi:10.1080/14792772143000003.

157. Bogers RP, Brug J, Van Assema P, Dagnelie PC. Explaining fruit and vegetable consumption: the theory of planned behaviour and misconception of personal intake levels. Appetite. 2004;42(2):157-66. doi:10.1016/j.appet.2003.08.015.

158. Brug J, Kok GJ. Misconceptions of consumers about their own fat consuption. Voeding. 1995;56;11-14.159.

159. Brug J, Van Assema P, Lenderink T, Glanz K, Kok GJ. Self-rated dietary fat intake: association with objective assessment of fat, psychosocial factors and intention to change. J Nutr Educ. 1994;26:218-223.

160. Bourdeaudhuij ID, Oost PV. Personal and family determinants of dietary behaviour in adolescents and their parents. Psychology \& Health. 2000;15(6):751-770. http://www.tandfonline.com/doi/abs/10.1080/08870440008405579\#.UuCV1mQo4y 4.

161. Bere E, Klepp KI. Correlates of fruit and vegetable intake among Norwegian schoolchildren: parental and self-reports. Public Health Nutr. 2004;7(8):991-8. doi:10.1079/PHN2004619.

162. Bere $\mathrm{E}, \mathrm{Klepp} \mathrm{KI}$. Changes in accessibility and preferences predict children's future fruit and vegetable intake. Int J Behav Nutr Phys Act. 2005;2(1):15. doi:10.1186/1479-5868-2-15.

163. Patrick $\mathrm{H}$, Nicklas TA. A review of family and social determinants of children's eating patterns and diet quality. J Am Coll Nutr. 2005;24(2):83-92. http://www.ncbi.nlm.nih.gov/pubmed/?term=15798074.

164. Young EM, Fors SW, Hayes DM. Associations between perceived parent behaviors and middle school student fruit and vegetable consumption. J Nutr Educ Behav. 2004;36(1):2-8. http://www.ncbi.nlm.nih.gov/pubmed/14756976.

165. Hannon PA, Bowen DJ, Moinpour CM, Mclerran DF. Correlations in perceived food use between the family food preparer and their spouses and children. Appetite. 2003;40(1):77-83. http://www.ncbi.nlm.nih.gov/pubmed/?term=12631508.

166. Gillman MW, Rifas-Shiman SL, Frazier AL, et al. Family dinner and diet quality among older children and adolescents. Arch Fam Med. 2000;9(3):235-40. http://www.ncbi.nlm.nih.gov/pubmed/10728109.

167. Scaglioni S, Arrizza C, Vecchi F, Tedeschi S. Determinants of children's eating behavior. Am J Clin Nutr. 2011;94(6 Suppl):2006S-2011S. doi:10.3945/ajcn.110.001685.

168. Laska MN, Larson NI, Neumark-Sztainer D, Story M. Does involvement in food preparation track from adolescence to young adulthood and is it associated with better dietary quality? Findings from a 10-year longitudinal study. Public Health Nutr. 2012;15(7):1150-8. doi:10.1017/S1368980011003004. 
169. Story M, French S. Food Advertising and Marketing Directed at Children and Adolescents in the US. Int J Behav Nutr Phys Act. 2004;1(1):3. doi:10.1186/14795868-1-3.

170. Bowman SA, Gortmaker SL, Ebbeling CB, Pereira MA, Ludwig DS. Effects of fastfood consumption on energy intake and diet quality among children in a national household survey. Pediatrics. 2004;113(1 Pt 1):112-8. http://www.ncbi.nlm.nih.gov/pubmed/?term=14702458.

171. French SA, Story M, Neumark-Sztainer D, Fulkerson JA, Hannan P. Fast food restaurant use among adolescents: associations with nutrient intake, food choices and behavioral and psychosocial variables. Int J Obes Relat Metab Disord. 2001;25(12):1823-33. http://www.ncbi.nlm.nih.gov/pubmed/?term=11781764.

172. Taveras EM, Berkey CS, Rifas-shiman SL, et al. Association of consumption of fried food away from home with body mass index and diet quality in older children and adolescents. Pediatrics. 2005;116(4):e518-24. doi:10.1542/peds.2004-2732.

173. Van der Horst K, Oenema A, Ferreira I, et al. A systematic review of environmental correlates of obesity-related dietary behaviors in youth. Health Educ Res. 2007;22(2):203-26. http://www.ncbi.nlm.nih.gov/pubmed/16861362.

174. Birch LL, Marlin DW. I don't like it; I never tried it: Effects of exposure on two-yearold children's food preferences. Appetite. 1982;3(4):353-360. doi:10.1016/S01956663(82)80053-6.

175. Wardle J, Cooke L. Genetic and environmental determinants of children's food preferences. Br J Nutr. 2008;99 Suppl 1(S1):S15-21. doi:10.1017/S000711450889246X.

176. Andaya AA, Arredondo EM, Alcaraz JE, Lindsay SP, Elder JP. The association between family meals, TV viewing during meals, and fruit, vegetables, soda, and chips intake among Latino children. J Nutr Educ Behav. 2011;43(5):308-15. doi:10.1016/j.jneb.2009.11.005.

177. Hearn, MD, Baranowski, T, Baranowski J, et al. Environmental influences on dietary behavior among children: Availability and accessibility of fruits and vegetables enable consumption. J Health Educ. 1998;29(1);26-32. http://www.tandfonline.com/doi/abs/10.1080/10556699.1998.10603294\#.UuCW9m Qo4y4.

178. Academy of Nutrition and Dietetics. Evidence Analysis Library. Topic: Schoolbased Programs. Child Nutrition and School-Based Programs.

http://andevidencelibrary.com/topic.cfm?cat=4755. Accessed February 14, 2013.

179. Richard L, Potvin L, Kishchuk N, Prlic H, Green LW. Assessment of the integration of the ecological approach in health promotion programs. Am J Health Promot. 1996;10(4):318-28. http://www.ncbi.nlm.nih.gov/pubmed/10159711.

180. Stokols D. Translating Social Ecological Theory into Guidelines for Community Health Promotion. Am J Health Promot. 1996;10(4):282-298. doi: 10.4278/08901171-10.4.282.

181. Van Cauwenberghe E, Maes L, Spittaels $H$, et al. Effectiveness of school-based interventions in Europe to promote healthy nutrition in children and adolescents: systematic review of published and 'grey' literature. Br J Nutr. 2010;103(6):781-97. doi:10.1017/S0007114509993370.

182. Christian MS, Evans CE, Hancock N, Nykjaer C, Cade JE. Family meals can help children reach their 5 a day: a cross-sectional survey of children's dietary intake from London primary schools. J Epidemiol Community Health. 2013;67(4):332-8. doi:10.1136/jech-2012-201604. 
183. Swanson M, Branscum A, Nakayima PJ. Promoting consumption of fruit in elementary school cafeterias. The effects of slicing apples and oranges. Appetite. 2009;53(2):264-7. doi:10.1016/j.appet.2009.07.015.

184. Hanks AS, Just DR, Smith LE, Wansink B. Healthy convenience: nudging students toward healthier choices in the lunchroom. J Public Health (Oxf). 2012;34(3):370-6. doi:10.1093/pubmed/fds003.

185. Wansink B, Just DR, Payne CR. Can branding improve school lunches? Arch Pediatr Adolesc Med. 2012;166(10):967-8. doi:10.1001/archpediatrics.2012.999.

186. Wansink B, Payne CR, North J. Fine as North Dakota wine: sensory expectations and the intake of companion foods. Physiol Behav. 2007;90(5):712-6. doi:10.1016/j.physbeh.2006.12.010.

187. Wansink B, Van Ittersum K, Painter JE. Ice cream illusions bowls, spoons, and self-served portion sizes. Am J Prev Med. 2006;31(3):240-3. doi:10.1016/j.amepre.2006.04.003.

188. Mathias KC, Rolls BJ, Birch LL, et al. Serving larger portions of fruits and vegetables together at dinner promotes intake of both foods among young children. J Am Diet Assoc. 2011;112(2):266-270. doi:10.1016/j.jada.2011.08.040.

189. Meinen A, Friese B, Wright W, Carrel A. Youth gardens increase healthy behaviors in young children. $J$ Hunger Environ Nutr. 2012;7(2-3):192-204. doi:10.1080/19320248.2012.704662.

190. Fisher JO, Mennella JA, Hughes SO, Liu Y, Mendoza PM, Patrick H. Offering "dip" promotes intake of a moderately-liked raw vegetable among preschoolers with genetic sensitivity to bitterness. J Acad Nutr Diet. 2012;112(2):235-45. http://www.ncbi.nlm.nih.gov/pubmed/2274116.

191. Spill MK, Birch LL, Roe LS, Rolls BJ. Hiding vegetables to reduce energy density: an effective strategy to increase children's vegetable intake and reduce energy intake. Am J Clin Nutr. 2011;94(3):735-41. doi:10.3945/ajcn.111.015206.

192. Harnack LJ, Oakes JM, French SA, Rydell SA, Farah FM, Taylor GL. Results from an experimental trial at a Head Start center to evaluate two meal service approaches to increase fruit and vegetable intake of preschool aged children. Int $J$ Behav Nutr Phys Act. 2012;9(1):51. doi:10.1186/1479-5868-9-51.

193. Roe LS, Meengs JS, Rolls BJ. Salad and satiety. The effect of timing of salad consumption on meal energy intake. Appetite. 2012;58(1):242-8. doi:10.1016/j.appet.2011.10.003.

194. Spill MK, Birch LL, Roe LS, Rolls BJ. Hiding vegetables to reduce energy density: an effective strategy to increase children's vegetable intake and reduce energy intake. Am J Clin Nutr. 2011;94(3):735-41. doi:10.3945/ajcn.111.015206.

195. Zeinstra GG, Renes RJ, Koelen MA, Kok FJ, De Graaf C. Offering choice and its effect on Dutch children's liking and consumption of vegetables: a randomized controlled trial. Am J Clin Nutr. 2010;91(2):349-56. doi:10.3945/ajcn.2009.28529.

196. Schwartz MB. The influence of a verbal prompt on school lunch fruit consumption: a pilot study. Int J Behav Nutr Phys Act. 2007;4(1):6. doi:10.1186/1479-5868-4-6.

197. Fisher JO, Birch LL, Zhang J, Grusak MA, Hughes SO. External influences on children's self-served portions at meals. Int J Obes (Lond). 2013;37(7):954-60. doi:10.1038/ijo.2012.216.

198. Perry CL, Bishop DB, Taylor G, et al. Changing fruit and vegetable consumption among children: the 5-a-Day Power Plus program in St. Paul, Minnesota. Am J Public Health. 1998;88(4):603-9. http://www.ncbi.nlm.nih.gov/pubmed/9551002. 
199. Foerster, S, Gregson, J, Beall, D, Hudes, M, Magnuson, H, Livingstone, S, et al. The California children's 5 a day-power play! campaign: evaluation of a large scale social marketing initiative. Fam Commun Health. 1998;21:46-64.

200. Reynolds KD, Franklin FA, Binkley D, et al. Increasing the fruit and vegetable consumption of fourth-graders: results from the high 5 project. Prev Med. 2000;30(4):309-19. doi:10.1006/pmed.1999.0630.

201. Reynolds KD, Franklin FA, Leviton LC, et al. Methods, Results, and Lessons Learned from Process Evaluation of the High 5 School-Based Nutrition Intervention. Health Educ Behav. 2000;27(2):177-186. doi:10.1177/109019810002700204.

202. Te Velde SJ, Brug J, Wind M, et al. Effects of a comprehensive fruit- and vegetable-promoting school-based intervention in three European countries: the Pro Children Study. Br J Nutr. 2008;99(4):893-903. doi:10.1017/S000711450782513X.

203. Wind M, Bjelland M, Pérez-Rodrigo C, et al. Appreciation and implementation of a school-based intervention are associated with changes in fruit and vegetable intake in 10- to 13-year old schoolchildren-the Pro Children study. Health Educ Res. 2008;23(6):997-1007. doi:10.1093/her/cym078.

204. Ransley JK, Greenwood DC, Cade JE, et al. Does the school fruit and vegetable scheme improve children's diet? A non-randomised controlled trial. J Epidemiol Community Health. 2007;61(8):699-703. doi:10.1136/jech.2006.052696.

205. Reinaerts E, Crutzen R, Candel M, De Vries NK, De Nooijer J. Increasing fruit and vegetable intake among children: comparing long-term effects of a free distribution and a multicomponent program. Health Educ Res. 2008;23(6):987-96. doi:10.1093/her/cyn027.

206. Spiegel SA, Foulk D. Reducing overweight through a multidisciplinary schoolbased intervention. Obesity (Silver Spring). 2006;14(1):88-96. http://www.ncbi.nlm.nih.gov/pubmed/?term=16493126.

207. Taylor RW, Mcauley KA, Barbezat W, Strong A, Williams SM, Mann JI. APPLE Project: 2-y findings of a community-based obesity prevention program in primary school age children. Am J Clin Nutr. 2007;86(3):735-42. http://www.ncbi.nlm.nih.gov/pubmed/?term=17823440.

208. Baranowski T, Baranowski J, Cullen KW, et al. Squire's Quest! Dietary outcome evaluation of a multimedia game. Am J Prev Med. 2003;24(1):52-61. http://www.ncbi.nlm.nih.gov/pubmed/?term=12554024.

209. McAleese JD, Rankin LL. Garden-based nutrition education affects fruit and vegetable consumption in sixth-grade adolescents. J Am Diet Assoc. 2007;107(4):662-5. doi:10.1016/j.jada.2007.01.015.

210. Robinson-O'Brien R, Story M, Heim S. Impact of garden-based youth nutrition intervention programs: a review. J Am Diet Assoc. 2009;109(2):273-80. doi:10.1016/j.jada.2008.10.051.

211. Tester J, Yen I, Laraia B. Using mobile fruit vendors to increase access to fresh fruit and vegetables for schoolchildren. Prev Chronic Dis. 2012;9:110222. doi:10.5888/pcd9.110222.

212. Larson N, Story M. Are 'competitive foods' sold at school making our children fat? Health Aff (Millwood). 2010;29(3):430-5. doi:10.1377/hlthaff.2009.0716.

213. Sanchez-Vaznaugh EV, Sánchez BN, Baek J, Crawford PB. 'Competitive' food and beverage policies: are they influencing childhood overweight trends?. Health Aff (Millwood). 2010;29(3):436-46. doi:10.1377/hlthaff.2009.0745. 


\section{Purpose and Hypotheses}

In the studies described in this thesis, the SCT, SEM and behavioral economic theories and concepts were applied in several ways. SCT was used to design the methods for both Study 1 and Study 2. The SEM was primarily used as a theoretical framework to explore constructs outside of SCT which may have influenced results in both studies. Although child involvement in food preparation was not strictly a behavioral economics approach, this was the primary concept underlying the methods for Study 1.

This thesis is comprised of two studies: a behavioral intervention aimed at increasing primary school children's consumption of vegetables during school lunch using a DIY salad, and a survey of parents of 5-12 year old children investigating children's participation in home meal preparation and barriers and facilitators to participation. In the first study, selection and consumption of two side salads were compared at baseline versus two intervention days, the DIY salad alone or the DIY salad plus promotion by research staff. The hypotheses included:

\section{Study 1}

1) The number of students who take a salad on the DIY and DIY plus promotion days will be greater than the number taking a salad on the baseline day. 
2) The average amount of salad consumed by students eating lunch on the DIY and DIY plus promotion days will be greater than the amount consumed on the baseline day.

In the second study, an online survey was completed by 344 parents via Amazon MTurk using a Qualtrics platform. The hypothesis tested was:

\section{Study 2}

1) Frequency of children's involvement with food/meal preparation will be associated with parental factors including perceptions of barriers and motivators with respect to child involvement in meal preparation, self-efficacy, intention, environmental support and social norms. 
Study 1: Applying the IKEA Effect to School Lunch 


\section{Methods}

The goal of Study 1 was to increase salad consumption in school-age (512 year-old) children applying a simple behavioral concept that children would value a salad they helped to create and therefore eat it. As there is limited research investigating children's involvement with meal preparation and its potential to increase vegetable consumption, the intervention included conditions where students played a role in assembling a simple vegetable-based side salad (Do it yourself or DIY). The intervention also included a promotional element to encourage children to engage in this meal preparation role. The objectives of the intervention were 1) to increase the number of students taking a side salad with their lunch and 2) to increase the amount of salad consumed by the average student eating lunch compared to a baseline condition on six experiment days conducted between February and May, 2013 in a low-income, ethnically diverse school with historically low vegetable consumption.

\section{Subjects}

Study 1 was conducted in the Richfield (Science, Technology, Engineering, and Mathematics - STEM) Elementary school in Richfield, MN during the 2012-2013 school year. Demographic data for students at this school were available for the 2012-2013 school year through the Minnesota Department of Education (MDE) website. ${ }^{214}$ According to MDE data, a total of 775 students were enrolled in grades K-5 with 424 males (55\%), 351 females (46\%), and 480 
children of a minority population. Of those minorities, 24 students (3\%) were American Indian, 91 (12\%) were Asian/Pacific Islander, 179 (23\%) were Hispanic and 186 (24\%) were African American. The number participating in free meals as part of the NSLP was $402(52 \%)$, with $64(8 \%)$ paying a reduced-price. The school foodservice staff estimated that $20-30 \%$ of students at this school leave or are newly enrolled each school semester which may have resulted in changes in the demographic characteristics throughout the school year. This study was approved by the University of Minnesota Institutional Review Board as exempt from full committee review under exempt category 2 involving observations of public behavior.

\section{Protocol}

The primary objectives of this study were twofold: 1) to increase the number of students who took a salad and 2) to increase the average amount of salad consumed per student who ate lunch on the intervention compared to baseline days. The experiment included two side salad types, a garden and spinach salad, and three delivery conditions. The menu was matched on intervention days so that pizza was always served as the main entrée when the garden salad was served and chicken teriyaki was always served as the main entrée with the spinach salad. Fried rice, fruit, and a breadstick were also available with the chicken teriyaki meal, and raw and cooked vegetables and fruit 
were served with the pizza meal. Milk was available on all baseline and intervention days.

\section{Salad composition}

The garden salad was comprised of one and a half cups of chopped lettuce and romaine (LRC), one ounce of shredded carrots, and one ounce of frozen peas. The spinach salad was comprised of one and a half cups of a mixture of LRC and chopped spinach (half LRC, half chopped spinach), one ounce of shredded carrots, and one ounce of dried cherries.

\section{Intervention conditions}

At the Richfield STEM school, salads are typically served pre-mixed by foodservice staff about six times per month. Salads are served in a bulk container on the lunch line immediately after students take their tray and milk. Students can serve salad directly onto their tray from the bulk container. The experiment included three intervention conditions: 1) baseline (no change from usual), 2) DIY (mix your own salad or do it yourself) condition, and 3) DIY condition with promotion. Each salad type was served once under each condition and in the same order: baseline, DIY, DIY plus promotion. On the baseline day, side salads were served pre-mixed and arranged on large serving trays in separate paper bowls in the same place on the cafeteria line as when they were pre-mixed. On the DIY-intervention day, salads were served with each 
component (greens, carrots, peas/cherries) in a separate paper cup for students to mix themselves. On the DIY plus promotion day, the salads were served with each component in separate containers for students to mix themselves, but promotion was also provided in two locations (at the entrance to the cafeteria and in the lunch line). During a practice day, the protocol was tested to identify and correct any logistical complications. For the garden salad, a baseline day was conducted on 27-Feb, a DIY-salad day on 20-March, and a DIY-salad plus promotion day on 10-April. For the spinach salad, a baseline day was conducted on 20-Feb, a DIY-salad day on 11-Mar, and a DIY-salad plus promotion day on 20-May. On baseline days, the research team measured and mixed salad ingredients and served them in a $7 \mathrm{~g}$ food boat. On DIY intervention days, the research team used a $5 \mathrm{~g}$ styrofoam container for the greens, a $2 \mathrm{~g}$ paper cup for the shredded carrots, and a $1 \mathrm{~g}$ paper cup for the frozen peas or dried cherries. These three containers were placed in a $7 \mathrm{~g}$ food boat. A $41 \mathrm{~g}$ (on average) plastic container of Ken's low-fat ranch dressing was also included with each salad, unless a student wanted French dressing, in which case they received a $44 \mathrm{~g}$ plastic packet of Marzetti's low-fat French dressing. The school's Kitchen Manager advised the research team to make 100-150 garden salads and 50-100 spinach salads on each experimental day based on her estimation of how many side salads would be taken with the menu items being served. 
Intervention data collection

Intervention data collection followed a standardized protocol. Students entered the lunch room by grade $\left(3^{\text {rd }}\right.$ grade at $10: 50 \mathrm{AM} ; 4^{\text {th }}$ at $11: 05 \mathrm{AM} ; 5^{\text {th }}$ at $11: 25 \mathrm{AM} ; 1^{\text {st }}$ at 11:35AM and 11:45AM; kindergarteners at 12:05PM, 12:15PM, and 12:20PM; and $2^{\text {nd }}$ at 12:30PM). In the Richfield STEM School, students had about 30 minutes to enter the lunchroom, go through the lunch line, sit down, and eat lunch. Students had an average of ten minutes to eat their lunch meal before being dismissed for recess each day. Walking down a hallway, students stopped to enter their unique personal identification number (PIN) via a computer system to pay for lunch before entering the lunch line. On every baseline and intervention day, a researcher stood behind the lunch line to refill the salads on the lunch line as needed. He or she also explained to students that they could take a side salad along with their entrée of the day because the alternate main entrée was sometimes a salad served in a similar but larger serving container. During the practice day, students were confused about whether the side salad was the alternate entrée salad; therefore, clarification was provided throughout the study.

On DIY intervention days, the research team made DIY salads with ingredients in individual containers as described. A member of the research team consistently clarified to each student from behind the side salads on the lunch line that he or she could "mix your own salad today." On DIY plus promotion days, a cart was set up in the hallway before students entered their 
PIN. This cart had signage on it reading "You can mix your own salad today!" and two 8.5 " by $11 "$ pictures of the spinach salads, one before and one after mixing the ingredients. A researcher stood behind the cart, saying "you can mix your own salad today" in an encouraging manner as students entered the hallway, and briefly demonstrated how the salads could be mixed in the containers provided. The researcher on the lunch line consistently repeated this encouragement by asking each student, "Would you like to mix your own salad today?"

After students who took salads sat down at a table in the lunch room, they were given a small paper card with an arbitrary ordinal number by another researcher. This researcher asked each student for their PIN number and wrote a corresponding ordinal number next to the PIN number on a list of PINs organized by classroom/grade. Each student who took a salad was asked to keep their card until they finished their lunch. The card was collected along with the salad waste from each student. Salad waste was weighed separately for each child and photographed by the research team. Notes were taken for any student where something unusual occurred (e.g., the student took and used extra ranch dressing or spilled their salad).

\section{Statistical Analysis}

SAS (version 9.3) was used to analyze demographic information, frequency of selecting a salad, and salad consumption data for each experiment 
day. Ten salads were weighed to calculate mean weights for the salads on each baseline and experimental day. Garden and spinach salad data were analyzed separately. A two-sample hypothesis test for proportions was used to detect differences in the number of students who took salads on each day. The salad consumption data were not normally distributed; therefore, a Wilcoxon signedrank tests was used to detect differences in mean consumption for students who ate lunch on baseline versus intervention days. A one-way analysis of variance (ANOVA) was used to determine whether the mean salad intake differed by grade or eligibility for free or reduced price lunch. 


\section{Results}

Subjects

Overall school demographic data from the MDE for the 2012-2013 school year were used to describe the school population. In addition, demographic information about students at the school who ate lunch at the time Study 1 was completed was obtained from data reports made by the school foodservice staff on each of the data collection days (Table 1). The information was taken from an "event log" from the computer system where children entered their PIN which was matched with funds available for students to purchase meals. Kindergarten had the highest number of students eating lunch $(n=175)$, while fourth grade had the lowest $(n=96)$. The total number of students eating lunch based on the mean for each grade on the six data collection days was 598 with about 66 percent eligible for a free meal and about 10 percent eligible for a reduced price meal.

Table 1: Demographic Information for Students Eating Lunch ${ }^{a}$

\begin{tabular}{|l|c|c|c|c|}
\hline Grade & $\begin{array}{l}\text { Students Eating } \\
\text { Lunch, Mean }\end{array}$ & \multicolumn{3}{|c|}{ Eligibility, Mean (\%) } \\
\hline & & Free, n (\%) & $\begin{array}{c}\text { Reduced- } \\
\text { Price, } \mathbf{n}(\%)\end{array}$ & $\begin{array}{c}\text { Full-Price, n } \\
\text { (\%) }\end{array}$ \\
\hline $\mathbf{K}$ & 175 & $75(42.9)$ & $17(9.7)$ & $50(28.6)$ \\
\hline $\mathbf{1}$ & 143 & $68(47.6)$ & $9(6.2)$ & $41(28.7)$ \\
\hline $\mathbf{2}$ & 126 & $71(56.3)$ & $7(5.6)$ & $41(32.5)$ \\
\hline $\mathbf{3}$ & 115 & $45(39.1)$ & $8(7.0)$ & $30(26.1)$ \\
\hline $\mathbf{4}$ & 96 & $66(68.8)$ & $8(8.3)$ & $36(37.5)$ \\
\hline $\mathbf{5}$ & 114 & $67(58.9)$ & $8(7.0)$ & $26(22.8)$ \\
\hline Total & 598 & $392(65.6)$ & $57(9.5)$ & $224(37.5)$ \\
\hline
\end{tabular}

a Data are means from "event logs" from each of the six experiment days to account for student turnover at the Richfield STEM school.

${ }^{b}$ Mean percentages for eligibility are derived from the number of students eating lunch. Where row totals for each eligibility status level do not add up to the number of students eating lunch, data are missing. 
Frequency of Students Taking Salad

Frequency data for the number of students who took salad on each intervention day for both salads are presented in Tables 2 and 3. On baseline days, about $9 \%$ of students took a garden salad and $5 \%$ took a spinach salad. This was consistent with the school Kitchen Manager's estimate that $10 \%$ of students would take a garden side salad and about $5-7.5 \%$ would take a spinach salad along with the specific entrées at this school. The number of students taking the garden salad increased to about $13 \%$ on the DIY day and to almost $17 \%$ on the DIY plus promotion day, but the increases were not statistically significant. The number of students taking the spinach salad increased to about $11 \%$ and $13 \%$ on DIY and DIY plus promotion days, respectively; however, these increases were also not statistically significant.

Table 2: Frequency of Students Taking Spinach Salad by Intervention Condition $^{\mathrm{a}}$

\begin{tabular}{|c|c|c|}
\hline Spinach Salad & Number taking (\%) & Number not taking (\%) \\
\hline Baseline & $28(4.8)$ & $558(95.2)$ \\
\hline DIY & $61(10.7)$ & $508(89.3)$ \\
\hline DIY plus promotion & $79(13.4)$ & $509(86.6)$ \\
\hline
\end{tabular}

${ }^{a}$ No significant differences were observed according to two-sample hypothesis tests for proportions after Bonferroni adjustment $(\alpha=0.05, P<0.017)$

Table 3: Frequency of Students Taking Garden Salad by Intervention Condition $^{\mathrm{a}}$

\begin{tabular}{|c|c|c|}
\hline Garden Salad & Number taking (\%) & Number not taking (\%) \\
\hline Baseline & $54(8.8)$ & $561(91.2)$ \\
\hline DIY & $79(12.9)$ & $536(87.1)$ \\
\hline DIY plus promotion & $85(16.6)$ & $426(83.4)$ \\
\hline
\end{tabular}

${ }^{a}$ No significant differences were observed according to two-sample hypothesis tests for proportions after Bonferroni adjustment $(\alpha=0.05, P<0.017)$ 


\section{Side Salad Consumption}

Mean side salad consumption was calculated based on intervention condition, salad type, eligibility status, and grade. Standard deviations are high because some students consumed much more than the average and some students consumed no salad or very little.

Tables 4 and 5 present mean consumption by intervention condition. For the garden salad, mean consumption per student increased from 3.3 at baseline to 4.6 grams and from 4.6 to 4.7 grams between DIY and DIY plus promotion days, however, the increases were not statistically significant. For the spinach salad, mean consumption significantly increased from 1.9 grams at baseline to 4.1 grams on the DIY day and then to 4.4 grams on the DIY plus promotion day $(P<0.001)$. However, the increase between the DIY day and DIY plus promotion day was not statistically significant $(P=0.375)$.

Table 4: Mean Spinach Salad Intake by Intervention Condition ${ }^{a, b}$

\begin{tabular}{|l|c|c|c|}
\hline $\begin{array}{l}\text { Spinach } \\
\text { Salad }\end{array}$ & $\begin{array}{c}\text { Mean (SD) } \\
\text { grams } \\
\text { consumed }\end{array}$ & $\begin{array}{c}\text { Students who took } \\
\text { a salad, } \mathbf{n} \text { (missing } \\
\text { student data) }\end{array}$ & $\begin{array}{c}\text { Students who ate } \\
\text { lunch, } \mathbf{n}\end{array}$ \\
\hline Baseline & $1.9(11.4)$ & $23(5)$ & 583 \\
\hline DIY & $4.1(17.0)$ & $50(11)$ & 559 \\
\hline $\begin{array}{l}\text { DIY plus } \\
\text { promotion }\end{array}$ & $4.4(16.4)$ & $61(18)$ & 578 \\
\hline
\end{tabular}

${ }^{a}$ Wilcoxon signed-rank tests after Bonferroni adjustment, $\alpha=0.05, P<0.017$ ${ }^{b}$ Baseline/DIY, $\mathrm{P}=0.0006$, baseline/DIY plus promotion, $\mathrm{P}<0.0001$, DIY/DIY plus promotion, $\mathrm{P}=0.375$ 
Table 5: Mean Garden Salad Intake by Intervention Condition ${ }^{\mathrm{a}, \mathrm{b}}$

\begin{tabular}{|l|c|c|c|}
\hline $\begin{array}{l}\text { Garden } \\
\text { Salad }\end{array}$ & $\begin{array}{c}\text { Mean (SD) } \\
\text { grams } \\
\text { consumed }\end{array}$ & $\begin{array}{c}\text { Students who took } \\
\text { a salad, } \mathbf{n} \text { (missing } \\
\text { student data) }\end{array}$ & $\begin{array}{c}\text { Students who ate } \\
\text { lunch, } \mathbf{n}\end{array}$ \\
\hline Baseline & $3.3(14.0)$ & $46(6)$ & 614 \\
\hline DIY & $4.6(16.6)$ & $62(17)$ & 604 \\
\hline $\begin{array}{l}\text { DIY plus } \\
\text { promotion }\end{array}$ & $4.7(17.7)$ & $59(26)$ & 603 \\
\hline
\end{tabular}

${ }^{a}$ No significant differences were observed according to Wilcoxon signed-rank tests after Bonferroni adjustment, $\alpha=0.05, P<0.017$

${ }^{\mathrm{b}}$ Baseline/DIY, $\mathrm{P}=0.088$, baseline/DIY plus promotion, $\mathrm{P}=0.069$, DIY/DIY plus promotion, $\mathrm{P}=0.912$

Side salad consumption data by grade are presented in Tables 6 and 7 .

Mean garden salad consumption differed by grade $(P=0.0005)$ with older children (grades 3-5) consuming more salad than younger children (grades K-2), but the overall mean intake of the spinach salad did not differ by grade.

Table 6: Mean Spinach Salad Intake by Grade ${ }^{a, b}$

\begin{tabular}{|c|c|c|c|c|c|c|}
\hline Grade & \multicolumn{2}{|c|}{ Baseline } & \multicolumn{2}{c|}{ DIY } & \multicolumn{2}{c|}{ DIY plus promotion } \\
\hline & $\mathbf{g}(\mathbf{S D})$ & $\mathbf{n}^{\mathrm{c}}$ & $\mathbf{g}(\mathbf{S D})$ & $\mathbf{N}$ & $\mathbf{g}(\mathbf{S D})$ & $\mathbf{n}$ \\
\hline $\mathbf{K}$ & $1.5(8.5)$ & 125 & $2.8(18.0)$ & 121 & $4.0(14.3)$ & 119 \\
\hline $\mathbf{1}$ & $0.9(5.1)$ & 107 & $2.2(9.3)$ & 108 & $2.9(10.8)$ & 104 \\
\hline $\mathbf{2}$ & $0.8(7.7)$ & 96 & $4.7(16.6)$ & 88 & $5.8(19.2)$ & 89 \\
\hline $\mathbf{3}$ & $0.0(0.0)$ & 61 & $3.6(12.0)$ & 60 & $3.4(17.6)$ & 66 \\
\hline $\mathbf{4}$ & $4.2(18.7)$ & 97 & $3.9(17.6)$ & 92 & $4.0(14.4)$ & 91 \\
\hline $\mathbf{5}$ & $3.3(15.9)$ & 93 & $6.7(21.8)$ & 82 & $4.9(18.2)$ & 91 \\
\hline
\end{tabular}

${ }^{a}$ No significant differences were observed according to one-way ANOVA

'Intake by grade at Baseline, $\mathrm{P}=0.636$; Intake by grade on DIY day, $\mathrm{P}=0.060$; Intake by grade on DIY plus promotion day, $\mathrm{P}=0.313$

'Number of students eating lunch 
Table 7: Mean Garden Salad Intake by Grade ${ }^{a, b}$

\begin{tabular}{|c|c|c|c|c|c|c|}
\hline Grade & \multicolumn{2}{|c|}{ Baseline } & \multicolumn{2}{c|}{ DIY } & \multicolumn{2}{c|}{ DIY plus promotion } \\
\hline & $\mathbf{g}(\mathbf{S D})$ & $\mathbf{n}^{\mathrm{c}}$ & $\mathbf{g}(\mathbf{S D})$ & $\mathbf{n}$ & $\mathbf{g}(\mathbf{S D})$ & $\mathbf{n}$ \\
\hline $\mathbf{K}$ & $0.6(5.3)$ & 135 & $3.2(9.9)$ & 132 & $3.3(12.2)$ & 128 \\
\hline $\mathbf{1}$ & $3.3(11.8)$ & 115 & $2.0(10.1)$ & 109 & $8.4(24.2)$ & 108 \\
\hline $\mathbf{2}$ & $4.9(16.1)$ & 103 & $4.9(17.9)$ & 98 & $\mathrm{NA}^{\mathrm{d}}$ & $\mathrm{NA}^{\mathrm{d}}$ \\
\hline $\mathbf{3}$ & $1.2(7.7)$ & 62 & $1.4(8.0)$ & 66 & $3.9(16.1)$ & 71 \\
\hline $\mathbf{4}$ & $4.3(16.4)$ & 97 & $4.8(17.9)$ & 97 & $6.9(20.8)$ & 90 \\
\hline $\mathbf{5}$ & $5.6(21.1)$ & 98 & $9.7(25.4)$ & 93 & $6.5(22.0)$ & 95 \\
\hline
\end{tabular}

${ }^{a}$ No significant differences were observed according to one-way ANOVA

bIntake by grade at Baseline, $\mathrm{P}=0.303$; Intake by grade on DIY day, $\mathrm{P}=0.164$; Intake by grade on DIY plus promotion day, $\mathrm{P}=0.885$

'Number of students eating lunch

${ }^{\mathrm{d}} \mathrm{NA}=$ not applicable. DIY salads were not made available to second grade children on the DIY plus promotion day because not enough salads were prepared ahead of time.

Side salad consumption data by eligibility for free or reduced price meal status are presented in Tables 8 and 9 . There were no overall significant differences in mean intake of either salad by eligibility status.

Table 8: Mean Spinach Salad Intake by Eligibility

\begin{tabular}{|l|c|c|c|c|c|c|}
\hline $\begin{array}{l}\text { Spinach } \\
\text { Salad }\end{array}$ & \multicolumn{2}{|c|}{ Baseline } & \multicolumn{2}{c|}{ DIY } & \multicolumn{2}{c|}{$\begin{array}{l}\text { DIY plus } \\
\text { Promotion }\end{array}$} \\
\hline & $\mathbf{g}($ SD) & $\mathbf{n}^{\mathrm{c}}$ & $\mathbf{g}($ (SD) & $\mathbf{n}$ & $\mathbf{g}$ (SD) & $\mathbf{n}$ \\
\hline Free & 2.5 & 361 & $\begin{array}{c}3.4 \\
(14.1)\end{array}$ & 345 & $\begin{array}{c}4.3 \\
(15.9)\end{array}$ & 362 \\
\hline $\begin{array}{l}\text { Reduced- } \\
\text { Price }\end{array}$ & $1.7(8.3)$ & 49 & $\begin{array}{c}5.3 \\
(17.4)\end{array}$ & 46 & $2.1(7.7)$ & 46 \\
\hline Full-Price & $0.6(6.9)$ & 173 & $\begin{array}{c}4.3 \\
(20.2)\end{array}$ & 164 & $\begin{array}{c}4.3 \\
(16.4)\end{array}$ & 164 \\
\hline
\end{tabular}

${ }^{a}$ No significant differences were observed according to one-way ANOVA

${ }^{b}$ Intake by eligibility at Baseline, $P=0.585$; Intake by eligibility on DIY day, $P=0.966$;

Intake by eligibility on DIY plus promotion day, $\mathrm{P}=0.966$; Overall, $\mathrm{P}=0.202$

'Number of students eating lunch 
Table 9: Mean Garden Salad Intake by Eligibility ${ }^{\mathrm{a}, \mathrm{b}}$

\begin{tabular}{|c|c|c|c|c|c|c|}
\hline \multirow[t]{2}{*}{$\begin{array}{l}\text { Garden } \\
\text { Salad }\end{array}$} & \multicolumn{2}{|c|}{ Baseline } & \multicolumn{2}{|c|}{ DIY } & \multicolumn{2}{|c|}{$\begin{array}{l}\text { DIY plus } \\
\text { Promotion }\end{array}$} \\
\hline & g (SD) & $\mathrm{n}^{\mathrm{c}}$ & g (SD) & $\mathbf{n}$ & g (SD) & $\mathbf{n}$ \\
\hline Free & $\begin{array}{c}3.7 \\
(15.6)\end{array}$ & 365 & $\begin{array}{c}4.9 \\
(16.7)\end{array}$ & 359 & $\begin{array}{c}4.1 \\
(16.7)\end{array}$ & 353 \\
\hline $\begin{array}{l}\text { Reduced- } \\
\text { Price }\end{array}$ & $\begin{array}{c}5.1 \\
(19.1) \\
\end{array}$ & 51 & $\begin{array}{c}5.7 \\
(17.6)\end{array}$ & 46 & $\begin{array}{c}5.5 \\
(20.6)\end{array}$ & 49 \\
\hline Full-Price & 1.9 & 196 & $\begin{array}{c}2.8 \\
(13.1)\end{array}$ & 194 & $\begin{array}{c}5.8 \\
(18.7)\end{array}$ & 199 \\
\hline
\end{tabular}

${ }^{a}$ No significant differences were observed according to one-way ANOVA.

${ }^{b}$ ntake by eligibility at Baseline, $P=0.852$; Intake by eligibility on $D I Y$ day, $P=0.193$; Intake by eligibility on DIY plus promotion day, $P=0.375$; Overall, $P=0.309$

"Number of students eating lunch

\section{References}

214. Minnesota Department of Education. Student Data. Data Reports and Analytics. http://w20.education.state.mn.us/MDEAnalytics/Data.jsp. Accessed May 29, 2013. 
Study 2: The Kids Cooking Survey 


\section{Methods}

The goal of Study 2 was to determine which theoretical constructs were related to children's involvement with home meal preparation. A statistical model incorporated these constructs to predict the frequency of children's involvement with meal preparation. An additional goal was to contribute to the limited body of research regarding children's involvement with meal preparation as it relates to vegetable consumption. Future research can thus utilize these factors in nutrition interventions involving a meal preparation component (e.g., cooking classes). Exploiting factors that are most strongly associated with increased frequency of child involvement in meal preparation may more effectively increase children's vegetable consumption.

\section{Survey Development}

The Kids Cooking survey was developed to identify factors associated with the frequency with which children (aged 5-12) were involved in meal/food preparation at home. Explanatory factors were based on Social Cognitive Theory and included parental self-efficacy, social norms, and barriers and motivators to involving children in food/meal preparation at home, home environment and intention to involve children in food/meal preparation. Items were also included in the survey to assess child cooking behaviors and family eating and food preparation habits. Items were taken from several existing surveys that have been used previously with parents or children and previous literature on 
children's involvement with meal preparation in the home. ${ }^{153,215-217}$ Participants were primarily asked about the dinner meal as more children are likely to be present to help prepare the dinner meal compared to breakfast or lunch.

\section{Subjects}

Participants were recruited to take the final Kids Cooking Survey via the internet using Amazon's Mechanical Turk (MTurk) program. Participants for the pretesting phase were also recruited via the internet, primarily through MTurk but also through social media websites (i.e., Facebook) and via word of mouth from the research team's social and professional networks. Amazon describes MTurk as an online marketplace for work where researchers can create an account as a "Requester," gather results from Human Intelligence Tasks (HITs) completed by a "Worker" and provide financial compensation for HITS through Amazon.com. For the current study, MTurk was used to recruit participants and compensate them for completing a Kids Cooking Survey, which was administered through Qualtrics, a well-reputed survey creation and distribution service available through the University of Minnesota. The introductory information provided to potential participants included a consent information sheet and a request that those taking the survey be a custodial (primary meal-preparing) parent of at least 1 child aged 5-12 years for 4 days per week on average. The survey administration was programmed to only allow participants located in the United States to complete the survey. Participants were compensated with $\$ 0.50$ each 
for completing the survey. In the pretesting phase, the goal was to recruit 30 participants to establish test-retest reliability and to develop several parental motivator/barriers scales to assess perceptions regarding child involvement in food preparation. For the final survey, the goal was to recruit 300 participants. A total of 38 participants were recruited to take the survey a first time, 13 of whom also completed it a second time (approximately 2 weeks apart), and 384 participants were recruited to take the final survey. This study was approved by the University of Minnesota Institutional Review Board as exempt from full committee review under exempt category 2 involving survey procedures.

\section{Pretesting}

An expert review of the first draft of the survey was conducted to establish content validity. Six experts in the nutrition field (faculty, post-doctoral associates and graduate students across three university nutrition departments) provided feedback about content and operationalization of Social Cognitive Theory, and made suggestions to clarify the wording of the questions. After revisions based on comments from experts, the survey was administered two times to a small sample of participants recruited via MTurk, social media, and peer networks ( $n=38$ for the first administration and $n=13$ for the second) to establish test-retest reliability. Spearman correlation analysis was used to determine how strongly responses were correlated between the first and second administration (Table 4). Those items with correlations $<0.37$ were removed from the survey, except for 
two items that were retained because of their alignment with the theoretical framework used.

A principal components analysis was conducted with varimax rotation of responses to 36 items related to parental motivators and barriers to child involvement with meal preparation to reduce the number of items to a smaller set of relevant variables. Factor or component solutions were generated for six factor scales based on retaining components with Eigenvalues greater than $1.0^{218}$ and ordering items according to factor loadings (Table 1). The factors/scales included: negative child attitudes (Factor 1); parent-perceived personal and social benefits for their child (Factor 2); opportunities for parents to make involving their child in meal preparation into a learning or educational experience (Factor 3); parent-perceived familial and social benefits for their child (Factor 4); parent-perceived child health benefits from preparing meals (Factor 5); and parent barriers to child involvement with meal preparation (Factor 6). Scale scores were calculated by summing the responses across the items that made up each factor scale and are presented as means (SD) (Table 1). Cronbach a coefficients were calculated to estimate the internal reliability of the scales with alpha $>0.7$ considered acceptable (Table 1) ${ }^{219}$ Correlation coefficients ranged from 0.67 (Factor 4) to 0.88 (Factor 1). Spearman correlation analysis was used to determine the correlation of each item with the corresponding scale (scale r) (Table 1). 
Factor loadings were between 0.58 and 0.82 for Factor 1 (negative child attitude scale) (6 items), with the scale $r$ ranging from 0.60 to 0.87 and an overall mean of 2.5 (where the response option was 1-5). The overall test-retest correlation coefficient was 0.91 . Factor 1 factor loadings ranged from 0.67 to 0.82 , Pearson correlation coefficients ranged from 0.52 to 0.93 , and means in this scale ranged from 2.2 to 3.1 . For Factor 2 (parent-perceived personal and social benefits of child involvement with meal preparation scale) (6 items), factor loadings ranged from 0.51 to 0.92 , Pearson correlation coefficients for each item and the scale ranged from 0.66 to 0.73 . Means in this scale were high with strong agreement with the statements, ranging from $3.7(S D=0.9)$ to 4.1 $(S D=0.8)$. The test-retest correlation coefficient for the scale was 0.83 . Factor 3 (parent-perceived learning opportunities for children) contained 5 items and means ranged from $3.7(S D=0.9)$ to $4.1(S D=0.7)$. Factor loadings for this scale ranged from 0.53 to 0.81 and Pearson correlation coefficients for each item and the scale ranged from 0.65 to 0.74 . The test-retest correlation coefficient was 0.76. Factor 4 (parent-perceived child familial and social benefits) contained 3 items with means of $4.1(\mathrm{SD}=0.5)$ to $4.2(\mathrm{SD}=0.6)$. Factor loadings for these three items ranged from 0.67 to 0.82 and Pearson correlation coefficients for each item and the scale ranged from 0.77 to 0.80 . Factor 5 (parent-perceived child health benefits of helping to prepare meals) contained two items, with high means (3.6 to 4.1), factor loadings ( 0.50 and 0.72 ), and scale $r$ between 0.89 and 0.90. Lastly, Factor 6 (parent-perceived barriers to involving their children with 
meal preparation) contained four items with means ranging from $2.3(S D=1.2)$ to 3.7 $(\mathrm{SD}=0.9)$. Test retest correlation coefficients were in the acceptable range for most items and scales (only two individual items had coefficients $<0.43$ while coefficients for all scales were $>.55)$.

Table 1: Factors Related to Child Involvement with Meal Preparation

\begin{tabular}{|c|c|c|c|c|}
\hline & $\begin{array}{l}\text { Factor } \\
\text { Loading }\end{array}$ & Scale $r^{a}$ & Mean (SD) & $\begin{array}{l}\text { Test-retest } \\
\text { correlation }^{c}\end{array}$ \\
\hline $\begin{array}{l}\text { Factor 1: Negative } \\
\text { child attitudes }(\alpha= \\
0.88)^{\mathrm{d}}\end{array}$ & & & $2.5(1.0)$ & 0.91 \\
\hline $\begin{array}{l}\text { Child views meal prep } \\
\text { as a chore }\end{array}$ & 0.82 & 0.80 & $2.4(1.2)$ & 0.93 \\
\hline $\begin{array}{l}\text { Child not interested in } \\
\text { helping }\end{array}$ & 0.81 & 0.87 & $2.3(1.1)$ & 0.75 \\
\hline $\begin{array}{l}\text { Child would rather do } \\
\text { other things }\end{array}$ & 0.81 & 0.75 & $3.1(1.1)$ & 0.88 \\
\hline $\begin{array}{l}\text { Child needs to be } \\
\text { bribed to help }\end{array}$ & 0.75 & 0.82 & $2.3(1.2)$ & 0.84 \\
\hline $\begin{array}{l}\text { Child easily frustrated } \\
\text { before dinner }\end{array}$ & 0.67 & 0.60 & $2.9(1.2)$ & 0.92 \\
\hline $\begin{array}{l}\text { Child complains when } \\
\text { asked to help }\end{array}$ & 0.58 & 0.84 & $2.2(0.9)$ & 0.52 \\
\hline $\begin{array}{l}\text { Factor 2: Parent- } \\
\text { perceived child } \\
\text { personal and social } \\
\text { benefits }(\alpha=0.77)\end{array}$ & & & $3.9(0.7)$ & 0.83 \\
\hline $\begin{array}{l}\text { Child would not be } \\
\text { watching TV }\end{array}$ & 0.92 & 0.67 & $3.7(1.0)$ & 0.88 \\
\hline $\begin{array}{l}\text { Child would learn new } \\
\text { vocabulary }\end{array}$ & 0.77 & 0.66 & $4.0(0.7)$ & 0.81 \\
\hline $\begin{array}{l}\text { Child would feel a } \\
\text { sense of belonging }\end{array}$ & 0.56 & 0.66 & $4.1(0.8)$ & 0.76 \\
\hline $\begin{array}{l}\text { Child would gain } \\
\text { understanding of } \\
\text { where food comes } \\
\text { from }\end{array}$ & 0.54 & 0.73 & $4.0(0.7)$ & 0.46 \\
\hline $\begin{array}{l}\text { Child would gain } \\
\text { understanding of }\end{array}$ & 0.52 & 0.68 & $3.8(1.0)$ & 0.71 \\
\hline
\end{tabular}




\begin{tabular}{|c|c|c|c|c|}
\hline $\begin{array}{l}\text { which foods are } \\
\text { healthy }\end{array}$ & & & & \\
\hline $\begin{array}{l}\text { Child would be more } \\
\text { likely to eat with family }\end{array}$ & 0.51 & 0.71 & $3.7(0.9)$ & 0.83 \\
\hline $\begin{array}{l}\text { Factor 3: Child } \\
\text { learning possibilities } \\
(\alpha=0.75)\end{array}$ & & & $4.0(0.6)$ & 0.76 \\
\hline $\begin{array}{l}\text { Child more likely to eat } \\
\text { vegetables }\end{array}$ & 0.81 & 0.74 & $3.7(0.9)$ & 0.89 \\
\hline $\begin{array}{l}\text { Child more likely to eat } \\
\text { what they prepare }\end{array}$ & 0.78 & 0.76 & $4.0(0.9)$ & 0.59 \\
\hline $\begin{array}{l}\text { Child would learn } \\
\text { cooking basics }\end{array}$ & 0.76 & 0.65 & $4.1(0.7)$ & 0.82 \\
\hline $\begin{array}{l}\text { Child would gain } \\
\text { confidence in cooking } \\
\text { skills }\end{array}$ & 0.59 & 0.70 & $4.1(0.6)$ & 0.54 \\
\hline $\begin{array}{l}\text { Child would gain } \\
\text { understanding of what } \\
\text { goes into food }\end{array}$ & 0.53 & 0.70 & $4.1(0.7)$ & 0.43 \\
\hline $\begin{array}{l}\text { Factor 4: Parent- } \\
\text { perceived child } \\
\text { familial and social } \\
\text { benefits }(\alpha=0.67)\end{array}$ & & & $4.1(0.4)$ & 0.62 \\
\hline $\begin{array}{l}\text { Child would feel like } \\
\text { they contribute to the } \\
\text { family }\end{array}$ & 0.82 & 0.79 & $4.1(0.6)$ & 0.64 \\
\hline $\begin{array}{l}\text { Parent can talk to child } \\
\text { about healthy food }\end{array}$ & 0.75 & 0.77 & $4.1(0.5)$ & 0.68 \\
\hline $\begin{array}{l}\text { Child would gain } \\
\text { appreciation for } \\
\text { cooking }\end{array}$ & 0.67 & 0.80 & $4.2(0.6)$ & 0.64 \\
\hline $\begin{array}{l}\text { Factor 5: Child } \\
\text { health benefits of } \\
\text { helping to prepare } \\
\text { meals ( } \alpha=0.73 \text { ) }\end{array}$ & & & $3.8(0.7)$ & 0.55 \\
\hline $\begin{array}{l}\text { Child more likely to try } \\
\text { new foods }\end{array}$ & 0.72 & 0.89 & $3.6(1.0)$ & 0.74 \\
\hline $\begin{array}{l}\text { Child more likely to eat } \\
\text { healthfully as an adult }\end{array}$ & 0.50 & 0.90 & $4.1(0.8)$ & 0.60 \\
\hline $\begin{array}{l}\text { Factor 6: Parent } \\
\text { barriers to child } \\
\text { involvement with } \\
\text { meal preparation ( } \alpha \\
=0.75 \text { ) }\end{array}$ & & & $3.3(0.8)$ & 0.74 \\
\hline
\end{tabular}




\begin{tabular}{|l|c|c|c|c|}
\hline $\begin{array}{l}\text { Child would make a } \\
\text { mess }\end{array}$ & 0.83 & 0.74 & $3.6(0.9)$ & 0.21 \\
\hline $\begin{array}{l}\text { Would take more time } \\
\text { for parent to involve } \\
\text { child }\end{array}$ & 0.70 & 0.78 & $3.7(0.9)$ & 0.37 \\
\hline $\begin{array}{l}\text { Would take more work } \\
\text { for parent to involve } \\
\text { child }\end{array}$ & 0.57 & 0.84 & $3.4(1.2)$ & 0.67 \\
\hline $\begin{array}{l}\text { Kitchen is too small to } \\
\text { involve child }\end{array}$ & 0.42 & 0.55 & $2.3(1.2)$ & 0.80 \\
\hline
\end{tabular}

${ }^{a}$ Scale r: correlation of each item score with the scale score (sum of scores for items making up the scale/number of items); Spearman correlation analysis

${ }^{\mathrm{b}}$ Mean +/- standard deviation (SD); five point scale (strongly disagree - strongly agree 1$5, N A=3$ )

${ }^{\mathrm{C}}$ Test-retest correlation coefficient, Spearman correlation analysis, $\mathrm{n}=29$ for first administration and $n=13$ for second

${ }^{\mathrm{d}}$ Cronbach alpha coefficient

Several of the factor scales were correlated with other factor scales according to Spearman correlation analysis. Factor 2 was highly correlated with Factors $3(r=0.73), 4(r=0.73)$, and $5(r=0.69)$. Cronbach alpha coefficients for other groups of items (self-efficacy, child cooking behaviors and family eating and food preparation habits) were also acceptable at alpha $>0.7$. This information was used to modify the survey prior to final administration.

Final survey

Items in each of the six factor scales related to parental barriers and motivators to child involvement in food/meal preparation were randomized for each participant in the final survey. Those items not included in a factor scale were not included in the final survey. Each item in other scales in the final survey was also randomized (the final version of the Kids Cooking Survey can be found at Appendix 1). Additional items were added to increase the number of questions 
related to the following scales: environment (4 items), social norms (4 items) and intention (1 item). Inadvertently, five questions in the final version of the survey were repeated. The means of the participant's responses were used where there were discrepancies in answers to the same question.

\section{Statistical Analysis}

SAS (version 9.31) was used to conduct the statistical analysis for the Kids Cooking Survey. According to the primary goals in conducting the survey, data are reported for several variables as assessed in the final survey. These include parent food preparation practices and child consumption practices; parental perceptions related to children's involvement with meal preparation grouped according to principal components analysis results (Table 1); socialcognitive factors related to child involvement with meal preparation, including self-efficacy, social norms, intention and environment; children's responsibilities during meal preparation; and a linear regression model using parental motivators/barriers regarding child involvement in meal preparation, environment, social norms, intention and self-efficacy to predict the frequency of child involvement with meal preparation. The dependent variable (child involvement in meal/food preparation) was assessed with the following items: When at home, how often does your child help prepare or cook... Breakfast, Lunch, Supper/Dinner, Snacks (?). The five response options ranged from "Never or almost never" (assigned a value of 1 ) to " 5 or more times a week" (assigned a 
value of 5). Responses to each question were added and divided by 4 to determine a mean response for the dependent variable.

Frequency data (number and percent for each item) are reported for demographic characteristics, the number of children in participants' homes, frequency of child involvement in meal preparation, parent food preparation practices, child food consumption practices, and child responsibilities during meal preparation. For assessment of parental motivators/barriers to child involvement with meal preparation and the environment, items representing barriers were reverse-coded.

For the linear regression analysis, the model included the dependent variable (frequency of child involvement with meal preparation at home) and several independent variables including parental self-efficacy, environment, social norms, intention, barrier/motivator factor scales 1, 2 and 6 (negative child attitudes, parent perceived benefits, and parent barriers) as well as controlling variables for parent age, gender, marital status, employment and race/ethnicity and child age and gender. Barrier/motivator factor scales 3, 4 and 5 were not included because they were highly correlated with factor scale 2 . 


\section{Results}

Final survey

A total of 384 responses were recorded in the University of Minnesota's Qualtrics website for the final Kids Cooking Survey. Of the total, most were recruited via MTurk; however, an unknown number of participants were also recruited via social media and peer networks (participants were not asked to report how they were recruited). Some respondents did not finish the survey or did not report having any children aged 5-12 years $(n=16)$, some completed it more than once as indicated by duplicate IP addresses $(n=9)$, and some completed the survey in under four minutes, the minimum time established that it should take to mindfully complete the final Kids Cooking Survey $(n=51)$. After eliminating invalid or incomplete responses and duplicate participant data, data from 344 participants who completed the final Kids Cooking Survey were included in data analysis.

Demographic characteristics for participants in the final Kids Cooking Survey are presented in Table 2. Almost all $(95 \%, n=187)$ had some college education. Two hundred and thirty-two (68\%) participants were either married or engaged in a domestic partnership. Differences in demographic characteristics were determined by gender, as it is a primary mediator of children's involvement with meal preparation in the home, and because women do the majority of food preparation in the home. There were significant differences in race $(0.027)$, education $(P=0.044)$, and employment status $(p<0.0001)$ by gender. Two 
hundred and sixty-nine (78\%) participants were White and $161(47 \%)$ of White participants were female. African American participation ranked second to White participation $(n=33,10 \%)$ and the majority $(n=27)$ of African American participants were also female. A higher proportion of women were white $(47 \%)$ than were men (31\%). The majority were employed for wages $(n=196,57 \%), 50$ (15\%) were self-employed, and $53(15.4 \%)$ were homemakers, 52 of whom were women, and 17 (4.9\%) participants were students. The high proportion of female homemakers accounted for the significant difference in employment by gender. There were no significant differences in age $(P=0.150)$ or marital status $(P=0.139)$ by gender.

Table 2: Demographic Characteristics of Kids Cooking Survey Participants $^{\mathrm{a}}$

\begin{tabular}{|l|c|c|c|c|}
\hline & All, n (\%) & $\begin{array}{c}\text { Men, } \mathbf{n} \\
\mathbf{( \% )}\end{array}$ & Women, n (\%) & P-value $^{\mathbf{b}}$ \\
\hline Total & $344(100)$ & $137(39.8)$ & $207(60.2)$ & \\
\hline Age & & & & 0.150 \\
\hline 18-34 years old & $202(58.7)$ & $90(44.6)$ & $112(55.4)$ & \\
\hline $35-54$ years old & $133(38.7)$ & $44(12.8)$ & $89(25.9)$ & \\
\hline $55-64$ years old & $6(1.7)$ & $3(0.9)$ & $3(0.9)$ & \\
\hline 65 years or older & $1(0.3)$ & $0(0.0)$ & $1(0.3)$ & \\
\hline Prefer not to answer & $2(0.6)$ & $0(0.0)$ & $2(0.6)$ & \\
\hline Race/Ethnicity & All, $\mathbf{n}(\mathbf{\%})$ & $\begin{array}{c}\text { Men, } \mathbf{n} \\
(\mathbf{\%})\end{array}$ & Women, $\mathbf{n ~ ( \% )}$ & 0.027 \\
\hline White & $269(78.2)$ & $108(31.4)$ & $161(46.8)$ & \\
\hline Hispanic & $24(7.0)$ & $10(3.0)$ & $14(4.1)$ & \\
\hline African American & $33(9.6)$ & $6(1.7)$ & $27(7.9)$ & \\
\hline Native American & $5(1.5)$ & $2(0.6)$ & $3(0.9)$ & \\
\hline $\begin{array}{l}\text { Asian/Pacific } \\
\text { Islander }\end{array}$ & $30(8.7)$ & $18(5.2)$ & $12(3.5)$ & \\
\hline Other & $5(1.5)$ & $1(0.3)$ & $2(0.6)$ & \\
\hline
\end{tabular}




\begin{tabular}{|c|c|c|c|c|}
\hline Prefer not to answer & $2(0.6)$ & $1(0.3)$ & $1(0.3)$ & \\
\hline Education & All, n (\%) & $\begin{array}{c}\text { Men, } n \\
(\%)\end{array}$ & Women, n (\%) & 0.044 \\
\hline 8th grade or less & $1(0.3)$ & $1(0.3)$ & $0(0.0)$ & \\
\hline $\begin{array}{l}\text { Some high school, } \\
\text { no diploma }\end{array}$ & $3(0.9)$ & $2(0.6)$ & $1(0.3)$ & \\
\hline $\begin{array}{l}\text { High school } \\
\text { graduate, diploma or } \\
\text { the equivalent }\end{array}$ & $33(9.6)$ & $16(4.7)$ & $17(4.9)$ & \\
\hline Some college credit & $103(30.3)$ & $32(9.3)$ & $71(20.7)$ & \\
\hline $\begin{array}{l}\text { Associate degree (2- } \\
\text { year) }\end{array}$ & $45(13.1)$ & $12(8.8)$ & $33(15.9)$ & \\
\hline Bachelor's degree & $122(35.6)$ & $56(16.3)$ & $66(19.2)$ & \\
\hline $\begin{array}{l}\text { Master's, } \\
\text { professional or } \\
\text { doctorate degree }\end{array}$ & $33(9.6)$ & $16(4.7)$ & $17(5.0)$ & \\
\hline Prefer not to answer & $3(0.9)$ & $1(0.3)$ & $2(0.6)$ & \\
\hline Marital Status & All, n (\%) & $\begin{array}{c}\text { Men, } n \\
(\%)\end{array}$ & Women, n (\%) & 0.139 \\
\hline $\begin{array}{l}\text { Single, never } \\
\text { married }\end{array}$ & $73(21.3)$ & $34(9.9)$ & $39(11.4)$ & \\
\hline $\begin{array}{l}\text { Married or domestic } \\
\text { partnership }\end{array}$ & $232(67.6)$ & $88(25.7)$ & $144(42.0)$ & \\
\hline $\begin{array}{l}\text { Widowed, divorced, } \\
\text { or separated }\end{array}$ & $27(7.9)$ & $8(2.3)$ & $19(5.5)$ & \\
\hline Prefer not to answer & $11(3.2)$ & $7(2.0)$ & $4(1.2)$ & \\
\hline $\begin{array}{l}\text { Employment } \\
\text { Status }\end{array}$ & All, n (\%) & $\begin{array}{c}\text { Men, } \mathbf{n} \\
(\%)\end{array}$ & Women, n (\%) & $<0.0001$ \\
\hline Employed for wages & $196(57.0)$ & $99(28.8)$ & $97(28.2)$ & \\
\hline Self-employed & $50(14.5)$ & $21(6.1)$ & $29(8.4)$ & \\
\hline $\begin{array}{l}\text { Out of work and } \\
\text { looking for work }\end{array}$ & $11(3.2)$ & $3(0.9)$ & $8(2.3)$ & \\
\hline $\begin{array}{l}\text { Out of work, not } \\
\text { looking for work }\end{array}$ & $3(0.9)$ & $1(0.3)$ & $2(0.6)$ & \\
\hline Homemaker & $53(15.4)$ & $1(0.3)$ & $52(15.1)$ & \\
\hline Student & $17(4.9)$ & $5(1.5)$ & $12(3.5)$ & \\
\hline Military & $4(1.2)$ & $3(0.9)$ & $1(0.3)$ & \\
\hline Retired & $2(0.6)$ & $0(0.0)$ & $2(0.6)$ & \\
\hline Unable to work & $3(0.9)$ & $1(0.3)$ & $2(0.6)$ & \\
\hline Prefer not to answer & $5(1.5)$ & $3(0.9)$ & $2(0.6)$ & \\
\hline
\end{tabular}

${ }^{a}$ Rounding error may result in percentages not adding up to 100; missing participant data may result in a total $\mathrm{n}$ less than 344 in some categories

${ }^{\mathrm{b}} \mathrm{P}$ value according to Chi square tests for differences by gender $(p<0.05)$ 
The number and age of children in participants' homes are presented in Table 3. There were a total of 298 boys and 238 girls in participants' homes with 338 between 5 and 8 years and 208 between 9 and 12 years. The majority of participants reported having between one and three children between the ages of 5 and 12 ( $n=282$ boys; $n=227$ girls). Participants were asked to indicate both gender and age of each child in their home between 5 and 12 years; however, some did not indicate both age and gender and may have had children outside the age range of 5-12 years.

Table 3: Number of Children by Gender and Age

\begin{tabular}{|c|c|c|c|c|c|c|c|c|c|c|}
\hline & \multicolumn{1}{|c|}{ Gender } & \multicolumn{10}{|c|}{ Age (yrs) } \\
\hline & Boy & Girl & $\mathbf{5}$ & $\mathbf{6}$ & $\mathbf{7}$ & $\mathbf{8}$ & $\mathbf{9}$ & $\mathbf{1 0}$ & $\mathbf{1 1}$ & $\mathbf{1 2}$ \\
\hline Child 1 & 195 & 131 & 62 & 55 & 49 & 41 & 34 & 31 & 27 & 43 \\
\hline Child 2 & 67 & 76 & 22 & 22 & 17 & 24 & 14 & 16 & 11 & 10 \\
\hline Child 3 & 20 & 20 & 11 & 3 & 5 & 5 & 4 & 2 & 6 & 3 \\
\hline Child 4 & 8 & 5 & 3 & 3 & 1 & 2 & 0 & 0 & 0 & 3 \\
\hline Child 5 & 3 & 3 & 1 & 1 & 1 & 1 & 0 & 1 & 0 & 1 \\
\hline Child 6 & 3 & 1 & 1 & 0 & 2 & 1 & 0 & 0 & 0 & 0 \\
\hline Child 7 & 1 & 1 & 1 & 0 & 0 & 2 & 0 & 0 & 0 & 0 \\
\hline Child 8 & 1 & 1 & 2 & 0 & 0 & 0 & 1 & 0 & 1 & 0 \\
\hline Total & 298 & 238 & 103 & 84 & 75 & 76 & 53 & 50 & 45 & 60 \\
\hline
\end{tabular}

${ }^{\text {a}}$ For every child under the age of 18 living in participants' home at least 4 days each week; where numbers in age do not match those in gender in a single row, participants did not report one or the other about that child.

Table 4 reports the frequency of parent food preparation practices and child food consumption practices in the home. Of all participants, 264 (77\%) reported preparing their child's dinner meal at least four times per week and 73 (21\%) reported preparing their child's dinner meal 1-3 times per week.

Participants indicated a need for convenience in meal preparation in the home. 
About half $(n=167,49 \%)$ reported buying takeout for their child's dinner meal 1-3 times per week. The majority of participants $(n=218,63 \%)$ reported using readymade sauces 1-3 times per week. Likewise, the majority of participants $(n=217$, $63 \%$ ) reported making pre-prepared dishes for their child 1-3 times per week. Of all participants, $85(25 \%)$ reported asking their child to help prepare meals once per week or never; $196(57 \%)$ 1-3 times per week, and 63 (18\%) at least four times per week. In terms of children's consumption behaviors, the majority of parents $(n=66-71 \%)$ reported their children eat their dinner meal at home with the family at the dinner table and eat the same foods as their parents at least four times per week. The majority of participants also reported their children eat dinner alone $(n=268,78 \%)$ and with siblings but not adults $(n=219,64 \%)$ less than once per week. Parents reported that $123(36 \%)$ children watch TV during dinner less than once per week; $137(40 \%)$ 1-3 times per week; and $83(24 \%)$ at least four times per week.

Table 4. Parent Food Preparation Practices and Child Consumption Practices $^{\mathrm{a}}$

\begin{tabular}{|c|c|c|c|}
\hline $\begin{array}{l}\text { Parent Food Preparation } \\
\text { Practices }\end{array}$ & $\begin{array}{c}\text { Never or } \\
<1 \mathrm{x} / \text { week, } \mathrm{n} \\
(\%)\end{array}$ & $\begin{array}{c}1- \\
3 x / \text { week, } \\
\text { n (\%) }\end{array}$ & $\begin{array}{c}4 \text { or more } \\
\text { times/week, } \\
n(\%)\end{array}$ \\
\hline Prepare child's dinner meal & $7(2.0)$ & $73(21.2)$ & $264(76.7)$ \\
\hline Get takeout for child's dinner & $168(48.8)$ & $167(48.6)$ & $9(2.6)$ \\
\hline Use ready-made sauces & $94(27.3)$ & $218(63.4)$ & $32(9.3)$ \\
\hline Make pre-prepared dishes & $109(31.7)$ & $217(63.1)$ & $18(5.2)$ \\
\hline $\begin{array}{l}\text { Parent asks child to help } \\
\text { prepare meals }\end{array}$ & $85(24.7)$ & $196(57.0)$ & $63(18.3)$ \\
\hline $\begin{array}{l}\text { Child Food Consumption } \\
\text { Practices }\end{array}$ & $\begin{array}{c}\text { Never or } \\
<1 \mathrm{x} / \text { week, } \mathrm{n} \\
(\%)\end{array}$ & $\begin{array}{c}1- \\
3 \times / w e e k, \\
\text { n (\%) }\end{array}$ & $\begin{array}{c}4 \text { or more } \\
\text { times/week, } \\
\text { n }(\%)\end{array}$ \\
\hline
\end{tabular}




\begin{tabular}{|l|c|c|c|}
\hline Child eats dinner at home table & $29(8.5)$ & $84(24.5)$ & $230(67.1)$ \\
\hline Child eats dinner alone & $268(78.1)$ & $63(18.4)$ & $12(3.5)$ \\
\hline $\begin{array}{l}\text { Child eats dinner with siblings, } \\
\text { not adults }\end{array}$ & $219(63.7)$ & $86(25.0)$ & $39(11.3)$ \\
\hline Child watches TV during dinner & $123(35.9)$ & $137(39.9)$ & $83(24.2)$ \\
\hline $\begin{array}{l}\text { Child eats same food as parent } \\
\text { for dinner }\end{array}$ & $12(3.5)$ & $88(25.6)$ & $244(70.9)$ \\
\hline $\begin{array}{l}\text { Family sits down together for } \\
\text { dinner }\end{array}$ & $19(5.6)$ & $97(28.5)$ & $225(66.0)$ \\
\hline
\end{tabular}

${ }^{a}$ Where $n$ does not equal 344 , data are missing

To assess the frequency of child involvement with meal preparation, participants were asked how often their child helps prepare or cook breakfast, lunch, dinner or supper, and snacks. Item responses ranged from almost never (1) to five or more times per week (5). The scale generated from the sum of these mean scores $($ Cronbach alpha $=0.71)$ served as the dependent variable in the linear regression analysis described later. Means for each meal ranged from 2.7 $(S D=1.4)$ for breakfast, $2.8(S D=1.2)$ for lunch, $2.9(S D=1.1)$ for dinner/supper to $3.4(\mathrm{SD}=1.3)$ for snacks.

Parents were asked to rate their agreement with 6 factor scales about barriers and facilitators to involving their child with meal preparation in the home (Table 5). Scales related to benefits had high scores $(\geq 4)$ while those related to negative child attitudes or parent barriers had lower mean scores $(\leq 3)$. 
Table 5: Factors Related to Child Involvement with Meal Preparation ${ }^{\mathrm{a}}$

\begin{tabular}{|l|c|}
\hline & Mean (SD) $^{\mathbf{a}}$ \\
\hline Factor 1: Negative child attitudes ( $\mathrm{n}=338)$ & $2.5(1.0)$ \\
\hline $\begin{array}{l}\text { Factor 2: Parent-perceived child personal and social benefits } \\
(\mathrm{n}=336)\end{array}$ & $4.2(0.6)$ \\
\hline Factor 3: Child learning possibilities ( $\mathrm{n}=342)$ & $4.3(0.6)$ \\
\hline $\begin{array}{l}\text { Factor 4: Parent-perceived child familial and social benefits } \\
(\mathrm{n}=339)\end{array}$ & $4.3(0.6)$ \\
\hline $\begin{array}{l}\text { Factor 5: Child health benefits from helping to prepare meals } \\
(\mathrm{n}=342)\end{array}$ & $4.1(0.6)$ \\
\hline $\begin{array}{l}\text { Factor 6: Parent barriers to child involvement with meal prep } \\
(\mathrm{n}=339)\end{array}$ & $3.1(0.6)$ \\
\hline
\end{tabular}

${ }^{\mathrm{a}}$ Mean \pm standard deviation (SD); five point scale (strongly disagree - strongly agree 1-5, $\mathrm{NA}$ and neither disagree nor agree $=3$ )

The survey assessed four social-cognitive factors related to child involvement with meal preparation: self-efficacy, social norms, the home meal preparation environment, and parental intentions (Table 6). The self-efficacy scale contained 9 items with means ranging from $2.3(S D=1.1)$ to $3.9(S D=1.0)$ based on whether the items were positively or negatively worded (negatively worded items were reverse-coded in calculating an overall self-efficacy scale score (mean 2.3, SD=0.5). The social norms scale contained six items with means ranging from $3.0(\mathrm{SD}=1.2)$ to $3.6(\mathrm{SD}=1.1)$ with an overall scale score of mean $3.2(S D=0.8)$. The environment scale contained four items with means ranging from $2.3(S D=1.1)$ to $3.6(S D=1.1)$ with one negatively worded item reverse-coded to calculate the overall environment scale score (mean 3.3, $\mathrm{SD}=0.7)$. Lastly, the intentions scale contained two items with means 3.6 $(S D=1.3)$ for the item related to likelihood of the parent involving the child in meal preparation and $3.0(S D=1.1)$ for the item related to the parent planning to 
involve the child in meal preparation over the next month. Cronbach alpha coefficients were calculated for each scale based on the data from the final survey and were in the acceptable to good range ( 0.70 to 0.85$)$. Test retest information is not available for these scales because some of the items in each were only included in the final survey and not in the pretesting phase.

Table 6: Social-Cognitive Factors Related to Child Involvement with Meal Preparation

\begin{tabular}{|c|c|}
\hline & Mean (SD) \\
\hline Self-Efficacy $^{a}(\alpha=0.85, n=331)$ & $2.3(0.5)$ \\
\hline Can involve child when tired & $2.5(1.2)$ \\
\hline Can involve child when busy & $2.4(1.2)$ \\
\hline Can involve child when there is an evening event & $2.4(1.2)$ \\
\hline $\begin{array}{l}\text { Can involve child when parent does not have necessary } \\
\text { ingredients }\end{array}$ & $2.3(1.1)$ \\
\hline Can involve child when kitchen is not clean & $2.6(1.2)$ \\
\hline Can involve child when kitchen is organized & $3.8(1.0)$ \\
\hline $\begin{array}{l}\text { Can involve child when it can be a learning experience for } \\
\text { the child }\end{array}$ & $3.8(1.0)$ \\
\hline Can involve child when they want to help & $3.9(1.0)$ \\
\hline Can involve child when making food they like & $3.8(0.9)$ \\
\hline Social Norms ${ }^{b}(\alpha=0.72, n=340)$ & $3.2(0.8)$ \\
\hline Parents of participant think children should help & $3.3(1.1)$ \\
\hline Spouse of participant thinks child should help & $3.6(1.1)$ \\
\hline Participant grew up helping & $3.4(1.3)$ \\
\hline Participant thinks all children are expected to help & $3.0(1.2)$ \\
\hline Participant's spouse grew up helping & $3.1(1.3)$ \\
\hline Participant's friends' children help & $3.2(1.0)$ \\
\hline Factor 3: Environment ${ }^{3}(\alpha=0.70, n=340)$ & $3.3(0.7)$ \\
\hline Layout of kitchen makes involving child easy & $3.5(1.1)$ \\
\hline Size of kitchen makes involving child easy & $3.6(1.1)$ \\
\hline Kitchen equipment makes involving child easy & $3.6(1.0)$ \\
\hline Limited food makes involving child difficult & $2.3(1.1)$ \\
\hline Factor 4: Intentions ${ }^{4}(\alpha=0.80, n=330)$ & $3.3(1.1)$ \\
\hline Likely to involve child $3 x /$ week next month ${ }^{c}$ & $3.6(1.3)$ \\
\hline
\end{tabular}




\begin{abstract}
\begin{tabular}{|l|l}
\hline Plan to involve child how many times per week next month & \\
\hline & $3.0(1.1)$
\end{tabular}
${ }^{a}$ Mean \pm standard deviation (SD); Five point scale (not at all sure to extremely sure 1-5); $\mathrm{n}=342-344$ for individual items; negatively worded items were reverse-coded

${ }^{\mathrm{b}}$ Mean \pm standard deviation (SD); Five point scale (strongly disagree - strongly agree 15 , NA = 3); $n=342-344$ for individual items

${ }^{c}$ Mean \pm standard deviation (SD); How likely is it you will involve your child in meal preparation at least three nights per week over the next month? Five point scale (very unlikely to very likely 1-5); $n=342-344$ for individual items; negatively worded item was reverse-coded

${ }^{\mathrm{d}}$ Mean \pm standard deviation (SD); How many times per week do you plan to involve your child in meal preparation over the next month? Five point scale (never/rarely to more than 5 times a week, 1-5); $n=342-344$ for individual items
\end{abstract}

Table 7 presents frequency data for parent's responses regarding their child's responsibilities during meal preparation. Generally, only about $5 \%$ indicated that each item was not applicable to them. Two hundred and thirty eight (70\%) participants reported their child follows a recipe, 291 (85\%) reported their child measures ingredients, $265(77 \%)$ reported their child uses a microwave, 302 (88\%) reported their child mixes ingredients, and 233 (68\%) reported their child makes a salad during meal preparation. On the other hand, $205(60 \%)$ of parents reported their child does not cut or chop fruits or vegetables, $194(57 \%)$ reported their child does not use a blender, $213(62 \%)$ reported their child does not use a stove, and 240 (70\%) reported their child does not use an oven during meal preparation. 
Table 7: Frequency of Child Responsibilities during Meal Preparation ${ }^{\mathrm{a}}$

\begin{tabular}{|l|c|c|c|}
\hline $\begin{array}{l}\text { Prompt: When child helps prepare } \\
\text { meals, he/she... }\end{array}$ & Yes (\%) & No (\%) & NA (\%) \\
\hline cuts/chops FV & $124(36.1)$ & $205(59.6)$ & $15(4.4)$ \\
\hline peels FV & $192(56.0)$ & $138(40.2)$ & $13(3.8)$ \\
\hline follows a recipe & $238(69.6)$ & $85(24.9)$ & $19(5.6)$ \\
\hline measures ingredients & $291(84.8)$ & $39(11.4)$ & $13(3.8)$ \\
\hline uses a blender & $127(37.0)$ & $194(56.6)$ & $22(6.4)$ \\
\hline uses a mixer & $180(52.6)$ & $147(43.0)$ & $15(4.4)$ \\
\hline uses a microwave & $265(77.0)$ & $62(18.0)$ & $17(4.9)$ \\
\hline uses a stove & $114(33.3)$ & $213(62.3)$ & $15(4.4)$ \\
\hline uses an oven & $86(25.2)$ & $240(70.4)$ & $15(4.4)$ \\
\hline cooks meat & $72(21.0)$ & $253(73.8)$ & $18(5.3)$ \\
\hline opens canned food & $159(46.4)$ & $169(49.3)$ & $15(4.4)$ \\
\hline mixes ingredients & $302(88.3)$ & $27(7.9)$ & $13(3.8)$ \\
\hline makes a salad & $233(68.3)$ & $92(27.0)$ & $16(4.7)$ \\
\hline
\end{tabular}

${ }^{a}$ Rounding may result in total percentages not equal to 100 ; where rows do not equal 344 indicates missing data

${ }^{\mathrm{b}}$ Participant chose not applicable or did not answer question

Table 8 provides the results from a linear regression analysis to predict child involvement in meal preparation using the frequency with which the child helps prepare meals as the dependent variable and barrier/motivators and social cognitive factors as independent variables and demographic characteristics as controlling variables. As Factor 2 was highly correlated with Factors 3, 4, and 5, these factors were not included in the analysis. Intentions $(P<0.0001)$ and participant gender $(P=0.044)$ were the only two statistically significant predictors of frequency of child meal preparation involvement. A 1-unit positive shift in the intentions scale would result in a 1.36 unit positive shift in frequency of child involvement in meal preparation, while if the participant was a female, frequency of child involvement in meal preparation would result in a 0.99 unit positive shift. Two variables were approaching significance at the $\alpha=0.05$ level, including self- 
efficacy $(P=0.103)$ and age of the child $(P=0.058)$. The model explained about $30 \%$ of the variance in the child meal preparation score indicating frequency of the child helping to prepare breakfast, lunch, dinner/supper and snacks $(\mathrm{P}<0.0001)$. 
Table 8: Linear Regression Analysis to Predict Child Meal Preparation Involvement $^{\mathrm{a}}$

\begin{tabular}{|l|c|c|c|}
\hline $\begin{array}{l}\text { Model } \\
\text { Overall R-square }\left(\boldsymbol{r}^{\mathbf{b}}\right)=\mathbf{0 . 3 3 4} \\
\left(\text { Adjusted } \boldsymbol{r}^{\mathbf{b}}=\mathbf{0 . 2 9 3}\right), \mathbf{P}<\mathbf{0 . 0 0 0 1}\end{array}$ & $\begin{array}{c}\text { Parameter } \\
\text { Estimate }^{2}\end{array}$ & $\begin{array}{c}\text { Standard } \\
\text { Error }\end{array}$ & $\mathbf{P}$-value \\
\hline Factors & -0.36 & 0.39 & 0.35 \\
\hline $\begin{array}{l}\text { Factor 2 (Parent-perceived } \\
\text { personal and social child benefits) }\end{array}$ & -0.2 & 0.3 & 0.508 \\
\hline Factor 1 (Negative child attitudes) & 0.02 & 0.31 & 0.952 \\
\hline Factor 6 (Parent barriers) & & & \\
\hline Social-Cognitive Factors & 1.36 & 0.26 & $<0.0001$ \\
\hline Intentions & 0.63 & 0.38 & 0.103 \\
\hline Self-efficacy & 0.55 & 0.47 & 0.247 \\
\hline Social norms & -0.22 & 0.41 & 0.589 \\
\hline Environment & & & \\
\hline Demographics & 0.99 & 0.49 & 0.044 \\
\hline Participant gender & 0.95 & 0.5 & 0.058 \\
\hline Age of child 1 & 0.59 & 0.49 & 0.225 \\
\hline Race/ethnicity: white & 0.39 & 0.47 & 0.413 \\
\hline Marital status & 0.19 & 0.19 & 0.310 \\
\hline Participant educational level & 0.001 & 0.43 & 0.998 \\
\hline Participant age & -0.06 & 0.523 & 0.907 \\
\hline Participant employment status & -0.415 & 0.435 & 0.341 \\
\hline Gender of child 1 & & & \\
\hline
\end{tabular}

${ }^{\mathrm{a}}$ Child meal preparation involvement $=$ sum of mean scores for frequency of child helping to prepare breakfast, lunch, dinner/supper, snacks; possible range was 0-20, higher scores indicate higher frequency of meal preparation involvement ${ }^{\mathrm{b}}$ Represents differences in frequency of child meal preparation involvement 


\section{References}

215. Fulkerson JA, Story M, Neumark-Sztainer D, Rydell S. Family meals: perceptions of benefits and challenges among parents of 8- to 10-year-old children. J Am Diet Assoc. 2008;108(4):706-9. doi:10.1016/j.jada.2008.01.005.

216. Campbell K, Crawford D, Jackson $M$, et al. Family food environments of 5-6-yearold-children: does socioeconomic status make a difference?. Asia Pac J Clin Nutr. 2002;11 Suppl 3:S553-61.

217. Campbell KJ, Crawford DA, Ball K. Family food environment and dietary behaviors likely to promote fatness in 5-6 year-old children. Int $J$ Obes (Lond). 2006;30(8):1272-80.

218. Kaiser HF, Caffrey J . Alpha factor analysis. Psychometrika. 1965;30:1-44. http://ideas.repec.org/a/spr/psycho/v30y1965i1p1-14.html.

219. Nunnally JC, Bernstein IH. Psychometric Theory. New York, NY: McGraw-Hill; 1994. 


\section{Discussion}


This thesis presented the results of two studies. The first used a DIY salad-kit and promotion in elementary school-age children as a means to increase vegetable consumption at school lunch. The second used a survey to explore the relationships between children's involvement in home meal preparation and parental motivators/barriers to their child's involvement, selfefficacy, social norms, environmental support, and intentions. Both studies used theoretical frameworks/concepts (SCT, SEM, and behavioral economics) in their methodological design. These frameworks/concepts can also be applied to help explain the findings.

\section{Study 1: Applying the IKEA Effect to School Lunch}

The results from Study 1 are consistent with previous studies, which collectively report that the overall effect of school-based interventions to increase vegetable intake has been minimal. ${ }^{26}$ Offering a DIY salad-kit along with promotional efforts resulted in an insignificant increase in the number of students taking a salad. Only about 5-9 percent of students on average were taking a salad at the Richfield STEM School at baseline, which was increased to about 13-17 percent in the DIY plus promotion condition, depending on salad type. One possible explanation for the low number of students taking salads could be a lack of familiarity with the salad ingredients, as these foods may not have been served at home, resulting in food neophobia. This would be consistent with previous reports on the powerful effects of food neophobia and the need for 
repeated exposure to overcome it. ${ }^{82}$ It is also possible that a high proportion of students consumed a considerable amount of vegetables at home for other meals, which is a frequently cited limitation to school-based studies and a variable that was not considered in the intervention. ${ }^{26}$ Social norms may have played a significant role in determining whether students took a salad, as many students came through the lunch line in groups of friends who were conversing with each other while the intervention took place. Students who were open to taking and mixing their own salads may have conferred some of this openness to their peers, and vice versa; students who did not want to take the salad may have influenced other students in the lunch line and made them less likely to take a side salad. A previous study has shown that social norms are associated with total vegetable intake at school lunch among fifth grade children. ${ }^{220}$

Mean consumption of the spinach salad, but not the garden salad, significantly increased during the intervention. However, because conditions were not randomized, statistical causality cannot be established, and thus the results are only associated with the condition. Consumption of both the spinach and garden salad at baseline and after the intervention was quite low, with the mean well below a tenth of a serving. Even though findings may have been statistically significant for the spinach salad, a much higher increase would be needed before the findings would be significant from a public health perspective. ${ }^{8}$ The low mean consumption level reflects a low number of students taking the salad, and only a few actually eating a substantial amount. 
As this research group has been working in the Richfield STEM School for several years, novelty was not expected to play a role in increasing consumption, although students may have become sensitized to the intervention efforts over time. This awareness may have accounted for the lack of statistically significant results. The significant differences in spinach salad consumption were between baseline and intervention days, although intakes on the two intervention days did not differ significantly. These findings suggest that promotional efforts may not have made a significant impact with respect to mean consumption. The Kitchen Manager correctly estimated that more students would take and eat the garden salad at baseline, indicating that it was a more popular menu item. Mean intake of the garden salad at baseline was about 3 grams compared to only about 1 gram for the spinach salad. This may explain the insignificant results with respect to the garden salad consumption after the DIY and DIY plus promotion. The DIY salad-kit and/or promotion intervention may be more effective with foods that children like less or do not eat as frequently. Mean garden salad consumption differed significantly between older children (grades 3-5) and younger children (grades K-2). This was expected, as older children eat more than younger children because they are larger, have higher caloric requirements, and greater appetites during school lunch. In addition, as younger children may need more help making food choices and navigating the cafeteria, they may have had less time to eat their salads. Younger children's gross motor and food preparation skills are inferior to their older counterparts. Thus, they may have 
been confused by the DIY salad kit, not known how to mix their salads together despite demonstration, or may not have had the physical capacity to mix and eat salads given the short amount of time students are allowed to eat lunch at the Richfield STEM school.

Children may have felt a lack of motivation to mix their own salads. The promotion of the DIY salads was based on promotional phrases found to be effective in the literature; however, students may not have found the basic language or adult enthusiasm either motivating or exciting. ${ }^{117,118,154,160}$ Motivation has been positively associated with vegetable consumption, both independently and dependently (via knowledge) in previous studies. ${ }^{118,136,158,159}$ The results of the current study were in agreement with this previous research utilizing verbal encouragement, praise, or other methods of motivation, as a lack of motivation translates to lower vegetable consumption.

Mean side salad intake did not differ by eligibility for free or reduced price meals in the current study. The literature on the relationship between SES and vegetable intake is inconclusive, as operationalizations of SES vary in the literature. ${ }^{107,108,116,117,119,127,128}$ This raises questions about the impact of SES on vegetable intake at school lunch. In the current study, low-income students may have been hungrier and thus more likely to take the DIY salad-kits and eat more of the salads, but this was not the case. Because students in higher SES strata may have more highly educated parents (who tend to have higher vegetable consumption), ${ }^{107,108,116,117,119,127,128}$ students in higher SES strata may have eaten 
more of the side salads as a result of the intervention in the current study. However, this was also not the case. Lastly, the fact that a large proportion of students at Richfield STEM school are low-income and qualify for free lunch may have negated the ability to observe a difference by eligibility for free or reduced price meals.

Ultimately, the costs outweigh the benefits of implementing the "IKEA Effect" intervention. Cost receipts indicate it would cost nearly $\$ 130.00$ for the materials for the kits for each week of implementation. The cost of the vegetables used was not a factor, as these foods would have been purchased and sold in the absence of the intervention. The biggest cost would be foodservice staff time. Salad preparation took about 90 minutes each day, and additional time was needed to promote the salads in two distinct locations in the cafeteria. Because the results were not meaningful in terms of changing eating behaviors and thus further health outcomes, this study has limited implications for nutrition practitioners working to improve children's vegetable consumption.

Modification of the methods to enhance the intervention efforts may be necessary to yield significant results. For example, additional marketing of the salads (e.g., with a familiar figure or brand) may have increased selection and/or intake. For example, others have found that changes in positioning or naming fruits and vegetables were effective means to increase intake in cafeteria settings. ${ }^{92,184,185,221}$ The elementary school could also make changes to create an environment more conducive to healthy eating and therefore promote higher 
vegetable intake. For example, the school could schedule recess before students eat lunch. This strategy has been shown to increase intake and reduce waste of several meal components in schools. ${ }^{222}$ When recess occurs before lunch, students can socialize, be physically active, and perform other behaviors which might otherwise interfere with eating lunch. Schools should also consider lengthening the lunch period to provide students with more time to eat lunch. This research team estimated students have about 10 minutes to eat their lunch at the Richfield STEM School after sitting down at a table in the cafeteria with their food. Previous studies have shown that elementary school-aged students typically eat lunch in less than 10 minutes. ${ }^{223-225}$ Allowing children a longer time to eat may enable children to eat more vegetables, given that these foods may take a longer time to eat than other foods, especially salads made with lettuce and/or spinach.

Application of theoretical frameworks and concepts was a strength in the approach to increase vegetable intake. The intervention was relatively low-cost, did not interfere with the lunch schedule at the Richfield STEM School, used ingredients already on-hand, and had the potential to yield significant increases in vegetable consumption. A pre-established standardized protocol was strictly followed for the intervention. On the other hand, the study had several limitations. At several points in the study, researchers expressed concern about the fidelity of the clarification and promotional efforts made by some of the research staff. Implementation fidelity is imperative for health behavior change 
studies to work. ${ }^{226}$ There are variables related to SEM which were not accounted for, such as the interactions between various levels described in SEM (e.g., environment, policy, the organization, i.e., school, and interpersonal factors). For example, recent NSLP policy changes went into effect that required the Richfield STEM School to serve each student a half-cup equivalent of fruit at school. This obligatory food serving could have affected consumption of vegetables during the school lunch meal. This may not have been the case, however, given that a low proportion of students took a side salad at the Richfield STEM School, both before and after the new NSLP-related policies went into effect. Gender data were not collected, and thus gender differences could not be examined in this study. This could have been meaningful, as research regarding gender differences in children's vegetable intake yielded conflicting results. ${ }^{6,64}$ 


\section{Study 2: The Kids Cooking Survey}

Study 2 was based on frequency data collected from parents of 5-12 year old children via an online survey with respect to parental food preparation practices, child food consumption practices, and child involvement in meal preparation. Survey results, by virtue of a principle components analysis, also included six constructs related to parent-perceived motivators, facilitators, and barriers to involving their children in meal preparation in the home. Social cognitive factors including parental self-efficacy, intentions, environmental support and social norms were also measured. These factors along with parental barriers/motivators were included in a linear regression model to predict the frequency of children's involvement with meal preparation. A study of this type was not identified in a literature search; thus, these results are unique in their contribution to knowledge with respect to factors affecting child assistance with meal preparation.

The demographic data indicated that a homogenous sample was recruited via Amazon's MTurk website, with most respondents being white women with some college education or a bachelor's degree. This is in agreement with recent reports on the demographic homogeneity of MTurk workers, although demographic characteristics of MTurk workers are becoming more diverse by

including more participants from outside the U.S. ${ }^{227-230}$ Antin and Shaw ${ }^{231}$ also reported significant social desirability bias in self-reports of motivation in a recent study of MTurk workers. 
The number of children in participant's homes by gender and age was relatively evenly distributed by gender, although there were more children between the ages of 5 and 8 years than between 9 and 12 years. Gender differences were examined as women do the majority of meal preparation in the home. ${ }^{232}$ The greater number of women respondents helps explain the significant differences found for race and education by gender $(\mathrm{P}=0.027$ and $\mathrm{P}=0.044$, respectively). There was also a significant difference in employment status by gender, possibly because of the greater number of homemakers who were women $(n=52)$ compared to men $(n=1)$.

\section{Pre-testing the Kids Cooking Survey}

The pre-testing phase allowed for the grouping of items that measured similar constructs. One construct involved negative attitudes of children toward food preparation. For example, viewing meal preparation activities as a chore, or not being interested in helping with meal preparation were considered negative child attitudes. The mean response for this construct was 2.5 on a 5 point strongly disagree-strongly agree scale, indicating that parents did not sense that children had strong negative attitudes toward food preparation. This is consistent with other interventions that involved children in gardening and cooking as a means of changing eating behaviors based on their enjoyment of these activities. ${ }^{153,189,209,210}$ Several scales were established that measured personal, social and familial benefits to child involvement in meal preparation. Responses 
for all these scales were positive (means for all three were about 4.0). Another scale was established with respect to parent barriers to child involvement in meal preparation. The overall mean was 3.3 on the 5 point scale indicating that parents did not generally have strong perceptions that children should not be involved in meal preparation.

Our data reporting on frequency of parent food preparation practices and child food consumption practices in the home are in agreement with previous literature in which parents report a need for convenience. ${ }^{215,233}$ The majority reported using ready-made sauces for the dinner meal or making pre-prepared dishes, and eating takeout for the dinner meal regularly. A majority of participants reported preparing their child's dinner meal more than four times per week, and that their children eat the same food as they do, indicating that family meals were common. The majority of participants also reported asking their child to help with meal preparation three times per week or less, indicating that parents regularly involve their children in meal preparation. As many participants reported their children watch television during dinner, distractions in the home or other barriers may be preventing parents from asking their children to help with meal preparation.

Pretesting data indicate our survey had valid content from the perspective of an expert review, and had acceptable test-retest and internal consistency reliability by conventional standards. It could be utilized in future research exploring children's involvement with meal preparation. However, some items 
were not reviewed by all experts, and some items were not included in the test/re-test cohort to establish their reliability. Further testing may be necessary to establish validity and reliability for all items.

\section{The Final Kids Cooking Survey}

The frequency of child involvement in meal preparation was related to several factors based on a multivariate linear regression analysis. Intentions and participant gender were the only statistically significant predictors of frequency of child involvement in meal preparation in the model $(\beta=1.36, P<0.0001 ; \beta=0.99$, $\mathrm{P}=0.044$, respectively). The association between intentions and parental frequency of child involvement with meal preparation is unclear as it relates to health behavior change research. ${ }^{154}$ There is also an intention-behavior gap described in this literature, which may negatively affect vegetable intake by virtue of self-report bias and perceived knowledge. ${ }^{155,156,158,159}$ In general, intentions to engage in a behavior have been predictive of actually engaging in the behavior, ${ }^{117,160}$ so the same findings may have been expected in the current study. The association between being female and higher frequency of child involvement with meal preparation was not surprising, as women tend to do the majority of meal preparation in U.S. homes. ${ }^{232}$

The age of the child was nearly significant as a predictor of frequency of child involvement in meal preparation $(\beta=0.99, P=0.058)$. This was expected as older children may be more likely to be involved in meal preparation because of 
their physical maturity. There may be an optimal age at which children should be introduced to the skills involved with simple meal preparation. This should be explored further as it is important to establish healthy dietary behaviors early in life. This investigation should occur among nationally representative populations, and should include ethnically diverse and/or low-income populations.

Of the social-cognitive factors tested for an association with frequency of child involvement in meal preparation, self-efficacy was the only factor that approached statistical significance $(\beta=0.63, P=0.103)$. These results indicate that both barriers and facilitators may affect the confidence parents have in their ability to involve their child in meal preparation. Parents may be able to somewhat easily involve their children in meal preparation when it requires little self-efficacy, but not when parental obstacles arise.

Other barriers and motivators identified through principle components analysis were not significantly associated with child involvement in meal preparation. Environmental support for child involvement in meal preparation was not a predictive factor in the current study. However, because environmental support for dietary behavior is a construct of SCT and SEM, further research investigating both the environment as a mediating factor in children's involvement in meal preparation and ways to enhance parental perceptions of the home environment as it relates to meal preparation are warranted.

Parent barriers were not significantly associated with child involvement in meal preparation indicating that parental barriers may not be an avenue worth 
pursuing in future meal preparation-related interventions. This was consistent with findings in the pretesting phase, where parent perceptions of barriers to involving children in meal preparation were only moderate. Likewise, a higher education level did not predict a significantly higher frequency of involvement in meal preparation, indicating that interventions utilizing the factors described in the current study may be applicable to parents at a broad range of educational levels.

Frequency of involvement in meal preparation was assessed based on involvement in preparation of breakfast, lunch, dinner and snacks. Participants were also asked to report whether their children engaged in various tasks involved in meal preparation. The data related to the frequency of child responsibilities during meal preparation indicate that a majority of parents involve young children in simple tasks related to meal preparation in the home. A slight majority of participants indicated their children engage in tasks such as peeling fruits and vegetables or using a mixer. These tasks are easier for children to accomplish, as they pose fewer risks with regard to safety compared to using a blender or stove. Only about a third of participants reported their children engage in those tasks as a part of meal preparation. Likewise, a relatively small proportion of participants reported their child engages in more complex and potentially dangerous tasks as using an oven, cooking meat, or cutting/chopping fruits and vegetables. Future interventions should focus on involving children in simple, low-risk activities involved in meal preparation, as parents will be more 
likely to be open to involving their children in these activities. While older children may be more comfortable and proficient in performing more complex and risky tasks, and while parents may be more comfortable with older children performing them, these data were not examined for significant differences by child's age. Future research could investigate age effects in an effort to optimally design interventions to increase vegetable intake via involvement in meal preparation. As only about five percent of the participants indicated that questions in each category were not applicable to them, incorporating these simple tasks into interventions should be feasible. This is in agreement with data collected regarding kitchen equipment, which indicated that parents generally felt their kitchen equipment made involving their child in meal preparation easy. A relatively high proportion of parents indicated that their child mixes ingredients or makes a salad when participating in meal preparation, implying that these are two tasks which children can easily perform. These findings indicate that the difficulty of both of these tasks should not have affected the results in Study 1 for children of all ages involved. However, future research related to specific tasks that younger and older elementary school-age children are capable of during meal preparation could be helpful in studies that expand on the concept of child involvement in school meal preparation. As described in the literature, dietary habits, including meal preparation habits, are initiated during childhood, ${ }^{15,16,18,19-}$ 21,56 although they may become more important in later childhood and 
adolescence, when children and adolescents begin to develop independence from their parents for meal preparation.

The survey had several strengths. First and foremost, the survey went through a rigorous examination and pre-testing phase to establish validity and reliability. Items were based on theoretical constructs and concepts and research related to important factors which influence children's involvement in meal preparation. Survey items were randomized so that participants were not primed to think about items in a way that would stimulate social desirability bias or self-report bias. In the analysis, participant responses were carefully examined to remove those who were ineligible, did not complete a majority of items in the survey, or completed it more than once. Statistical analysis showed that the validity and reliability of the survey was good by conventional standards. The survey also had several limitations. While the survey reached a wide audience and was relatively inexpensive to distribute, a more diverse sample is warranted for research of this type so the sample is more representative and thus findings can be generalized to a broader population. As mentioned, some of the items were not reviewed by all experts, and some items were not included in the test/re-test cohort to establish their reliability. Only 13 participants completed test and re-test versions of the survey for reliability; therefore, MTurk may not be an optimal method to establish reliability of survey items. The item related to the gender, age, and number of children in each home could have been improved such that results by demographic categories could have been more easily 
examined. As the item was designed, participants could report their child's gender and/or age, and some participants did not report one or the other for one or more of their children. Furthermore, the analysis did not include an examination of differences by number of children in the household, and it is possible there were differences in parent-perceived motivators and barriers to meal preparation related to household size.

Research is needed to further explore the relationship between parentperceived facilitators, motivators, and barriers to involving their children in meal preparation. Research in child-perceived facilitators, motivators, and barriers related to involvement in meal preparation is also warranted. Future research should aim to develop methodologies attractive to both children and parents and it should be conducted among nationally representative and/or low-income populations. It should also take into account the reciprocal determinism construct that is part of SCT and the interactions of various levels explained in SEM (e.g., environment, the school organization, and interpersonal factors). 


\section{References}

220. Thompson VJ, Bachman CM, Baranowski T, Cullen KW. Self-efficacy and norm measures for lunch fruit and vegetable consumption are reliable and valid among fifth grade students. J Nutr Educ Behav. 2007;39(1):2-7. doi:10.1016/j.jneb.2006.06.006.

221. Just $D$, Wansink $B$. Smarter lunchrooms: using behavioral economics to improve meal selection. Choices. 2009:24(3). http://www.choicesmagazine.org/magazine/article.php?article=87.

222. Getlinger MJ, Laughlin VT, Bell E, Akre C, Arjmandi BH. Food waste is reduced when elementary-school children have recess before lunch. $J$ Am Diet Assoc. 1996;96(9):906-8. http://www.ncbi.nIm.nih.gov/pubmed/8784336.

223. Bergman EA, Buergel NS, Joseph E, Sanchez A. Time spent by schoolchildren to eat lunch. J Am Diet Assoc. 2000;100(6):696-698. doi:10.1016/S00028223(00)00202-9.

224. Buergel N. Students consuming sack lunches devote more time to eating than those consuming school lunches. J Am Diet Assoc. 2002;102(9):1283-1286. doi:10.1016/S0002-8223(02)90282-8.

225. Zandian M, loakimidis I, Bergström J, et al. Children eat their school lunch too quickly: an exploratory study of the effect on food intake. BMC Public Health. 2012;12(1):351. doi:10.1186/1471-2458-12-351.

226. Mihalic, S. The importance of implementation fidelity. Emotional \& Behavioral Disorders in Youth. 2004;4(4):83-109.

http://www.blueprintsprograms.com/publications/EBDY_4-4--Mihalic.pdf.

227. Ipeirotis, PG. Mechanical Turk: the demographics. A Computer Scientist in a Business School. http://behind-the-enemy-lines.blogspot.com/2008/03/mechanicalturk-demographics.html. Published March 19, 2008.

228. Ipeirotis, PG. The new demographics of Mechanical Turk. A Computer Scientiest in a Business School. http://www.behind-the-enemy-lines.com/2010/03/newdemographics-of-mechanical-turk.html. Published March 9, 2010.

229. Murray GR, Rugeley CR, Mitchell DG, Mondak JJ. Convenient yet not a convenience sample: Jury pools as experimental subject pools. Soc Sci Res. 2013;42(1):246-53. doi:10.1016/j.ssresearch.2012.06.002.

230. Paolacci, G, Chandler, J, Ipeirotis, PG. Running experiments on Amazon Mechanical Turk. Judgment and Decision Making. 2010;5(5):411-419. http://papers.ssrn.com/sol3/papers.cfm?abstract_id=1626226. Published July 1, 2010. Updated September 2, 2010.

231. Antin, J, Shaw, A. Social desirability bias and self-reports of motivation: a study of Amazon Mechanical Turk in the US and India. Paper presented at: CHI 2012: ACM Conference on Human Factors in Computing Systems; May 2012; Austin, TX. http://aaronshaw.org/Antin_Shaw-2012-Social_desirability_bias-CHI2012.pdf.

232. Harnack L, Story M, Martinson B, Neumark-Sztainer D, Stang J. Guess Who's Cooking? The Role of Men in Meal Planning, Shopping, and Preparation in US Families. J Am Diet Assoc. 1998;98(9):995-1000. doi:10.1016/S00028223(98)00228-4.

233. Fulkerson JA, Kubik MY, Rydell S, et al. Focus groups with working parents of school-aged children: what's needed to improve family meals?. J Nutr Educ Behav. 2011;43(3):189-93. doi:10.1016/j.jneb.2010.03.006. 


\section{Comprehensive Bibliography}

1. Deckelbaum RJ, Williams CL. Childhood obesity: the health issue. Obes Res. 2001;9 Suppl 4(11S):239S-243S. doi:10.1038/oby.2001.125.

2. Ogden CL, Carroll MD, Kit BK, Flegal KM. Prevalence of obesity and trends in body mass index among US children and adolescents, 1999-2010. JAMA. 2012;307(5):483-90. doi:10.1001/jama.2012.40.

3. National Cancer Institute. Usual Intake of Dark-green \& Orange Vegetables. Risk Factor Monitoring and Methods Branch Web site. Applied Research Program. http://riskfactor.cancer.gov/diet/usualintakes/pop/veg_drkgreen_orange.html 2010. Updated August 25, 2010. Accessed August 13, 2013.

4. U.S. Department of Agriculture and U.S. Department of Health and Human Services. Dietary Guidelines for Americans, 2010. $7^{\text {th }}$ Edition, Washington, DC: U.S. Government Printing Office, December 2010.

http://www.health.gov/dietaryguidelines/dga2010/DietaryGuidelines2010.pdf

5. Krebs-Smith SM. Fruit and Vegetable Intakes of Children and Adolescents in the United States. Arch Pediatr Adolesc Med. 1996;150(1):81. doi:10.1001/archpedi.1996.02170260085014.

6. Lorson BA, Melgar-Quinonez HR, Taylor CA. Correlates of fruit and vegetable intakes in US children. J Am Diet Assoc. 2009;109(3):474-8. doi:10.1016/j.jada.2008.11.022.

7. Patterson BH, Block G, Rosenberger WF, Pee D, Kahle LL. Fruit and vegetables in the American diet: data from the NHANES II survey. $\mathrm{Am} \mathrm{J}$ Public Health. 1990;80(12):1443-1449. doi:10.2105/AJPH.80.12.1443.

8. Healthy People 2010 midcourse review [Internet]. Washington: Department of Health and Human Services, Office of Disease Prevention and Health Promotion. http://www.healthypeople.gov/2010/Data/midcourse/html/focusareas/FA19P rogressHP.htm. Updated April 7, 2007. Accessed May 3, 2013.

9. Appel LJ, Moore TJ, Obarzanek E, et al. A clinical trial of the effects of dietary patterns on blood pressure. DASH Collaborative Research Group. N Engl J Med. 1997;336(16):1117-24. doi:10.1056/NEJM199704173361601.

10. Daniels SR. Complications of obesity in children and adolescents. Int $J$ Obes (Lond). 2009;33 Suppl 1:S60-5. doi:10.1038/ijo.2009.20.

11. Holt EM, Steffen LM, Moran A, et al. Fruit and vegetable consumption and its relation to markers of inflammation and oxidative stress in adolescents. $J$ Am Diet Assoc. 2009;109(3):414-21. doi:10.1016/j.jada.2008.11.036.

12. Ogden CL, Fryar CD, Carroll MD, Flegal KM. Mean body weight, height, and body mass index, United States 1960-2002. Adv Data. 2004;(347):1-17. http://www.ncbi.nlm.nih.gov/pubmed/15544194.

13. Parikh NI, Pencina MJ, Wang TJ, et al. Increasing trends in incidence of overweight and obesity over 5 decades. Am J Med. 2007;120(3):242-50. http://www.ncbi.nlm.nih.gov/pubmed/17349447. 
14. Wang Y, Beydoun MA, Liang L, Caballero B, Kumanyika SK. Will all Americans become overweight or obese? estimating the progression and cost of the US obesity epidemic. Obesity (Silver Spring). 2008;16(10):232330. doi:10.1038/oby.2008.351.

15. Johnson SL, Taylor-Holloway LA. Non-Hispanic white and Hispanic elementary school children's self-regulation of energy intake. Am J Clin Nutr. 2006;83(6):1276-82. http://www.ncbi.nlm.nih.gov/pubmed/?term=16762937.

16. Maynard M, Gunnell D, Ness AR, Abraham L, Bates CJ, Blane D. What influences diet in early old age? Prospective and cross-sectional analyses of the Boyd Orr cohort. Eur J Public Health. 2006;16(3):316-24. doi:10.1093/eurpub/cki167.

17. Hung $\mathrm{HC}$, Joshipura $\mathrm{KJ}$, Jiang $\mathrm{R}$, et al. Fruit and vegetable intake and risk of major chronic disease. J Natl Cancer Inst. 2004;96(21):1577-84. doi:10.1093/jnci/djh296.

18. Kelder SH, Perry CL, Klepp KI, Lytle LL. Longitudinal tracking of adolescent smoking, physical activity, and food choice behaviors. Am J Public Health. 1994;84(7):1121-6. http://www.ncbi.nlm.nih.gov/pubmed/?term=8017536.

19. Mikkilä V, Räsänen $L$, Raitakari $O$, Pietinen $P$, Viikari J. Consistent dietary patterns identified from childhood to adulthood: The Cardiovascular Risk in Young Finns Study. BJN. 2005;93(06):923. doi:10.1079/BJN20051418.

20. Resnicow K, Smith M, Baranowski T, Baranowski J, Vaughan R, Davis M. 2-year tracking of children's fruit and vegetable intake. J Am Diet Assoc. 1998;98(7):785-9. http://www.ncbi.nlm.nih.gov/pubmed/9664920.

21. Singer MR, Moore LL, Garrahie EJ, Ellison RC. The tracking of nutrient intake in young children: the Framingham Children's Study. Am J Public Health. 1995;85(12):1673-1677. doi:10.2105/AJPH.85.12.1673.

22. Zhang $X$, Shu $X O$, Xiang $Y B$, et al. Cruciferous vegetable consumption is associated with a reduced risk of total and cardiovascular disease mortality. Am J Clin Nutr. 2011;94(1):240-6. doi:10.3945/ajcn.110.009340.

23. Birch LL, Ventura AK. Preventing childhood obesity: what works? Int $J$ Obes (Lond). 2009;33 Suppl 1:S74-81. doi:10.1038/ijo.2009.22.

24. Van Duyn MA, Pivonka E. Overview of the health benefits of fruit and vegetable consumption for the dietetics professional: selected literature. $J$ Am Diet Assoc. 2000;100(12):1511-21. http://www.ncbi.nlm.nih.gov/pubmed/?term=11138444.

25. Ledoux TA, Hingle MD, Baranowski T. Relationship of fruit and vegetable intake with adiposity: a systematic review. Obes Rev. 2011;12(5):e143-50. doi:10.1111/j.1467-789X.2010.00786.x.

26. Evans CE, Christian MS, Cleghorn CL, Greenwood DC, Cade JE. Systematic review and meta-analysis of school-based interventions to improve daily fruit and vegetable intake in children aged 5 to 12 y. Am J Clin Nutr. 2012;96(4):889-901. doi:10.3945/ajcn.111.030270. 
27. Larson NI, Story M, Eisenberg ME, Neumark-Sztainer D. Food preparation and purchasing roles among adolescents: associations with sociodemographic characteristics and diet quality. J Am Diet Assoc. 2006;106(2):211-8. doi:10.1016/j.jada.2005.10.029.

28. Howarth NC, Saltzman E, Roberts SB. Dietary fiber and weight regulation. Nutr Rev. 2001;59(5):129-39. http://www.ncbi.nlm.nih.gov/pubmed/11396693.

29. Fox MK, Condon E, Crepinsek, MK, et. al. School Nutrition Dietary Assessment Study IV, Vol. I: School Foodservice Operations, School Environments, and Meals Offered and Served. Alexandria, VA: U.S. Department of Agriculture, Food and Nutrition Service, Office of Research and Analysis; 2012. http://www.fns.usda.gov/sites/default/files/SNDAIV_Vol1Pt1_0.pdf. Accessed May 15, 2013.

30. Vernarelli $\overline{J A}$, Mitchell DC, Hartman TJ, Rolls BJ. Dietary energy density is associated with body weight status and vegetable intake in U.S. children. $J$ Nutr. 2011;141(12):2204-10. doi:10.3945/jn.111.146092.

31. Patterson E, Wärnberg J, Poortvliet E, Kearney JM, Sjöström M. Dietary energy density as a marker of dietary quality in Swedish children and adolescents: the European Youth Heart Study. Eur J Clin Nutr. 2010;64(4):356-63. doi:10.1038/ejcn.2009.160.

32. Academy of Nutrition and Dietetics. Fruit and Vegetable Intake and Childhood Overweight. Evidence Analysis Library. http://andevidencelibrary.com/evidence.cfm?evidence_summary_id=25. Accessed February 14, 2013.

33. Lin B-H, Morrison RM. Higher fruit consumption linked with lower body mass index. Food Rev. 2002;25:28-32.

34. Lin B-H, Huang CL, French SA. Factors associated with women's and children's body mass indices by income status. Int $\mathrm{J}$ Obes Relat Metab Disord. 2004;28(4):536-42. http://www.nature.com/ijo/journal/v28/n4/full/0802604a.html.

35. Newby PK, Peterson KE, Berkey CS, Leppert J, Willett WC, Colditz GA. Dietary composition and weight change among low-income preschool children. Arch Pediatr Adolesc Med. 2003;157(8):759-64. doi:10.1001/archpedi.157.8.759.

36. Bandini LG, Vu D, Must A, Cyr H, Goldberg A, Dietz WH. Comparison of high-calorie, low-nutrient-dense food consumption among obese and nonobese adolescents. Obes Res. 1999;7(5):438-43. http://www.ncbi.nlm.nih.gov/pubmed/10509600.

37. Gillis LJ, Bar-or O. Food away from home, sugar-sweetened drink consumption and juvenile obesity. J Am Coll Nutr. 2003;22(6):539-45. http://www.ncbi.nlm.nih.gov/pubmed/?term=14684760.

38. Kelishadi R, Pour MH, Sarraf-Zadegan N, et al. Obesity and associated modifiable environmental factors in Iranian adolescents: Isfahan Healthy 
Heart Program - Heart Health Promotion from Childhood. Pediatr Int. 2003;45(4):435-42. http://www.ncbi.nlm.nih.gov/pubmed/?term=12911481.

39. Tanasescu M, Ferris AM, Himmelgreen DA, Rodriguez N, Pérez-escamilla R. Biobehavioral factors are associated with obesity in Puerto Rican children. J Nutr. 2000;130(7):1734-42. http://www.ncbi.nlm.nih.gov/pubmed/?term=10867044.

40. Melgar-Quiñonez HR, Kaiser LL. Relationship of child-feeding practices to overweight in low-income Mexican-American preschool-aged children. J Am Diet Assoc. 2004;104(7):1110-9. http://www.ncbi.nlm.nih.gov/pubmed/?term=15215770.

41. Rockett HR, Berkey CS, Field AE, Colditz GA. Cross-sectional measurement of nutrient intake among adolescents in 1996. Prev Med. 2001;33(1):27-37. http://www.ncbi.nlm.nih.gov/pubmed/?term=11482993.

42. Hanley AJ, Harris SB, Gittelsohn J, Wolever TM, Saksvig B, Zinman B. Overweight among children and adolescents in a Native Canadian community: prevalence and associated factors. Am J Clin Nutr. 2000;71(3):693-700. http://www.ncbi.nlm.nih.gov/pubmed/?term=10702161.

43. Wang Y, Ge K, Popkin BM. Why do some overweight children remain overweight, whereas others do not? Public Health Nutr. 2003;6(6):549-58. http://www.ncbi.nlm.nih.gov/pubmed/14690036.

44. Faith MS, Dennison BA, Edmunds LS, Stratton HH. Fruit juice intake predicts increased adiposity gain in children from low-income families: weight status-by-environment interaction. Pediatrics. 2006;118(5):2066-75. http://www.ncbi.nlm.nih.gov/pubmed/?term=17079580.

45. Epstein LH, Gordy CC, Raynor HA, Beddome M, Kilanowski CK, Paluch R. Increasing fruit and vegetable intake and decreasing fat and sugar intake in families at risk for childhood obesity. Obes Res. 2001;9(3):171-8. doi:10.1038/oby.2001.18.

46. Field AE, Gillman MW, Rosner B, Rockett HR, Colditz GA. Association between fruit and vegetable intake and change in body mass index among a large sample of children and adolescents in the United States. Int $\mathrm{J}$ Obes Relat Metab Disord. 2003;27(7):821-6. http://www.ncbi.nlm.nih.gov/pubmed/?term=12821968.

47. Matthews VL, Wien M, Sabaté J. The risk of child and adolescent overweight is related to types of food consumed. Nutr J. 2011;10(1):71. doi:10.1186/1475-2891-10-71.

48. Newby PK. Plant foods and plant-based diets: protective against childhood obesity? Am J Clin Nutr. 2009;89(5):1572S-1587S. doi:10.3945/ajcn.2009.26736G.

49. Biro FM, Wien M. Childhood obesity and adult morbidities. Am J Clin Nutr. 2010;91(5):1499S-1505S. http://www.ncbi.nlm.nih.gov/pmc/articles/PMC2854915/.

50. Bazzano LA. The high cost of not consuming fruits and vegetables. J Am Diet Assoc. 2006;106(9):1364-8. doi:10.1016/j.jada.2006.06.021. 
51. Muñoz de Chávez M, Chávez A. Diet that prevents cancer: recommendations from the American Institute for Cancer Research. Int $\mathrm{J}$ Cancer Suppl. 1998;11:85-9. http://www.ncbi.nlm.nih.gov/pubmed/9876487.

52. Ludwig DS, Pereira MA, Kroenke $\mathrm{CH}$, et al. Dietary fiber, weight gain, and cardiovascular disease risk factors in young adults. JAMA. 1999;282(16):1539-46. http://www.ncbi.nlm.nih.gov/pubmed/?term=10546693.

53. Mikkilä V, Räsänen L, Raitakari OT, Pietinen P, Viikari J. Longitudinal changes in diet from childhood into adulthood with respect to risk of cardiovascular diseases: The Cardiovascular Risk in Young Finns Study. Eur J Clin Nutr. 2004;58(7):1038-45. http://www.ncbi.nlm.nih.gov/pubmed/?term=15220946.

54. He FJ, Nowson CA, MacGregor GA. Fruit and vegetable consumption and stroke: meta-analysis of cohort studies. The Lancet. 2006;367(9507):320326. http://www.ncbi.nlm.nih.gov/pubmed/16443039.

55. Northstone K, Emmett PM. Are dietary patterns stable throughout early and mid-childhood? A birth cohort study. Br J Nutr. 2008;100(5):1069-76. doi:10.1017/S0007114508968264.

56. Schwartz C, Scholtens PA, Lalanne A, Weenen H, Nicklaus S. Development of healthy eating habits early in life. Review of recent evidence and selected guidelines. Appetite. 2011;57(3):796-807. doi:10.1016/j.appet.2011.05.316.

57. Van't Riet J, Sijtsema SJ, Dagevos H, De Bruijn GJ. The importance of habits in eating behaviour. An overview and recommendations for future research. Appetite. 2011;57(3):585-96. doi:10.1016/j.appet.2011.07.010.

58. Ebbeling CB, Leidig MM, Sinclair KB, Hangen JP, Ludwig DS. A reducedglycemic load diet in the treatment of adolescent obesity. Arch Pediatr Adolesc Med. 2003;157(8):773-9. doi:10.1001/archpedi.157.8.773.

59. Livesey G, Taylor R, Hulshof T, Howlett J. Glycemic response and health--a systematic review and meta-analysis: relations between dietary glycemic properties and health outcomes. Am J Clin Nutr. 2008;87(1):258S-268S. http://www.ncbi.nlm.nih.gov/pubmed/?term=18175766.

60. Knekt $P$, Kumpulainen J, Järvinen $R$, et al. Flavonoid intake and risk of chronic diseases. Am J Clin Nutr. 2002;76(3):560-8. http://www.ncbi.nlm.nih.gov/pubmed/12198000.

61. Maynard M, Gunnell D, Emmett P, Frankel S, Davey Smith G. Fruit, vegetables, and antioxidants in childhood and risk of adult cancer: the Boyd Orr cohort. J Epidemiol Community Health. 2003;57(3):218-25. http://www.ncbi.nlm.nih.gov/pubmed/12594199.

62. Rolls BJ. The relationship between dietary energy density and energy intake. Physiol Behav. 2009;97(5):609-15. doi:10.1016/j.physbeh.2009.03.011.

63. Krebs-Smith SM, Guenther PM, Subar AF, Kirkpatrick SI, Dodd KW. Americans do not meet federal dietary recommendations. $J$ Nutr. 2010;140(10):1832-8. doi:10.3945/jn.110.124826. 
64. Hiza HA, Casavale KO, Guenther PM, Davis CA. Diet quality of Americans differs by age, sex, race/ethnicity, income, and education level. J Acad Nutr Diet. 2013;113(2):297-306. doi:10.1016/j.jand.2012.08.011.

65. Guenther PM, Reedy J, Krebs-Smith SM. Development of the Healthy Eating Index-2005. J Am Diet Assoc. 2008;108(11):1896-901. doi:10.1016/j.jada.2008.08.016.

66. Guenther PM, Casavale KO, Reedy J, et al. Update of the Healthy Eating Index: HEI-2010. J Acad Nutr Diet. 2013;113(4):569-80. doi:10.1016/j.jand.2012.12.016.

67. Krølner R, Rasmussen M, Brug J, Klepp KI, Wind M, Due P. Determinants of fruit and vegetable consumption among children and adolescents: a review of the literature. Part II: qualitative studies. Int J Behav Nutr Phys Act. 2011;8(1):112. doi:10.1186/1479-5868-8-112.

68. Story M, Kaphingst KM, French $\mathrm{S}$. The role of schools in obesity prevention. Future Child. 2006;16(1):109-42. http://www.ncbi.nlm.nih.gov/pubmed/16532661.

69. Gleason P, Suitor C. Children's Diets in the Mid-1990s: Dietary Intake and Its Relationship with School Meal Participation. Mathematica Policy Research. 2001. http://ideas.repec.org/p/mpr/mprres/2443.html.

70. Lantz EM, Wood P. Nutritional condition of New Mexican children. J Am Diet Assoc. 1958;34(11):1199-207. http://www.ncbi.nlm.nih.gov/pubmed/13587156.

71. Melnik TA, Rhoades SJ, Wales KR, Cowell C, Wolfe WS. Food Consumption Patterns of Elementary Schoolchildren in New York City. J Am Diet Assoc. 1998;98(2):159-164. doi:10.1016/S0002-8223(98)00040-6.

72. Roos EB, Hirvonen T, Mikkilä V, Karvonen S, Rimpelä M. Household educational level as a determinant of consumption of raw vegetables among male and female adolescents. Prev Med. 2001;33(4):282-91. doi:10.1006/pmed.2001.0882.

73. Fox MK, Hamilton WL, Lin B-H. Effects Of Food Assistance And Nutrition Programs On Nutrition And Health: Volume 4, Executive Summary Of The Literature Review. 2004. http://ideas.repec.org/p/ags/uersfa/33871.html.

74. Department of Agriculture. Nutrition standards in the national school lunch and school breakfast programs; final rule. 2012;77(17):4088-4167. http://www.gpo.gov/fdsys/pkg/FR-2012-01-26/pdf/2012-1010.pdf.

75. Condon EM, Crepinsek MK, Fox MK. School meals: types of foods offered to and consumed by children at lunch and breakfast. J Am Diet Assoc. 2009;109(2 Suppl):S67-78. doi:10.1016/j.jada.2008.10.062.

76. Upton D, Upton $P$, Taylor $C$. Fruit and vegetable intake of primary school children: a study of school meals. J Hum Nutr Diet. 2012;25(6):557-62. doi:10.1111/j.1365-277X.2012.01270.x.

77. Rasmussen M, Krølner R, Klepp KI, et al. Determinants of fruit and vegetable consumption among children and adolescents: a review of the 
literature. Part I: Quantitative studies. Int J Behav Nutr Phys Act. 2006;3:22. http://www.ncbi.nlm.nih.gov/pubmed/16904006.

78. De Bourdeaudhuij I, Te Velde S, Brug J, et al. Personal, social and environmental predictors of daily fruit and vegetable intake in 11-year-old children in nine European countries. Eur J Clin Nutr. 2008;62(7):834-41. doi:10.1038/sj.ejcn.1602794.

79. Bandura A. Social Foundations of Thought and Action: A Social Cognitive Theory. Prentice Hall; 1986.

80. Gaines A, Turner LW. Improving Fruit and Vegetable Intake Among Children: A Review of Interventions Utilizing the Social Cognitive Theory. Californian J Health Promot. 2009;7(1);52-66. http://cjhp.fullerton.edu/Volume7_2009//ssue1/gaines.pdf.

81. McLeroy KR, Bibeau D, Steckler A, Glanz K. An ecological perspective on health promotion programs. Health Educ Q. 1988;15(4):351-77. http://www.uib.no/filearchive/filetopic_paper-ecological-perspectivemcleroy.pdf.

82. Birch LL. Development of food preferences. Annu Rev Nutr. 1999;19(1):4162. doi: 0.1146/annurev.nutr.19.1.41.

83. Bernstein $\mathrm{A}$, Nelson ME, Tucker KL, et al. A home-based nutrition intervention to increase consumption of fruits, vegetables, and calcium-rich foods in community dwelling elders. J Am Diet Assoc. 2002;102(10):1421-7. http://www.ncbi.nlm.nih.gov/pubmed/12396159.

84. French SA, Stables G. Environmental interventions to promote vegetable and fruit consumption among youth in school settings. Prev Med. 2003;37(6 Pt 1):593-610. http://www.ncbi.nlm.nih.gov/pubmed/?term=14636793.

85. Perry CL, Bishop DB, Taylor GL, et al. A randomized school trial of environmental strategies to encourage fruit and vegetable consumption among children. Health Educ Behav. 2004;31(1):65-76. http://www.ncbi.nlm.nih.gov/pubmed/?term=14768658.

86. Townsend N, Foster $\mathrm{C}$. Developing and applying a socio-ecological model to the promotion of healthy eating in the school. Public Health Nutr. 2013;16(6):1101-8. doi:10.1017/S1368980011002655.

87. Fitzgerald N, Spaccarotella K. Barriers to a healthy lifestyle: from individuals to public policy-an ecological perspective. Journal of Extension. 2009;47(1). http://www.joe.org/joe/2009february/a3.php.

88. Glanz K, Rimer BK, Viswanath K. Health Behavior and Health Education: Theory, Research, and Practice. John Wiley \& Sons; 2008.

89. Reicks M, Redden JP, Mann T, Mykerezi E, Vickers Z. Photographs in lunch tray compartments and vegetable consumption among children in elementary school cafeterias. JAMA. 2012;307(8):784-5. doi:10.1001/jama.2012.170.

90. Wansink B, Shimizu M, Camps G. What would Batman eat?: priming children to make healthier fast food choices. Pediatr Obes. 2012;7(2):121-3. doi:10.1111/j.2047-6310.2011.00003.x. 
91. Wansink B, Just DR, Hanks AS, Smith LE. Pre-sliced fruit in school cafeterias: children's selection and intake. Am J Prev Med. 2013;44(5):47780. doi:10.1016/j.amepre.2013.02.003.

92. Wansink B, Just DR, Payne CR, Klinger MZ. Attractive names sustain increased vegetable intake in schools. Prev Med. 2012;55(4):330-2. doi:10.1016/j.ypmed.2012.07.012.

93. Moore L, De Silva-Sanigorski A, Moore SN. A socio-ecological perspective on behavioural interventions to influence food choice in schools: alternative, complementary or synergistic? Public Health Nutr. 2013;16(6):1000-5. doi:10.1017/S1368980012005605.

94. Norton MI, Mochon D, Ariely D. The IKEA effect: When labor leads to love. $J$ Consum Psychol. 2012;22(3):453-460. doi:10.1016/j.jcps.2011.08.002.

95. Ahuvia AC. Beyond the extended self: Loved objects and consumers' identity narratives. J Consum Res. 2005;32(1):171-184. http://ideas.repec.org/a/ucp/jconrs/v32y2005i1p171-184.html.

96. Belk RW. Possessions and the extended self. Journal of Consumer Research. 1988;15(22):139-168. http://www.jstor.org/stable/2489522.

97. Dittmar H. The Social Psychology of Material Possessions: To Have Is to Be. Wheatsheaf Books; 1992.

98. Furby L. Understanding the psychology of possession and ownership: A personal memoir and an appraisal of our progress. J Soc Behav Pers. 1991;66:457-463.

99. Blanchette L, Brug J. Determinants of fruit and vegetable consumption among 6-12-year-old children and effective interventions to increase consumption. J Hum Nutr Diet. 2005;18(6):431-43. doi:10.1111/j.1365277X.2005.00648.x.

100. Hanson NI, Neumark-Sztainer D, Eisenberg ME, Story M, Wall M. Associations between parental report of the home food environment and adolescent intakes of fruits, vegetables and dairy foods. Public Health Nutr. 2005;8(1):77-85. http://www.ncbi.nlm.nih.gov/pubmed/15705248.

101. Kratt $P$, Reynolds $K$, Shewchuk $R$. The role of availability as a moderator of family fruit and vegetable consumption. Health Educ Behav. 2000;27(4):471-82. http://www.ncbi.nlm.nih.gov/pubmed/10929754.

102. Brug J, Tak NI, Te Velde SJ, Bere E, De Bourdeaudhuij I. Taste preferences, liking and other factors related to fruit and vegetable intakes among schoolchildren: results from observational studies. Br J Nutr. 2008;99 Suppl 1(S1):S7-S14. doi:10.1017/S0007114508892458.

103. Birch LL, Mcphee L, Shoba BC, Pirok E, Steinberg L. What kind of exposure reduces children's food neophobia? Looking vs. tasting. Appetite. 1987;9(3):171-8. http://www.ncbi.nlm.nih.gov/pubmed/3435134.

104. Galloway AT, Lee Y, Birch LL. Predictors and consequences of food neophobia and pickiness in young girls. J Am Diet Assoc. 2003;103(6):6928. doi:10.1053/jada.2003.50134. 
105. Oliveria SA, Ellison RC, Moore LL, Gillman MW, Garrahie EJ, Singer MR. Parent-child relationships in nutrient intake: the Framingham Children's Study. Am J Clin Nutr. 1992;56(3):593-8. http://www.ncbi.nlm.nih.gov/pubmed/1503074.

106. Pearson N, Biddle SJ, Gorely T. Family correlates of fruit and vegetable consumption in children and adolescents: a systematic review. Public Health Nutr. 2009;12(2):267-83. doi:10.1017/S1368980008002589.

107. Vereecken $C A$, Maes $L$, De Bfacquer $D$. The influence of parental occupation and the pupils' educational level on lifestyle behaviors among adolescents in Belgium. J Adolesc Health. 2004;34(4):330-8. doi:10.1016/j.jadohealth.2003.07.011.

108. Vereecken CA, Keukelier E, Maes L. Influence of mother's educational level on food parenting practices and food habits of young children. Appetite. 2004;43(1):93-103. doi:10.1016/j.appet.2004.04.002.

109. Johansson L, Thelle DS, Solvoll K, Bjørneboe GE, Drevon CA. Healthy dietary habits in relation to social determinants and lifestyle factors. $\mathrm{Br} J$ Nutr. 1999;81(3):211-20. http://www.ncbi.nlm.nih.gov/pubmed/?term=10434847.

110. Cullen KW, Baranowski T, Rittenberry L, Olvera N. Social-environmental influences on children's diets: results from focus groups with African-, Euroand Mexican-American children and their parents. Health Educ Res. 2000;15(5):581-90. http://www.ncbi.nlm.nih.gov/pubmed/?term=11184217.

111. Neumark-Sztainer D, Wall M, Perry C, Story M. Correlates of fruit and vegetable intake among adolescents. Findings from Project EAT. Prev Med. 2003;37(3):198-208. http://www.ncbi.nlm.nih.gov/pubmed/?term=12914825.

112. Neumark-Sztainer D, Hannan PJ, Story M, Croll J, Perry C. Family meal patterns: associations with sociodemographic characteristics and improved dietary intake among adolescents. J Am Diet Assoc. 2003;103(3):317-22. doi:10.1053/jada.2003.50048.

113. Klepp KI, Pérez-Rodrigo C, De Bourdeaudhuij I, et al. Promoting fruit and vegetable consumption among European schoolchildren: rationale, conceptualization and design of the pro children project. Ann Nutr Metab. 2005;49(4):212-20. http://www.ncbi.nlm.nih.gov/pubmed/?term=16088084.

114. Baranowski T, Smith M, Hearn MD, et al. Patterns in children's fruit and vegetable consumption by meal and day of the week. J Am Coll Nutr. 1997;16(3):216-23. http://www.ncbi.nlm.nih.gov/pubmed/9176827.

115. Glynn L, Emmett P, Rogers I. Food and nutrient intakes of a population sample of 7-year-old children in the south-west of England in 1999/2000 what difference does gender make? J Hum Nutr Diet. 2005;18(1):7-19. doi:10.1111/j.1365-277X.2004.00582.x

116. Lien N, Jacobs DR, Klepp KI. Exploring predictors of eating behaviour among adolescents by gender and socio-economic status. Public Health Nutr. 2002;5(5):671-81. doi:10.1079/PHN2002334. 
117. Lien N, Lytle LA, Komro KA. Applying theory of planned behavior to fruit and vegetable consumption of young adolescents. Am J Health Promot. 2002;16(4):189-97. http://www.ncbi.nlm.nih.gov/pubmed/?term=11913324.

118. Reynolds KD, Baranowski T, Bishop DB, et al. Patterns in child and adolescent consumption of fruit and vegetables: effects of gender and ethnicity across four sites. J Am Coll Nutr. 1999;18(3):248-54. http://www.ncbi.nlm.nih.gov/pubmed/?term=10376781.

119. Vereecken CA, Inchley J, Subramanian SV, Hublet A, Maes L. The relative influence of individual and contextual socio-economic status on consumption of fruit and soft drinks among adolescents in Europe. Eur $\mathrm{J}$ Public Health. 2005;15(3):224-32. doi:10.1093/eurpub/cki005.

120. Burdine JN, Chen MS, Gottlieb NH, Peterson FL, Demetri Vacalis T. The effects of ethnicity, sex and father's occupation on heart health knowledge and nutrition behavior of school children: the Texas youth health awareness survey. J Sch Health. 1984;54(2):87-90. http://www.ncbi.nlm.nih.gov/pubmed/?term=6563319.

121. Musaiger AO, Gregory WB. Dietary habits of school-children in Bahrain. $J R$ Soc Health. 1992;112(4):159-62. http://www.ncbi.nlm.nih.gov/pubmed/1433145.

122. Monge Rojas R. Fruits and vegetables consumption among Costa Rican adolescents. Arch Latinoam Nutr. 2001;51(1):81-5. http://www.ncbi.nlm.nih.gov/pubmed/11515237.

123. Woodward DR. What sort of teenager has high intakes of energy and nutrients? Br J Nutr. 1985;54(2):325-33. http://www.ncbi.nlm.nih.gov/pubmed/4063320.

124. Woodward DR, Boon JA, Cumming FJ, Ball PJ, Williams HM, Hornsby H. Adolescents' reported usage of selected foods in relation to their perceptions and social norms for those foods. Appetite. 1996;27(2):109-17. doi:10.1006/appe.1996.0039.

125. Lowry R, Kann L, Collins JL, Kolbe LJ. The effect of socioeconomic status on chronic disease risk behaviors among US adolescents. JAMA. 1996;276(10):792-7. http://www.ncbi.nlm.nih.gov/pubmed/8769588.

126. Videon TM, Manning CK. Influences on adolescent eating patterns: the importance of family meals. J Adolesc Health. 2003;32(5):365-73. http://www.ncbi.nlm.nih.gov/pubmed/12729986.

127. Adamson AJ, Rugg-Gum AJ, Appleton DR, Butler TJ, Hackett AF. Dietary sources of energy, protein, unavailable carbohydrate and fat in 11-12-yearold English children in 1990 compared with results in 1980. J Hum Nutr Diet. 1992;5(6):371-385. doi:10.1111/j.1365-277X.1992.tb00177.x.

128. Sweeting $\mathrm{H}$, Anderson $A$, West $P$. Socio-demographic correlates of dietary habits in mid- to late adolescence. Eur J Clin Nutr. 1994;48(10):736-48. http://www.ncbi.nlm.nih.gov/pubmed/7835328. 
129. Cartwright M, Wardle J, Steggles N, Simon AE, Croker H, Jarvis MJ. Stress and dietary practices in adolescents. Health Psychol. 2003;22(4):362-9. http://www.ncbi.nlm.nih.gov/pubmed/12940392.

130. Osler M, Hansen ET. Dietary knowledge and behaviour among schoolchildren in Copenhagen, Denmark. Scand J Soc Med. 1993;21(2):135-40. http://www.ncbi.nlm.nih.gov/pubmed/8367681.

131. Rafiroiu AC, Anderson EP, Sargent RG, Evans A. Dietary practices of South Carolina adolescents and their parents. Am J Health Behav. 2002;26(3):200-12. http://www.ncbi.nlm.nih.gov/pubmed/12018756.

132. Wrieden W. Fruit and vegetable consumption of 10-11-year-old children in a region of Scotland. Health Education Journal. 1996;55(2):185-193. doi:10.1177/001789699605500206.

133. Brown T, Summerbell C. Systematic review of school-based interventions that focus on changing dietary intake and physical activity levels to prevent childhood obesity: an update to the obesity guidance produced by the National Institute for Health and Clinical Excellence. Obes Rev. 2009;10(1):110-41. doi:10.1111/j.1467-789X.2008.00515.x.

134. Connelly JB, Duaso MJ, Butler G. A systematic review of controlled trials of interventions to prevent childhood obesity and overweight: a realistic synthesis of the evidence. Public Health. 2007;121(7):510-7. doi:10.1016/j.puhe.2006.11.015.

135. Kropski JA, Keckley PH, Jensen GL. School-based obesity prevention programs: an evidence-based review. Obesity (Silver Spring). 2008;16(5):1009-18. doi:10.1038/oby.2008.29.

136. Resnicow K, Davis-Hearn M, Smith M, et al. Social-cognitive predictors of fruit and vegetable intake in children. Health Psychol. 1997;16(3):272-6. http://www.ncbi.nlm.nih.gov/pubmed/?term=9152706.

137. Gibson EL, Wardle J, Watts CJ. Fruit and vegetable consumption, nutritional knowledge and beliefs in mothers and children. Appetite. 1998;31(2):20528. http://www.ncbi.nlm.nih.gov/pubmed/?term=9792733.

138. Reynolds KD, Yaroch AL, Franklin FA, Maloy J. Testing mediating variables in a school-based nutrition intervention program. Health Psychol. 2002;21(1):51-60. http://www.ncbi.nlm.nih.gov/pubmed/11846345.

139. Reynolds KD, Bishop DB, Chou CP, Xie B, Nebeling L, Perry CL. Contrasting mediating variables in two 5-a-day nutrition intervention programs. Prev Med. 2004;39(5):882-93. doi:10.1016/j.ypmed.2004.03.022.

140. Birch LL, Fisher JA. Appetite and eating behavior in children. Pediatr Clin North Am. 1995;42(4):931-53. http://www.ncbi.nlm.nih.gov/pubmed/7610021.

141. Domel SB, Baranowski T, Davis H, Leonard SB, Riley P, Baranowski J. Measuring fruit and vegetable preferences among 4th- and 5th-grade students. Prev Med. 1993;22(6):866-79. doi:http://www.ncbi.nlm.nih.gov/pubmed/8115344. 
142. Cullen KW, Baranowski T, Owens E, Marsh T, Rittenberry L, De Moor C. Availability, accessibility, and preferences for fruit, $100 \%$ fruit juice, and vegetables influence children's dietary behavior. Health Educ Behav. 2003;30(5):615-26. http://www.ncbi.nlm.nih.gov/pubmed/?term=14582601.

143. Rozin P. Acquisition of food preferences and attitudes to food. Int J Obes. 1980;4(4):356-63. http://www.ncbi.nlm.nih.gov/pubmed/?term=6998884.

144. Wardle J, Herrera ML, Cooke L, Gibson EL. Modifying children's food preferences: the effects of exposure and reward on acceptance of an unfamiliar vegetable. Eur J Clin Nutr. 2003;57(2):341-8. doi:10.1038/sj.ejcn.1601541.

145. Cooke LJ, Chambers LC, Añez EV, et al. Eating for pleasure or profit: the effect of incentives on children's enjoyment of vegetables. Psychol Sci. 2011;22(2):190-6. doi:10.1177/0956797610394662.

146. Pittman DW, Parker JS, Getz BR, et al. Cost-free and sustainable incentive increases healthy eating decisions during elementary school lunch. Int $J$ Obes (Lond). 2012;36(1):76-9. doi:10.1038/ijo.2011.205.

147. Raju S, Rajagopal P, Gilbride TJ. Marketing healthful eating to children: the effectiveness of incentives, pledges, and competitions. Journal of Marketing. 2010;74(3):93-106. http://connection.ebscohost.com/c/articles/49071066/marketing-healthfuleating-children-effectiveness-incentives-pledges-competitions

148. Wengreen HJ, Madden GJ, Aguilar SS, Smits RR, Jones BA. Incentivizing children's fruit and vegetable consumption: results of a United States pilot study of the Food Dudes Program. J Nutr Educ Behav. 2013;45(1):54-9. doi:10.1016/j.jneb.2012.06.001.

149. Rosenstock IM, Strecher VJ, Becker MH. Social learning theory and the Health Belief Model. Health Educ Q. 1988;15(2):175-83. http://www.ncbi.nlm.nih.gov/pubmed/3378902.

150. Sheeshka JD, Woolcott DM, Mackinnon NJ. Social Cognitive Theory as a Framework to Explain Intentions to Practice Healthy Eating Behaviors1. J Appl Social Pyschol. 1993;23(19):1547-1573. doi:10.1111/j.15591816.1993.tb01047.x.

151. Domel S, Thompson W, Davis H, Baranowski T, Leonard S, Baranowski J. Psychosocial predictors of fruit and vegetable consumption among elementary school children. Health Educ Res. 1996;11(3):299-308. doi:10.1093/her/11.3.299.

152. Parcel GS, Edmundson E, Perry CL, et al. Measurement of self-efficacy for diet-related behaviors among elementary school children. J Sch Health. 1995;65(1):23-7. http://www.ncbi.nlm.nih.gov/pubmed/?term=7731197.

153. Chu YL, Farmer A, Fung C, Kuhle S, Storey KE, Veugelers PJ. Involvement in home meal preparation is associated with food preference and selfefficacy among Canadian children. Public Health Nutr. 2013;16(1):108-12. doi:10.1017/S1368980012001218. 
154. Brug J, Oenema A, Ferreira I. Theory, evidence and Intervention Mapping to improve behavior nutrition and physical activity interventions. Int J Behav Nutr Phys Act. 2005;2(1):2. doi:10.1186/1479-5868-2-2.

155. Gollwitzer PM. Implementation intentions: Strong effects of simple plans. American Psychologist. 1999;54(7):493-503. doi:10.1037/0003066X.54.7.493.

156. Sheeran P. Intention-Behavior Relations: A Conceptual and Empirical Review. European Review of Social Psychology. 2002;12(1):1-36. doi:10.1080/14792772143000003.

157. Bogers RP, Brug J, Van Assema P, Dagnelie PC. Explaining fruit and vegetable consumption: the theory of planned behaviour and misconception of personal intake levels. Appetite. 2004;42(2):157-66. doi:10.1016/j.appet.2003.08.015.

158. Brug J, Kok GJ. Misconceptions of consumers about their own fat consuption. Voeding. 1995;56;11-14.159.

159. Brug J, Van Assema P, Lenderink T, Glanz K, Kok GJ. Self-rated dietary fat intake: association with objective assessment of fat, psychosocial factors and intention to change. J Nutr Educ. 1994;26:218-223.

160. Bourdeaudhuij ID, Oost PV. Personal and family determinants of dietary behaviour in adolescents and their parents. Psychology \& Health. 2000;15(6):751-770. http://www.tandfonline.com/doi/abs/10.1080/08870440008405579\#.UuCV1 mQo4y4.

161. Bere E, Klepp KI. Correlates of fruit and vegetable intake among Norwegian schoolchildren: parental and self-reports. Public Health Nutr. 2004;7(8):9918. doi:10.1079/PHN2004619.

162. Bere E, Klepp KI. Changes in accessibility and preferences predict children's future fruit and vegetable intake. Int J Behav Nutr Phys Act. 2005;2(1):15. doi:10.1186/1479-5868-2-15.

163. Patrick $\mathrm{H}$, Nicklas TA. A review of family and social determinants of children's eating patterns and diet quality. J Am Coll Nutr. 2005;24(2):83-92. http://www.ncbi.nlm.nih.gov/pubmed/?term=15798074.

164. Young EM, Fors SW, Hayes DM. Associations between perceived parent behaviors and middle school student fruit and vegetable consumption. $J$ Nutr Educ Behav. 2004;36(1):2-8. http://www.ncbi.nlm.nih.gov/pubmed/14756976.

165. Hannon PA, Bowen DJ, Moinpour CM, Mclerran DF. Correlations in perceived food use between the family food preparer and their spouses and children. Appetite. 2003;40(1):77-83. http://www.ncbi.nlm.nih.gov/pubmed/?term=12631508.

166. Gillman MW, Rifas-Shiman SL, Frazier AL, et al. Family dinner and diet quality among older children and adolescents. Arch Fam Med. 2000;9(3):235-40. http://www.ncbi.nlm.nih.gov/pubmed/10728109. 
167. Scaglioni S, Arrizza C, Vecchi F, Tedeschi S. Determinants of children's eating behavior. Am J Clin Nutr. 2011;94(6 Suppl):2006S-2011S. doi:10.3945/ajen.110.001685.

168. Laska MN, Larson NI, Neumark-Sztainer D, Story M. Does involvement in food preparation track from adolescence to young adulthood and is it associated with better dietary quality? Findings from a 10-year longitudinal study. Public Health Nutr. 2012;15(7):1150-8. doi:10.1017/S1368980011003004.

169. Story M, French S. Food Advertising and Marketing Directed at Children and Adolescents in the US. Int J Behav Nutr Phys Act. 2004;1(1):3. doi:10.1186/1479-5868-1-3.

170. Bowman SA, Gortmaker SL, Ebbeling CB, Pereira MA, Ludwig DS. Effects of fast-food consumption on energy intake and diet quality among children in a national household survey. Pediatrics. 2004;113(1 Pt 1):112-8. http://www.ncbi.nlm.nih.gov/pubmed/?term=14702458.

171. French SA, Story M, Neumark-Sztainer D, Fulkerson JA, Hannan P. Fast food restaurant use among adolescents: associations with nutrient intake, food choices and behavioral and psychosocial variables. Int $\mathrm{J}$ Obes Relat Metab Disord. 2001;25(12):1823-33. http://www.ncbi.nlm.nih.gov/pubmed/?term=11781764.

172. Taveras EM, Berkey CS, Rifas-shiman SL, et al. Association of consumption of fried food away from home with body mass index and diet quality in older children and adolescents. Pediatrics. 2005;116(4):e518-24. doi:10.1542/peds.2004-2732.

173. Van der Horst K, Oenema A, Ferreira I, et al. A systematic review of environmental correlates of obesity-related dietary behaviors in youth. Health Educ Res. 2007;22(2):203-26. http://www.ncbi.nlm.nih.gov/pubmed/16861362.

174. Birch LL, Marlin DW. I don't like it; I never tried it: Effects of exposure on two-year-old children's food preferences. Appetite. 1982;3(4):353-360. doi:10.1016/S0195-6663(82)80053-6.

175. Wardle J, Cooke L. Genetic and environmental determinants of children's food preferences. Br J Nutr. 2008;99 Suppl 1(S1):S15-21. doi:10.1017/S000711450889246X.

176. Andaya AA, Arredondo EM, Alcaraz JE, Lindsay SP, Elder JP. The association between family meals, TV viewing during meals, and fruit, vegetables, soda, and chips intake among Latino children. J Nutr Educ Behav. 2011;43(5):308-15. doi:10.1016/j.jneb.2009.11.005.

177. Hearn, MD, Baranowski, T, Baranowski J, et al. Environmental influences on dietary behavior among children: Availability and accessibility of fruits and vegetables enable consumption. $J$ Health Educ. 1998;29(1);26-32. http://www.tandfonline.com/doi/abs/10.1080/10556699.1998.10603294\#.Uu CW9mQo4y4. 
178. Academy of Nutrition and Dietetics. Evidence Analysis Library. Topic: School-based Programs. Child Nutrition and School-Based Programs. February 14, 2013. http://andevidencelibrary.com/topic.cfm?cat $=4755$.

179. Richard L, Potvin L, Kishchuk N, Prlic H, Green LW. Assessment of the integration of the ecological approach in health promotion programs. Am J Health Promot. 1996;10(4):318-28. http://www.ncbi.nlm.nih.gov/pubmed/10159711.

180. Stokols D. Translating Social Ecological Theory into Guidelines for Community Health Promotion. Am J Health Promot. 1996;10(4):282-298. doi: 10.4278/0890-1171-10.4.282.

181. Van Cauwenberghe E, Maes L, Spittaels $\mathrm{H}$, et al. Effectiveness of schoolbased interventions in Europe to promote healthy nutrition in children and adolescents: systematic review of published and 'grey' literature. Br J Nutr. 2010;103(6):781-97. doi:10.1017/S0007114509993370.

182. Christian MS, Evans CE, Hancock N, Nykjaer C, Cade JE. Family meals can help children reach their 5 a day: a cross-sectional survey of children's dietary intake from London primary schools. J Epidemiol Community Health. 2013;67(4):332-8. doi:10.1136/jech-2012-201604.

183. Swanson M, Branscum A, Nakayima PJ. Promoting consumption of fruit in elementary school cafeterias. The effects of slicing apples and oranges. Appetite. 2009;53(2):264-7. doi:10.1016/j.appet.2009.07.015.

184. Hanks AS, Just DR, Smith LE, Wansink B. Healthy convenience: nudging students toward healthier choices in the lunchroom. J Public Health (Oxf). 2012;34(3):370-6. doi:10.1093/pubmed/fds003.

185. Wansink B, Just DR, Payne CR. Can branding improve school lunches? Arch Pediatr Adolesc Med. 2012;166(10):967-8. doi:10.1001/archpediatrics.2012.999.

186. Wansink B, Payne CR, North J. Fine as North Dakota wine: sensory expectations and the intake of companion foods. Physiol Behav. 2007;90(5):712-6. doi:10.1016/j.physbeh.2006.12.010.

187. Wansink B, Van Ittersum K, Painter JE. Ice cream illusions bowls, spoons, and self-served portion sizes. Am J Prev Med. 2006;31(3):240-3. doi:10.1016/j.amepre.2006.04.003.

188. Mathias KC, Rolls BJ, Birch LL, et al. Serving larger portions of fruits and vegetables together at dinner promotes intake of both foods among young children. J Am Diet Assoc. 2011;112(2):266-270. doi:10.1016/j.jada.2011.08.040.

189. Meinen A, Friese B, Wright W, Carrel A. Youth gardens increase healthy behaviors in young children. J Hunger Environ Nutr. 2012;7(2-3):192-204. doi:10.1080/19320248.2012.704662.

190. Fisher JO, Mennella JA, Hughes SO, Liu Y, Mendoza PM, Patrick H. Offering "dip" promotes intake of a moderately-liked raw vegetable among preschoolers with genetic sensitivity to bitterness. J Acad Nutr Diet. 2012;112(2):235-45. http://www.ncbi.nlm.nih.gov/pubmed/2274116. 
191. Spill MK, Birch LL, Roe LS, Rolls BJ. Hiding vegetables to reduce energy density: an effective strategy to increase children's vegetable intake and reduce energy intake. Am J Clin Nutr. 2011;94(3):735-41. doi:10.3945/ajen.111.015206.

192. Harnack LJ, Oakes JM, French SA, Rydell SA, Farah FM, Taylor GL. Results from an experimental trial at a Head Start center to evaluate two meal service approaches to increase fruit and vegetable intake of preschool aged children. Int J Behav Nutr Phys Act. 2012;9(1):51. doi:10.1186/14795868-9-51.

193. Roe LS, Meengs JS, Rolls BJ. Salad and satiety. The effect of timing of salad consumption on meal energy intake. Appetite. 2012;58(1):242-8. doi:10.1016/j.appet.2011.10.003.

194. Spill MK, Birch LL, Roe LS, Rolls BJ. Hiding vegetables to reduce energy density: an effective strategy to increase children's vegetable intake and reduce energy intake. Am J Clin Nutr. 2011;94(3):735-41. doi:10.3945/ajen.111.015206.

195. Zeinstra GG, Renes RJ, Koelen MA, Kok FJ, De Graaf C. Offering choice and its effect on Dutch children's liking and consumption of vegetables: a randomized controlled trial. Am J Clin Nutr. 2010;91(2):349-56. doi:10.3945/ajcn.2009.28529.

196. Schwartz MB. The influence of a verbal prompt on school lunch fruit consumption: a pilot study. Int J Behav Nutr Phys Act. 2007;4(1):6. doi:10.1186/1479-5868-4-6.

197. Fisher JO, Birch LL, Zhang J, Grusak MA, Hughes SO. External influences on children's self-served portions at meals. Int $J$ Obes (Lond). 2013;37(7):954-60. doi:10.1038/ijo.2012.216.

198. Perry CL, Bishop DB, Taylor G, et al. Changing fruit and vegetable consumption among children: the 5-a-Day Power Plus program in St. Paul, Minnesota. Am J Public Health. 1998;88(4):603-9. http://www.ncbi.nlm.nih.gov/pubmed/9551002.

199. Foerster, S, Gregson, J, Beall, D, Hudes, M, Magnuson, H, Livingstone, S, et al. The California children's 5 a day-power play! campaign: evaluation of a large scale social marketing initiative. Fam Commun Health. 1998;21:4664.

200. Reynolds KD, Franklin FA, Binkley D, et al. Increasing the fruit and vegetable consumption of fourth-graders: results from the high 5 project. Prev Med. 2000;30(4):309-19. doi:10.1006/pmed.1999.0630.

201. Reynolds KD, Franklin FA, Leviton LC, et al. Methods, Results, and Lessons Learned from Process Evaluation of the High 5 School-Based Nutrition Intervention. Health Educ Behav. 2000;27(2):177-186. doi:10.1177/109019810002700204.

202. Te Velde SJ, Brug J, Wind M, et al. Effects of a comprehensive fruit- and vegetable-promoting school-based intervention in three European countries: 
the Pro Children Study. Br J Nutr. 2008;99(4):893-903.

doi:10.1017/S000711450782513X.

203. Wind M, Bjelland M, Pérez-Rodrigo C, et al. Appreciation and implementation of a school-based intervention are associated with changes in fruit and vegetable intake in 10- to 13-year old schoolchildren-the Pro Children study. Health Educ Res. 2008;23(6):997-1007. doi:10.1093/her/cym078.

204. Ransley JK, Greenwood DC, Cade JE, et al. Does the school fruit and vegetable scheme improve children's diet? A non-randomised controlled trial. J Epidemiol Community Health. 2007;61(8):699-703. doi:10.1136/jech.2006.052696.

205. Reinaerts E, Crutzen R, Candel M, De Vries NK, De Nooijer J. Increasing fruit and vegetable intake among children: comparing long-term effects of a free distribution and a multicomponent program. Health Educ Res. 2008;23(6):987-96. doi:10.1093/her/cyn027.

206. Spiegel SA, Foulk D. Reducing overweight through a multidisciplinary school-based intervention. Obesity (Silver Spring). 2006;14(1):88-96. http://www.ncbi.nlm.nih.gov/pubmed/?term=16493126.

207. Taylor RW, Mcauley KA, Barbezat W, Strong A, Williams SM, Mann JI. APPLE Project: 2-y findings of a community-based obesity prevention program in primary school age children. Am J Clin Nutr. 2007;86(3):735-42. http://www.ncbi.nlm.nih.gov/pubmed/?term=17823440.

208. Baranowski T, Baranowski J, Cullen KW, et al. Squire's Quest! Dietary outcome evaluation of a multimedia game. Am J Prev Med. 2003;24(1):5261. http://www.ncbi.nlm.nih.gov/pubmed/?term=12554024.

209. McAleese JD, Rankin LL. Garden-based nutrition education affects fruit and vegetable consumption in sixth-grade adolescents. J Am Diet Assoc. 2007;107(4):662-5. doi:10.1016/j.jada.2007.01.015.

210. Robinson-O'Brien R, Story M, Heim S. Impact of garden-based youth nutrition intervention programs: a review. J Am Diet Assoc. 2009;109(2):273-80. doi:10.1016/j.jada.2008.10.051.

211. Tester J, Yen I, Laraia B. Using mobile fruit vendors to increase access to fresh fruit and vegetables for schoolchildren. Prev Chronic Dis. 2012;9:110222. doi:10.5888/pcd9.110222.

212. Larson N, Story M. Are 'competitive foods' sold at school making our children fat? Health Aff (Millwood). 2010;29(3):430-5. doi:10.1377/hlthaff.2009.0716.

213. Sanchez-Vaznaugh EV, Sánchez BN, Baek J, Crawford PB. 'Competitive' food and beverage policies: are they influencing childhood overweight trends?. Health Aff (Millwood). 2010;29(3):436-46. doi:10.1377/hlthaff.2009.0745.

214. Minnesota Department of Education. Student Data. Data Reports and Analytics. http://w20.education.state.mn.us/MDEAnalytics/Data.jsp. Accessed May 29, 2013. 
215. Fulkerson JA, Story M, Neumark-sztainer D, Rydell S. Family meals: perceptions of benefits and challenges among parents of 8- to 10-year-old children. J Am Diet Assoc. 2008;108(4):706-9. doi:10.1016/j.jada.2008.01.005.

216. Campbell K, Crawford D, Jackson M, et al. Family food environments of 5-6year-old-children: does socioeconomic status make a difference?. Asia Pac J Clin Nutr. 2002;11 Suppl 3:S553-61. http://www.ncbi.nlm.nih.gov/pubmed/12492647.

217. Campbell KJ, Crawford DA, Ball K. Family food environment and dietary behaviors likely to promote fatness in 5-6 year-old children. Int $J$ Obes (Lond). 2006;30(8):1272-80. doi:http://www.ncbi.nlm.nih.gov/pubmed/?term=16491108.

218. Kaiser HF, Caffrey J . Alpha factor analysis. Psychometrika. 1965;30:1-44. http://ideas.repec.org/a/spr/psycho/v30y1965i1p1-14.html.

219. Nunnally JC, Bernstein IH. Psychometric Theory. New York, NY: McGrawHill; 1994.

220. Thompson VJ, Bachman CM, Baranowski T, Cullen KW. Self-efficacy and norm measures for lunch fruit and vegetable consumption are reliable and valid among fifth grade students. J Nutr Educ Behav. 2007;39(1):2-7. doi:10.1016/j.jneb.2006.06.006.

221. Just $D$, Wansink B. Smarter lunchrooms: using behavioral economics to improve meal selection. Choices. 2009:24(3). http://www.choicesmagazine.org/magazine/article.php?article=87.

222. Getlinger MJ, Laughlin VT, Bell E, Akre C, Arjmandi BH. Food waste is reduced when elementary-school children have recess before lunch. $J A m$ Diet Assoc. 1996;96(9):906-8. http://www.ncbi.nlm.nih.gov/pubmed/8784336.

223. Bergman EA, Buergel NS, Joseph E, Sanchez A. Time spent by schoolchildren to eat lunch. J Am Diet Assoc. 2000;100(6):696-698. doi:10.1016/S0002-8223(00)00202-9.

224. Buergel N. Students consuming sack lunches devote more time to eating than those consuming school lunches. J Am Diet Assoc. 2002;102(9):12831286. doi:10.1016/S0002-8223(02)90282-8.

225. Zandian M, loakimidis I, Bergström J, et al. Children eat their school lunch too quickly: an exploratory study of the effect on food intake. BMC Public Health. 2012;12(1):351. doi:10.1186/1471-2458-12-351.

226. Mihalic, S. The importance of implementation fidelity. Emotional \& Behavioral Disorders in Youth. 2004;4(4):83-109. http://www.blueprintsprograms.com/publications/EBDY_4-4--Mihalic.pdf.

227. Ipeirotis, PG. Mechanical Turk: the demographics. A Computer Scientist in a Business School. http://behind-the-enemylines.blogspot.com/2008/03/mechanical-turk-demographics.html. Published March 19, 2008. 
228. Ipeirotis, PG. The new demographics of Mechanical Turk. A Computer Scientiest in a Business School. http://www.behind-the-enemylines.com/2010/03/new-demographics-of-mechanical-turk.html. Published March 9, 2010.

229. Murray GR, Rugeley CR, Mitchell DG, Mondak JJ. Convenient yet not a convenience sample: Jury pools as experimental subject pools. Soc Sci Res. 2013;42(1):246-53. doi:10.1016/j.ssresearch.2012.06.002.

230. Paolacci, G, Chandler, J, Ipeirotis, PG. Running experiments on Amazon Mechanical Turk. Judgment and Decision Making. 2010;5(5):411-419. http://papers.ssrn.com/sol3/papers.cfm?abstract_id=1626226. Published July 1, 2010. Updated September 2, 2010.

231. Antin, J, Shaw, A. Social desirability bias and self-reports of motivation: a study of Amazon Mechanical Turk in the US and India. Paper presented at: CHI 2012: ACM Conference on Human Factors in Computing Systems; May 2012; Austin, TX. http://aaronshaw.org/Antin_Shaw-2012Social_desirability_bias-CHI2012.pdf.

232. Harnack L, Story M, Martinson B, Neumark-Sztainer D, Stang J. Guess Who's Cooking? The Role of Men in Meal Planning, Shopping, and Preparation in US Families. J Am Diet Assoc. 1998;98(9):995-1000. doi:10.1016/S0002-8223(98)00228-4.

233. Fulkerson JA, Kubik MY, Rydell S, et al. Focus groups with working parents of school-aged children: what's needed to improve family meals?. J Nutr Educ Behav. 2011;43(3):189-93. doi:10.1016/j.jneb.2010.03.006. 


\section{Appendices}




\section{Appendix 1: The Kids Cooking Survey}

Choose the response that is best for you.

\begin{tabular}{|c|c|c|c|c|c|c|c|}
\hline & Never/rarely & $\begin{array}{l}\text { Less than } \\
\text { once a } \\
\text { week }\end{array}$ & $\begin{array}{c}\text { Once a } \\
\text { week }\end{array}$ & $\begin{array}{c}\text { Twice a } \\
\text { week }\end{array}$ & $\begin{array}{l}3 \text { times a } \\
\text { week }\end{array}$ & $\begin{array}{c}4 \text { times a } \\
\text { week }\end{array}$ & $\begin{array}{l}5 \text { or more } \\
\text { times a } \\
\text { week }\end{array}$ \\
\hline $\begin{array}{l}\text { How often do you } \\
\text { prepare your child's } \\
\text { dinner meal? }\end{array}$ & 0 & 0 & $\odot$ & 0 & 0 & 0 & 0 \\
\hline $\begin{array}{l}\text { How often does your child } \\
\text { eat his or her dinner meal } \\
\text { alone? }\end{array}$ & ○ & 0 & $\bigcirc$ & ○ & 0 & $\bigcirc$ & $\bigcirc$ \\
\hline $\begin{array}{l}\text { How often does your child } \\
\text { eat his or her dinner meal } \\
\text { with siblings and no } \\
\text { adults? }\end{array}$ & 0 & $\odot$ & 0 & 0 & ○ & 0 & 0 \\
\hline \multirow[t]{2}{*}{$\begin{array}{l}\text { How often does your child } \\
\text { eat the same food as you } \\
\text { for the dinner meal? }\end{array}$} & ○ & 0 & 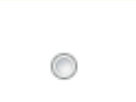 & ○ & 0 & 0 & 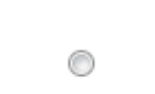 \\
\hline & Never/rarely & $\begin{array}{l}\text { Less than } \\
\text { once a } \\
\text { week }\end{array}$ & $\begin{array}{c}\text { Once a } \\
\text { week }\end{array}$ & $\begin{array}{c}\text { Twice a } \\
\text { week }\end{array}$ & $\begin{array}{l}3 \text { times a } \\
\text { week }\end{array}$ & $\begin{array}{c}4 \text { times a } \\
\text { week }\end{array}$ & $\begin{array}{l}5 \text { or more } \\
\text { times a } \\
\text { week }\end{array}$ \\
\hline $\begin{array}{l}\text { How often does your } \\
\text { family sit down together } \\
\text { for a dinner meal? }\end{array}$ & ○ & 0 & ○ & ○ & 0 & 0 & ○ \\
\hline $\begin{array}{l}\text { How often does your child } \\
\text { watch TV during the } \\
\text { dinner meal? }\end{array}$ & ○ & $\bigcirc$ & $\bigcirc$ & ○ & $\bigcirc$ & 0 & ○ \\
\hline $\begin{array}{l}\text { How often do you use } \\
\text { pre-prepared dishes } \\
\text { (e.g., frozen pizza) for } \\
\text { your child's dinner meal? }\end{array}$ & 0 & 0 & $\odot$ & 0 & 0 & $\odot$ & $\odot$ \\
\hline \multirow[t]{2}{*}{$\begin{array}{l}\text { How often do you use } \\
\text { ready-made sauces for } \\
\text { your child's dinner meal? }\end{array}$} & ○ & $\bigcirc$ & $\bigcirc$ & 0 & $\odot$ & $\bigcirc$ & 0 \\
\hline & Never/rarely & $\begin{array}{l}\text { Less than } \\
\text { once a } \\
\text { week }\end{array}$ & $\begin{array}{c}\text { Once a } \\
\text { week }\end{array}$ & $\begin{array}{c}\text { Twice a } \\
\text { week }\end{array}$ & $\begin{array}{l}3 \text { times a } \\
\text { week }\end{array}$ & $\begin{array}{c}4 \text { times a } \\
\text { week }\end{array}$ & $\begin{array}{l}5 \text { or more } \\
\text { times a } \\
\text { week }\end{array}$ \\
\hline $\begin{array}{l}\text { How often does your child } \\
\text { eat his or her dinner meal } \\
\text { at home sitting at a } \\
\text { table? }\end{array}$ & 0 & $\odot$ & $\odot$ & 0 & $\odot$ & 0 & 0 \\
\hline $\begin{array}{l}\text { How often do you buy } \\
\text { takeout for your child's } \\
\text { dinner meal? }\end{array}$ & $\odot$ & $\bigcirc$ & $\odot$ & ○ & $\bigcirc$ & $\bigcirc$ & 0 \\
\hline $\begin{array}{l}\text { How often do you ask } \\
\text { your child to help prepare } \\
\text { meals? }\end{array}$ & ○ & $\bigcirc$ & $\odot$ & 0 & 0 & 0 & ○ \\
\hline
\end{tabular}


When at home, how often does your child help prepare or cook...

\begin{tabular}{|c|c|c|c|c|c|}
\hline & $\begin{array}{l}\text { Never or } \\
\text { almost never }\end{array}$ & $\begin{array}{l}\text { About once a } \\
\text { month }\end{array}$ & $\begin{array}{c}\text { 1-2 times a } \\
\text { week }\end{array}$ & $\begin{array}{l}\text { 3-4 times a } \\
\text { week }\end{array}$ & $\begin{array}{c}5 \text { or more } \\
\text { times a week }\end{array}$ \\
\hline breakfast? & ○ & 0 & 0 & 0 & 0 \\
\hline lunch? & ○ & ○ & ○ & O & ○ \\
\hline snacks? & ○ & O & O & O & 0 \\
\hline dinner/supper? & ○ & ○ & $\odot$ & ○ & ○ \\
\hline
\end{tabular}

When helping at home, how often does your child prepare or cook...

\begin{tabular}{|c|c|c|c|c|}
\hline & Never & Sometimes & Often & Always \\
\hline fruits? & ○ & 0 & 0 & 0 \\
\hline $\begin{array}{l}\text { ready-made foods (such } \\
\text { as frozen pizza, boxed } \\
\text { macaroni and cheese)? }\end{array}$ & ○ & ○ & ○ & 0 \\
\hline vegetables? & 0 & 0 & 0 & 0 \\
\hline $\begin{array}{l}\text { sweets, snacks and } \\
\text { desserts (such as } \\
\text { cookies, cakes and pies)? }\end{array}$ & ○ & ○ & 0 & 0 \\
\hline
\end{tabular}


Please rate your agreement with the following statements.

\begin{tabular}{|c|c|c|c|c|c|c|}
\hline & $\begin{array}{l}\text { Strongly } \\
\text { Disagree }\end{array}$ & Disagree & $\begin{array}{l}\text { Neither } \\
\text { Agree nor } \\
\text { Disagree }\end{array}$ & Agree & $\begin{array}{l}\text { Strongly } \\
\text { Agree }\end{array}$ & $\begin{array}{c}\text { Not } \\
\text { Applicable }\end{array}$ \\
\hline $\begin{array}{l}\text { My kitchen is too small for } \\
\text { my child to help prepare } \\
\text { meals. }\end{array}$ & 0 & 0 & ○ & 0 & 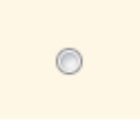 & 0 \\
\hline $\begin{array}{l}\text { My child would make a } \\
\text { mess if he or she helped } \\
\text { prepare meals. }\end{array}$ & 0 & 0 & 0 & 0 & 0 & 0 \\
\hline $\begin{array}{l}\text { If my child helps to } \\
\text { prepare meals, he or she } \\
\text { will be more likely to eat } \\
\text { with the family. }\end{array}$ & ○ & ○ & 0 & 0 & 0 & 0 \\
\hline $\begin{array}{l}\text { I worry about my child } \\
\text { getting cut or burned } \\
\text { when he or she helps } \\
\text { prepare meals. }\end{array}$ & ○ & ○ & 0 & 0 & 0 & 0 \\
\hline $\begin{array}{l}\text { My child would not be } \\
\text { spending time watching } \\
\text { TV or on the computer if } \\
\text { he or she helps prepare } \\
\text { meals. }\end{array}$ & ○ & 0 & 0 & ○ & 0 & ○ \\
\hline $\begin{array}{l}\text { My kitchen is too small for } \\
\text { my child to help prepare } \\
\text { meals. }\end{array}$ & ○ & ○ & 0 & 0 & ○ & ○ \\
\hline $\begin{array}{l}\text { My child would develop a } \\
\text { better appreciation for } \\
\text { cooking if he or she helps } \\
\text { prepare meals. }\end{array}$ & O & ○ & ○ & 0 & ○ & ○ \\
\hline
\end{tabular}


My child would be more likely to try new foods if he or she helps prepare meals.

My child would have a better understanding of where his or her food comes from if he or she helps prepare meals.

My child would learn cooking basics by helping prepare meals.

My child would be more likely to try new foods if he or she helps prepare meals.

My child is not interested in preparing meals.

If my child helps prepare meals, he or she would be more likely to eat healthfully as an adult.

My child would be more confident in his or her cooking skills if he or she

helps prepare meals.

Strongly

Disagree
Neither

Agree nor

Disagree

Disagree

Disag

○

(1)

○

0

○

○

(

0

○

○
Agree $\quad \begin{gathered}\text { Strongly } \\ \text { Agree }\end{gathered}$

Not

Applicable 


\begin{tabular}{|c|c|c|c|c|c|c|}
\hline & $\begin{array}{l}\text { Strongly } \\
\text { Disagree }\end{array}$ & Disagree & $\begin{array}{l}\text { Neither } \\
\text { Agree nor } \\
\text { Disagree }\end{array}$ & Agree & $\begin{array}{l}\text { Strongly } \\
\text { Agree }\end{array}$ & $\begin{array}{c}\text { Not } \\
\text { Applicable }\end{array}$ \\
\hline $\begin{array}{l}\text { I need to bribe or force } \\
\text { my child to help prepare } \\
\text { meals. }\end{array}$ & ○ & ○ & ○ & ○ & ○ & O \\
\hline $\begin{array}{l}\text { If my child helps to } \\
\text { prepare meals, he or she } \\
\text { will be more likely to eat } \\
\text { with the family. }\end{array}$ & ○ & ○ & ○ & ○ & ○ & ○ \\
\hline $\begin{array}{l}\text { My child would have a } \\
\text { better understanding of } \\
\text { what goes into his or her } \\
\text { food if he or she helps } \\
\text { prepare meals. }\end{array}$ & ○ & ○ & ○ & ○ & ○ & 0 \\
\hline $\begin{array}{l}\text { My child is likely to eat } \\
\text { what he or she helps } \\
\text { prepare. }\end{array}$ & ○ & ○ & ○ & $\bigcirc$ & ○ & 0 \\
\hline $\begin{array}{l}\text { My child is not interested } \\
\text { in preparing meals. }\end{array}$ & ○ & ○ & ○ & ○ & ○ & ○ \\
\hline $\begin{array}{l}\text { I can talk about healthy } \\
\text { foods with my child when } \\
\text { he or she helps prepare } \\
\text { meals. }\end{array}$ & ○ & ○ & ○ & ○ & ○ & 0 \\
\hline $\begin{array}{l}\text { Preparing food together } \\
\text { builds a sense of } \\
\text { belonging for my child. }\end{array}$ & ○ & ○ & ○ & ○ & ○ & O \\
\hline
\end{tabular}




\begin{tabular}{l|l} 
My child would learn new \\
vocabulary related to \\
food preparation when \\
preparing meals. \\
Having my child help \\
prepare meals makes \\
more work for me.
\end{tabular}


My child would be more
likely to try new foods if likely to try new foods if he or she helps prepare meals.

My child would rather do other things than help prepare meals.

My child is easily frustrated before dinner.

Food preparation would take more time if my child helps prepare meals.

My child complains a lot when asked to help prepare meals.

My child is likely to eat vegetables when he or she helps prepare meals

\section{Strongly}

Disagree

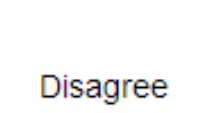

Neither

Agree nor

Disagree

Agree

Strongly

Agree

Not Applicable

○

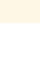

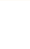

\begin{tabular}{|c|c|c|c|c|}
\hline ○ & 0 & $\bigcirc$ & 0 & $\bigcirc$ \\
\hline 0 & 0 & $\bigcirc$ & $\bigcirc$ & 0 \\
\hline$\bigcirc$ & $\bigcirc$ & ○ & 0 & 0 \\
\hline$\bigcirc$ & 0 & $\bigcirc$ & 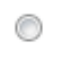 & $\bigcirc$ \\
\hline$\odot$ & 0 & 0 & $\bigcirc$ & ○ \\
\hline 0 & 0 & 0 & 0 & $\bigcirc$ \\
\hline
\end{tabular}

Please rate your agreement with the following statements.

\begin{tabular}{|c|c|c|c|c|c|c|}
\hline & $\begin{array}{l}\text { Strongly } \\
\text { Disagree }\end{array}$ & Disagree & $\begin{array}{l}\text { Neither } \\
\text { Agree nor } \\
\text { Disagree }\end{array}$ & Agree & $\begin{array}{l}\text { Strongly } \\
\text { Agree }\end{array}$ & $\begin{array}{c}\text { Not } \\
\text { applicable }\end{array}$ \\
\hline $\begin{array}{l}\text { All children are expected } \\
\text { to help with meal } \\
\text { preparation. }\end{array}$ & 0 & ○ & ○ & 0 & 0 & ○ \\
\hline $\begin{array}{l}\text { My friends' children } \\
\text { participate in meal } \\
\text { preparation. }\end{array}$ & 0 & 0 & 0 & 0 & 0 & ○ \\
\hline $\begin{array}{l}\text { My parents/parents-in-law } \\
\text { think my child should help } \\
\text { prepare meals. }\end{array}$ & ○ & 0 & ○ & ○ & 0 & $\bigcirc$ \\
\hline $\begin{array}{l}\text { When my spouse } \\
\text { (significant other) was } \\
\text { growing up, children } \\
\text { participated in meal } \\
\text { preparation. }\end{array}$ & ○ & ○ & 0 & 0 & $\bigcirc$ & 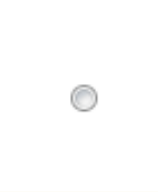 \\
\hline $\begin{array}{l}\text { When I was growing up, } \\
\text { my family included me in } \\
\text { meal preparation. }\end{array}$ & 0 & 0 & 0 & 0 & ○ & ○ \\
\hline $\begin{array}{l}\text { My spouse (significant } \\
\text { other) thinks our child } \\
\text { should help prepare } \\
\text { meals. }\end{array}$ & ○ & ○ & ○ & 0 & ○ & ○ \\
\hline
\end{tabular}


Please rate your agreement with the following statements.

\begin{tabular}{|c|c|c|c|c|c|c|}
\hline & $\begin{array}{l}\text { Strongly } \\
\text { Disagree }\end{array}$ & Disagree & $\begin{array}{l}\text { Neither } \\
\text { Agree nor } \\
\text { Disagree }\end{array}$ & Agree & $\begin{array}{l}\text { Strongly } \\
\text { Agree }\end{array}$ & $\begin{array}{c}\text { Not } \\
\text { Applicable }\end{array}$ \\
\hline $\begin{array}{l}\text { The equipment in my } \\
\text { kitchen makes it easy for } \\
\text { my child to help prepare } \\
\text { meals. }\end{array}$ & ○ & ○ & O & ○ & ○ & 0 \\
\hline $\begin{array}{l}\text { The limited amount of } \\
\text { food in our home makes it } \\
\text { difficult for my child to } \\
\text { help prepare meals. }\end{array}$ & ○ & O & ○ & ○ & 0 & 0 \\
\hline $\begin{array}{l}\text { My kitchen layout makes } \\
\text { it easy for my child to } \\
\text { help prepare meals }\end{array}$ & 0 & 0 & 0 & 0 & 0 & 0 \\
\hline $\begin{array}{l}\text { The size of my kitchen } \\
\text { work space makes it easy } \\
\text { for child to help prepare } \\
\text { meals. }\end{array}$ & ○ & 0 & ○ & ○ & ○ & ○ \\
\hline
\end{tabular}

How sure are you that you can involve your child in meal preparation...

\begin{tabular}{l|l|l} 
& Not at all sure Slightly sure Somewhat sure Very sure Extremely sure \\
when your kitchen is not \\
clean? \\
when you don't have the \\
ingredients you need on \\
hand?
\end{tabular}


When my child helps prepare meals, he or she...

\begin{tabular}{|c|c|c|c|}
\hline & Yes & No & Not Applicable \\
\hline uses the stove? & O & 0 & ○ \\
\hline $\begin{array}{l}\text { cuts or chops fruits or } \\
\text { vegetables? }\end{array}$ & 0 & 0 & 0 \\
\hline uses the oven? & ○ & O & 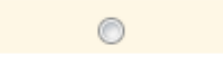 \\
\hline uses a microwave? & O & ○ & $\odot$ \\
\hline opens canned food? & O & ○ & ○ \\
\hline uses a mixer? & O & O & 0 \\
\hline cooks meat? & O & $\odot$ & 0 \\
\hline follows a recipe? & O & ○ & 0 \\
\hline mixes ingredients? & ○ & ○ & O \\
\hline makes a salad? & O & O & O \\
\hline uses a blender? & O & O & 0 \\
\hline measures ingredients? & O & ○ & O \\
\hline peels fruits or vegetables? & $\odot$ & ○ & ○ \\
\hline
\end{tabular}

Choose the response that is best for you.

\begin{tabular}{l|ccccc} 
& Very unlikely & $\begin{array}{c}\text { Somewhat } \\
\text { Unlikely }\end{array}$ & Undecided & $\begin{array}{c}\text { Somewhat } \\
\text { Likely }\end{array}$ & Very Likely \\
\hline $\begin{array}{l}\text { How likely is it you will } \\
\text { involve your child in meal } \\
\text { preparation at least three } \\
\text { nights per week over the } \\
\text { next month? }\end{array}$ & 0 & & & \\
\end{tabular}

Choose the response that is best for you.

\begin{tabular}{|c|c|c|c|c|c|}
\hline & Never/Rareley & $\begin{array}{l}0-1 \text { times per } \\
\text { week }\end{array}$ & $\begin{array}{l}2-3 \text { times per } \\
\text { week }\end{array}$ & $\begin{array}{l}\text { 4-5 times per } \\
\text { week }\end{array}$ & $\begin{array}{l}\text { More than } 5 \\
\text { times per week }\end{array}$ \\
\hline $\begin{array}{l}\text { How many times per week } \\
\text { do you plan to involve } \\
\text { your child in meal } \\
\text { preparation over the next } \\
\text { month? }\end{array}$ & 0 & 0 & ○ & ○ & ○ \\
\hline
\end{tabular}


What is your age? (Mark only one response)

18-34 years old

(. 35-54 years old

55-64 years old

65 years or older

Prefer not to answer

Are you a man or woman? (Mark only one response)

- Male

- Female

Please specify your ethnicity or race (Mark all that apply).

$\square$ White

$\square$ Hispanic or Latino

$\square$ African American

$\square$ Native American

Asian / Pacific Islander

$\square$ Other

$\square$ Prefer not to answer 
What is the highest degree or level of school you have completed? If currently enrolled, mark the highest degree received. (Mark only one response).

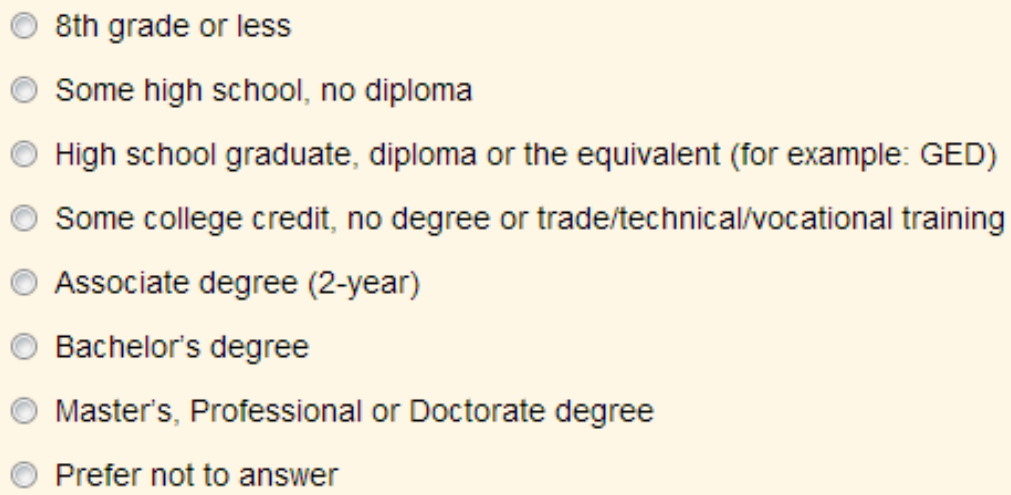

What is your marital status?

Single, never married

Married or domestic partnership

Widowed, divorced, or separated

Prefer not to answer 
For every child under the age of 18 living in your home at least 4 days each week, complete the following.

\begin{tabular}{|c|c|c|c|c|c|c|c|c|c|c|}
\hline & Boy & Girl & $\begin{array}{c}5 \\
\text { years } \\
\text { old }\end{array}$ & $\begin{array}{c}6 \\
\text { years } \\
\text { old }\end{array}$ & $\begin{array}{c}7 \\
\text { years } \\
\text { old }\end{array}$ & $\begin{array}{c}8 \\
\text { years } \\
\text { old }\end{array}$ & $\begin{array}{c}9 \\
\text { years } \\
\text { old }\end{array}$ & $\begin{array}{c}10 \\
\text { years } \\
\text { old }\end{array}$ & $\begin{array}{c}11 \\
\text { years } \\
\text { old }\end{array}$ & $\begin{array}{c}12 \\
\text { years } \\
\text { old }\end{array}$ \\
\hline Child 1 & 口 & 口 & $\square$ & 口 & 口 & 回 & 口 & 口 & 回 & 回 \\
\hline Child 2 & $\square$ & 口 & 口 & $\square$ & 口 & 口 & $\square$ & $\square$ & 回 & $\square$ \\
\hline Child 3 & 回 & 口 & 口 & 口 & 口 & 回 & 回 & 口 & 口 & 口 \\
\hline Child 4 & 回 & 回 & $\square$ & $\square$ & 回 & $\square$ & $\square$ & $\square$ & 口 & $\square$ \\
\hline Child 5 & 回 & 回 & 口 & 口 & 口 & 口 & 回 & 口 & 回 & 口 \\
\hline Child 6 & 口 & 口 & 口 & $\square$ & $\square$ & 口 & 口 & $\square$ & 口 & $\square$ \\
\hline Child 7 & 回 & 口 & $\square$ & $\square$ & 回 & $\square$ & 回 & 回 & 回 & $\square$ \\
\hline Child 8 & 回 & 回 & 回 & 回 & 回 & 回 & 回 & 口 & 回 & 回 \\
\hline
\end{tabular}

If there are additional children in your home, write the ages and gender below.

Are you currently...? (Mark only one response.)
Employed for wages
Self-employed
Out of work and looking for work
Out of work but not currently looking for work
A homemaker
A student
Military
Retired
Unable to work
Prefer not to answer

Please enter the following completion code into MTurk to be paid for your participation in this survey. Thank you!

\section{5}

